
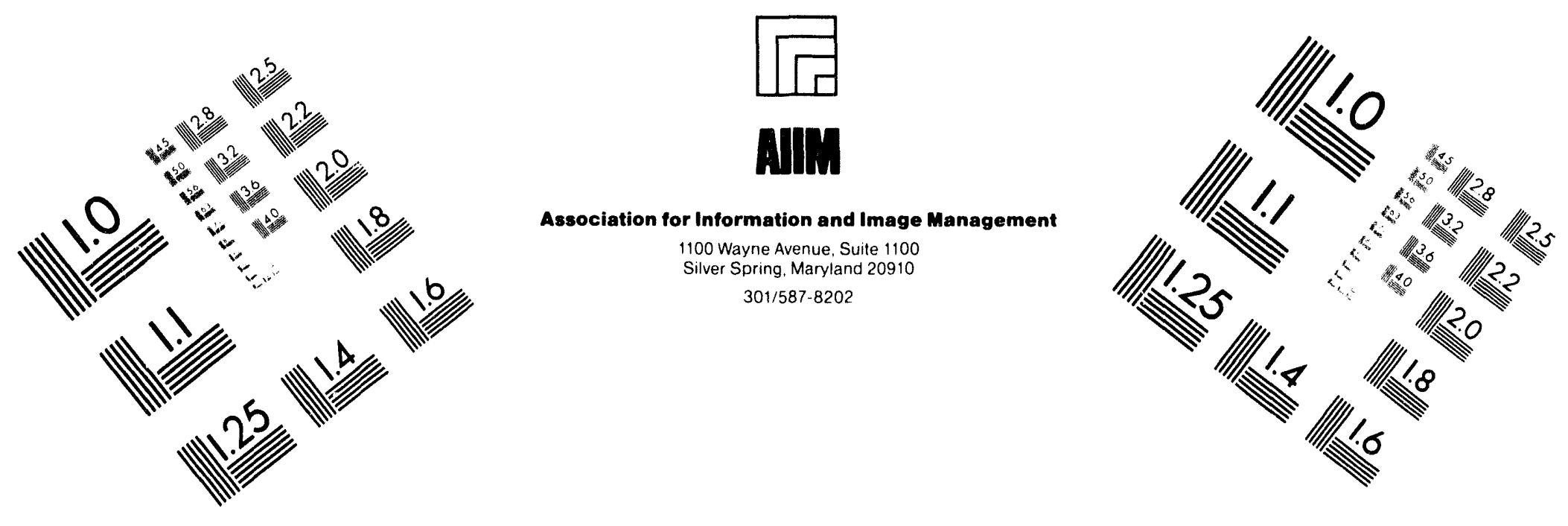

\title{
Centimeter
}

| Inches
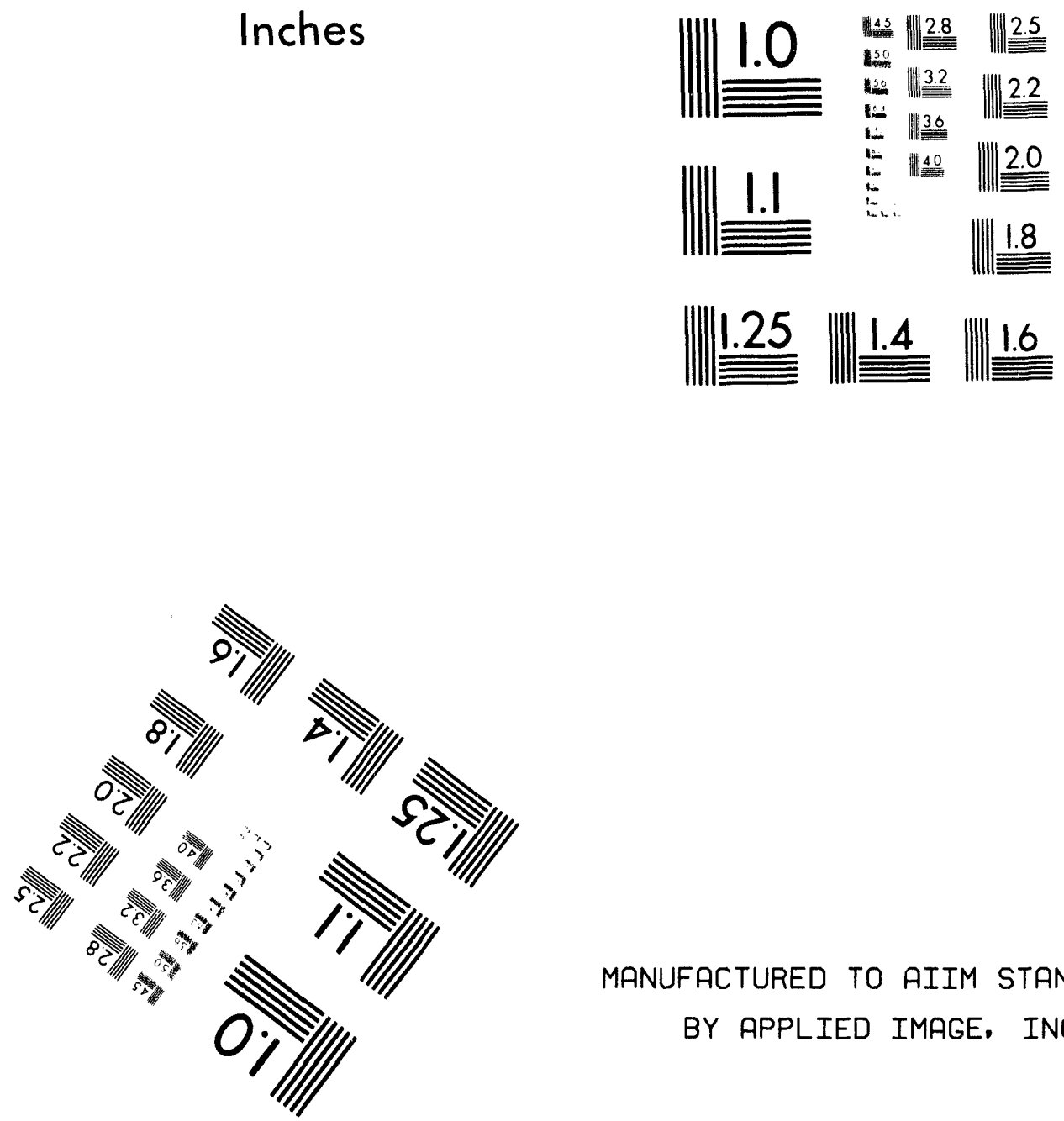

MANUFACTURED TO AIIM STANDARDS BY APPLIED IMAGE, INC.

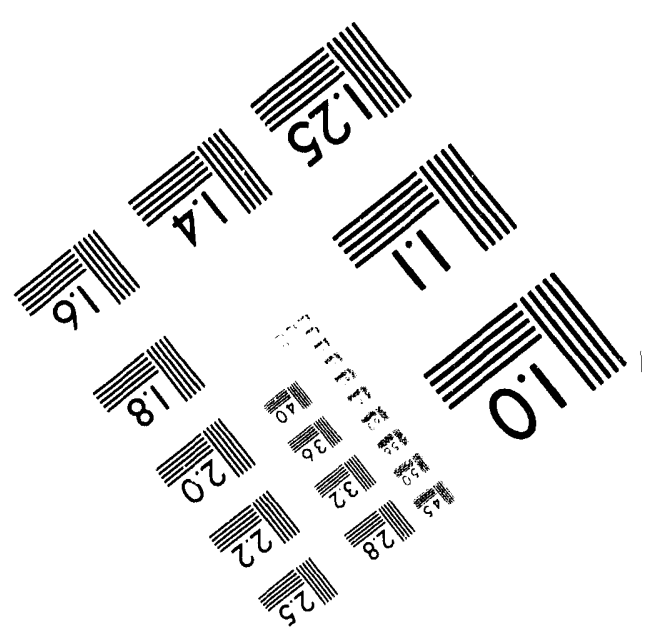



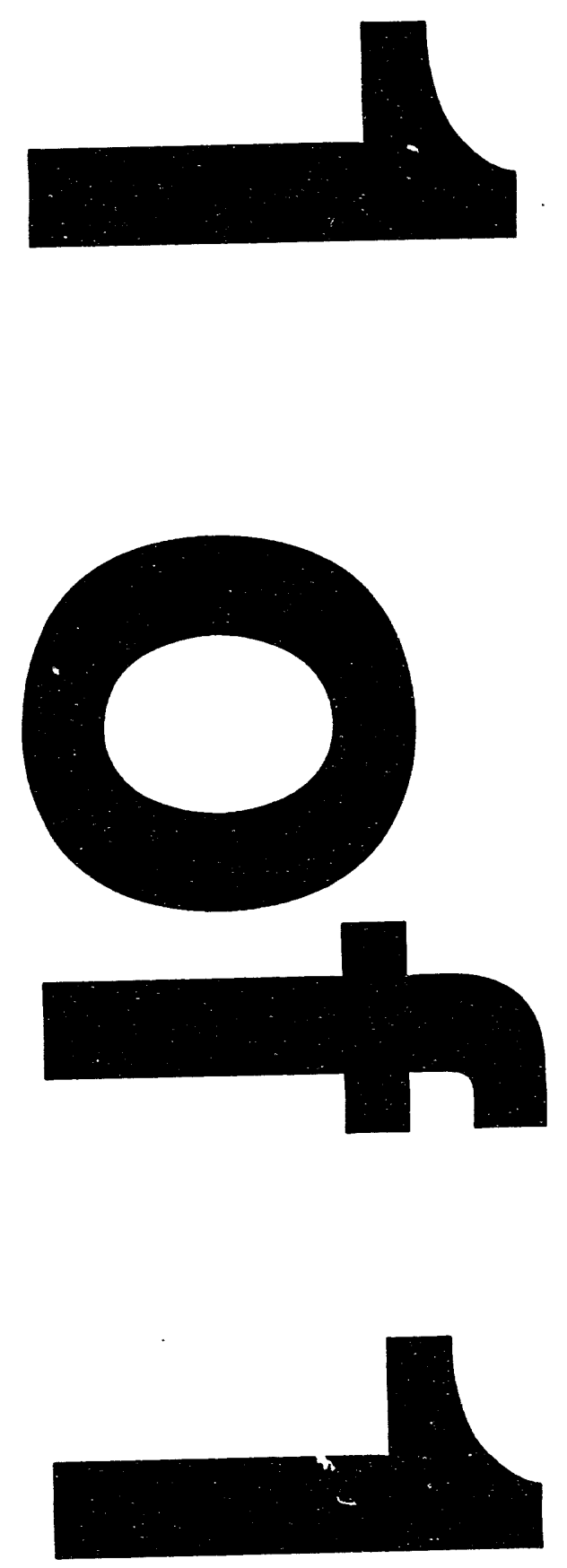
UC-224

\title{
FUELED EMITTER \\ FINAL TEST REPORT \\ TFE VERIFICATION PROGRAM
}

\author{
Prepared under \\ CONTRACT DE-ACO3-86SF16298 \\ FOR THE SAN FRANCISCO OPERATIONS OFFICE \\ DEPARTMENT OF ENERGY
}

GENERAL ATOMICS PROJECT 3450

JULY 1994

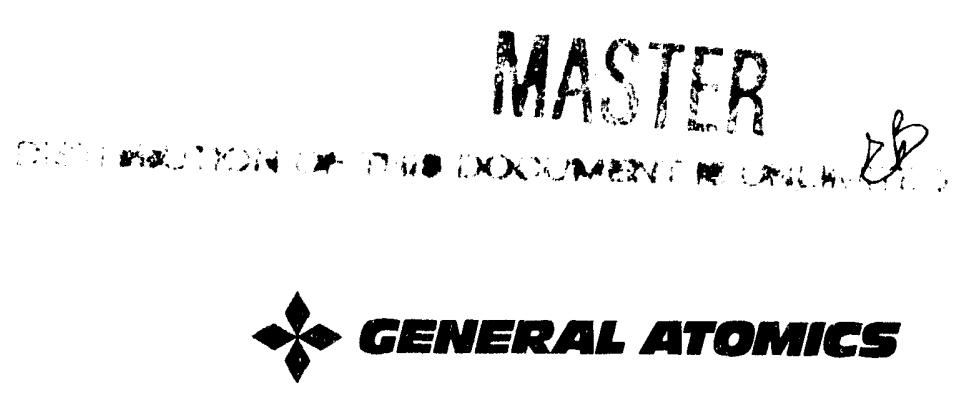




\section{FUELED EMITTER \\ FINAL TEST REPORT \\ TFE VERIFICATION PROGRAM}

1. INTRODUCTION

1.1 Objective of TFE Verification Program 2

1.2 Technical Approach 2

1.3 Organization of the Program 4

1.4 Structure of Test Program 4

1.4.1 Conceptual Design 7

1.4.2 Converter Performance 7

1.4.3 Insulator Seals 7

1.4.4 Sheath Insulators

1.4.5 Fueled Emitters

1.4.6 Cesium Reservoir and Interconnective Components 8

$\begin{array}{ll}1.4 .7 \text { TFEs } & 8\end{array}$

1.5 Semiannual Progress Reports $\quad 8$

1.6 Final Reports 8

1.7 Westinghouse Hanford Company Reports on Cesium Reservoirs 9

2. OBJECTIVES OF THE TEST PROGRAM 11

2.1 Funcison of the Fueled Emitter 11

2.2 Requirements of the Fueled Emitter 11

2.2.1 Design Requirements 11

2.2.2 Performance Requirements 11

2.3 Goals of the Test Program 12

2.4 Test Matrix 12

3. FABRICATION DEVELOPMENT 15

3.1 UFAC Batch 1 Fabrication 15

3.2 Bonding at the Tungsten-to-Tantalum Transition Joint 17

$\begin{array}{ll}3.3 \text { As Built Operating Temperature } & 19\end{array}$

3.4 Rhenium Fuel Pedestals and Heat Shields 20

3.5 UFAC Batch 2 Fabrication 20

3.5.1 Insulated Fuel Design 21

3.5.2 Wafered Fuel Design 21

3.5.3 Thermal Modeling for Batch 2

3.5.4 As-Fabricated Data 21

3.6 Advanced Materials 23

4. IN-REACTOR TESTING 25

4.1 Test Specimen Irradiations 25

4.1.1 Reactor Operation 25

4.1.2 Review of Test Specimen Performance 25 
4.2 Consequences of Emitter Fracture 30

4.3 Temperature Measurement Evaluations 31

$\begin{array}{ll}4.4 \text { Emitter Thinning } & 31\end{array}$

4.4.1 Chemical Reactions Considered 33

4.4.2 Emitter Thinning in Test Articles 33

4.5 UFAC-1 Metallography 36

4.5.1 Emitter SU1-4 37

4.5.2 Emitter SU1-5 37

4.5.3 Emitters SU1-8 and SU1-9 38

4.5.4 Electron Microprobe Examination 38

4.5.5 Conclusions 38

4.6 Fuel Burnup Prediction 39

4.7 Emitter Distortion Analysis 39

4.7.1 Neutron Radiography 39

4.7.2 Reference Fueled Emitters 40

4.7.3 Advanced Fueled Emitters 41

5. FUELED EMITTER MODEL DEVELOPMENT 47

5.1 Ratchet Effect in Emitter Distortion 47

5.2 LIFE-4 Code Development 49

5.2.1 Background 49

5.2.2 Data Base for Evaluating LIFE-4 Code Predictions 50

5.2.3 LIFE-4 Predictions 51

6. FUELED EMITTER SPECIFICATION 52

6.1 Reference Materials $\quad 52$

6.2 Advanced Emitter Materials $\quad 52$

6.3 Advanced Fuel 52

7. REFERENCES 53

APPENDIX: EMITTER DISTORTION DATA DERIVED FROM NEUTRON RADIOGRAPH MEASUREMENTS 


\section{INTRODUCTION}

\subsection{Objective of TFE Verification Program}

The program cbjective is to demonstrate the technology readiness of a TFE suitable for use as the basic element in a thermionic reactor with electric power output in the 0.5 to 5.0 MW(e) range, and a full-power life of 7 years. A TFE for a megawatt class system is shown on Figure 1-1. Only six cells are shown for simplicity; a megawatt class TFE would have many more cells, the exact number dependent on optimization trade studies.

\subsection{Technical Approach}

The TFE Verification Program built directly on the technology and data base developed in the 1960s and early 1970s in an AEC/NASA program, and in the SP-100 program conducted in 1983, 1984 and 1985. In the SP-100 program, the attractive features of thermionic power conversion technology were recognized but concern was expressed over the lack of fast reactor irradiation data. The TFE Verification Program addressed that concern.

The technical approach followed to achieve the program objective is shown on Fig. 1-2. Five prior programs form the basis for the TFE Verification Program:

1) AEC/NASA program of the 1960s and early 1970s.

1) SP-100 concept development program (Ref. 1-1).

3) SP-100 thermionic technology program (Ref. 1-2).

4) Thermionic irradiations program in TRIGA in FY-86 (Ref. 1-3).

5) Thermionic Technology Program in 1986 and 1987 (Refs. 1-4, 1-5).

These programs provided both the systems and technology expertise necessary to design and demonstrate a megawatt class TFE.

A TFE was designed that met the reliability and lifetime requirements for a $2 \mathrm{MW}(\mathrm{e})$ conceptual reactor design. Analysis showed that this TFE could be used over the range of 0.5 to 5 megawatts. This was used as the basis for designing components for test and evaluation. The demonstration of a 7-year component lifetime capability was through the combined use of analytical models and accelerated, confirmatory tests in a fast test reactor. Iterative testing was performed where the results of one test series led to evolutionary improvements in the next test specimens.

The TFE components underwent screening and initial development testing in ex-reactor tests. Several design and materials options were considered for each component. As screening tests permitted, down selection occurred.

In parallel with ex-reactor testing, and fast reactor component testing, components were integrated into a TFE and tested in the TRIGA test reactor at GA. Realtime testing of partial 
$N$

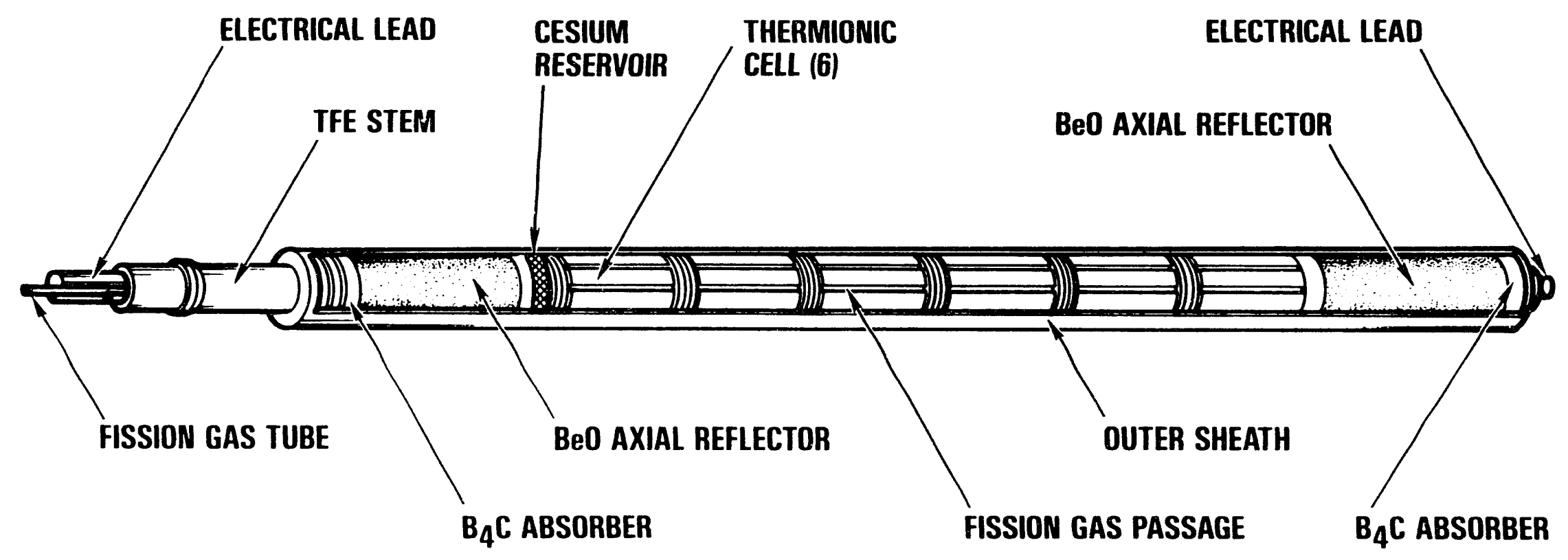

Figure 1-1. TFE for Megawatt Class System 


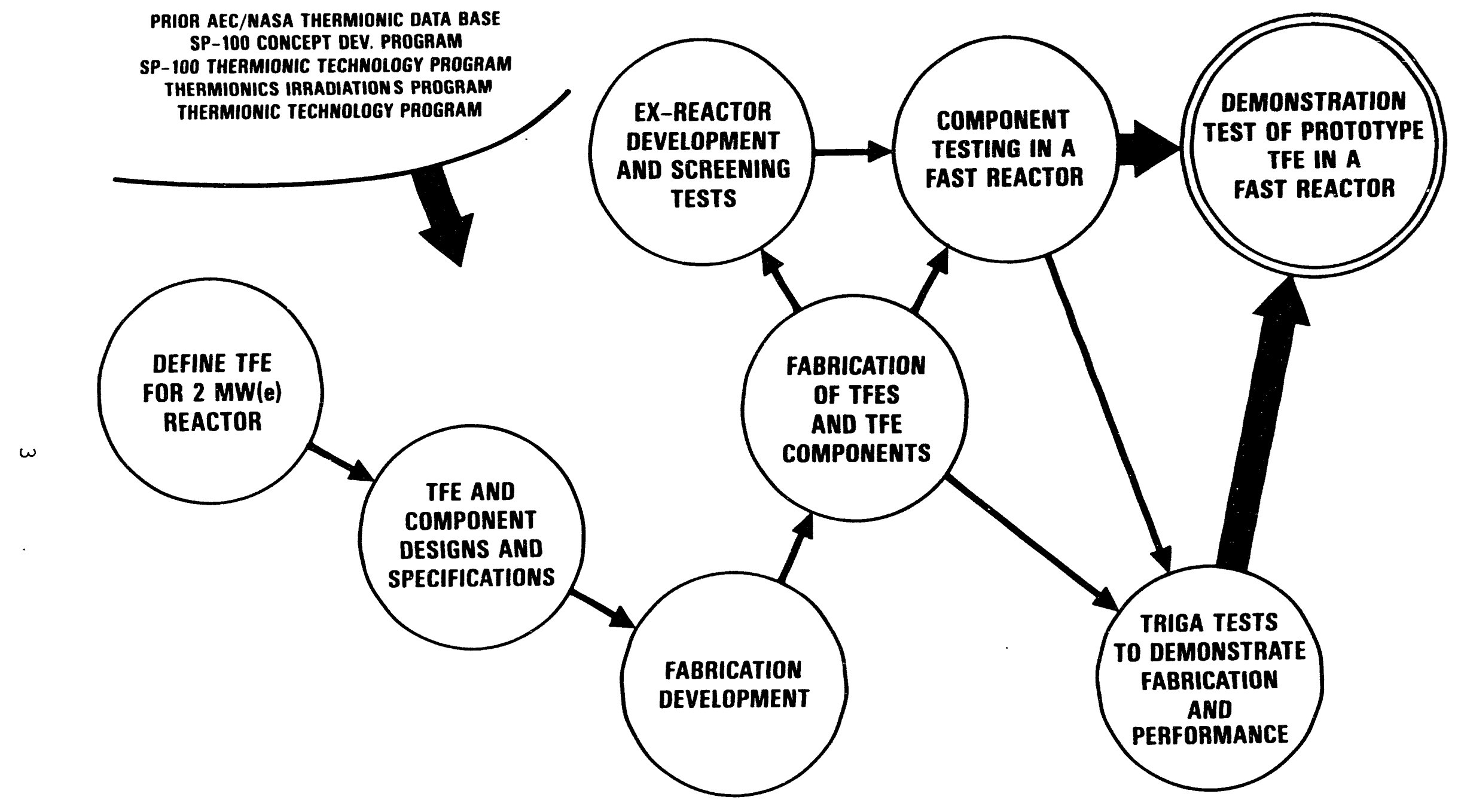

Figure 1-2. Logic to Demonstrate Technology Readiness of Megawatt Class TFE 
length TFEs was used to test support, alignment and interconnective TFE components, and to verify TFE performance in-reactor with integral cesium reservoirs. Realtime testing was also used to verify the relation between TFE performance and fueled emitter swelling, to test the durability of intercell insulation, to check temperature distributions, and to verify the adequacy over time of the fission gas venting channels.

Predictions of TFE lifetime rested primarily on the accelerated component testing results, as correlated and extended to realtime by the use of analytical models.

\subsection{Organization of the Program}

Contracting Agency: Department of Energy, San Francisco Operations Office

Prime Contractor: General Atomics (GA)

Subcontractors:

ThermoTrex Corporation (TTC), a subsidiary of Thermo Electron Corporation

Rasor Associates, Incorporated (RAI)

Space Power Incorporated (SPI)

Fast reactor testing manager:

Westinghouse Hanford Corporation (WHC)

Fast reactor facilities:

Fast Flux Test Reactor (FFTF), with testing managed by WHC.

EBR-II, with testing managed by Argonne National Laboratory-West (ANL-W)

Technical oversight for DOE: Los Alamos National Laboratory (LANL).

\subsection{Structure of Test Program}

The TFE-VP was broken down into 7 tasks, generally corresponding to the components of a TFE. Figure 1-3 shows a thermionic cell with the various components identified.

Figure 1-4 shows a one cell TFE fabricated for test in the program. A multi-cell TFE has 2 or more cells in series.

When compared to Figure 1-1, it is clear that this test article is not quite prototypical. The test conditions dictate the design to some extent. Also, the test approach is to first test simple TFEs and then gradually test TFEs more prototypic.

For each component, the work involved:

1) Component design and analyses 


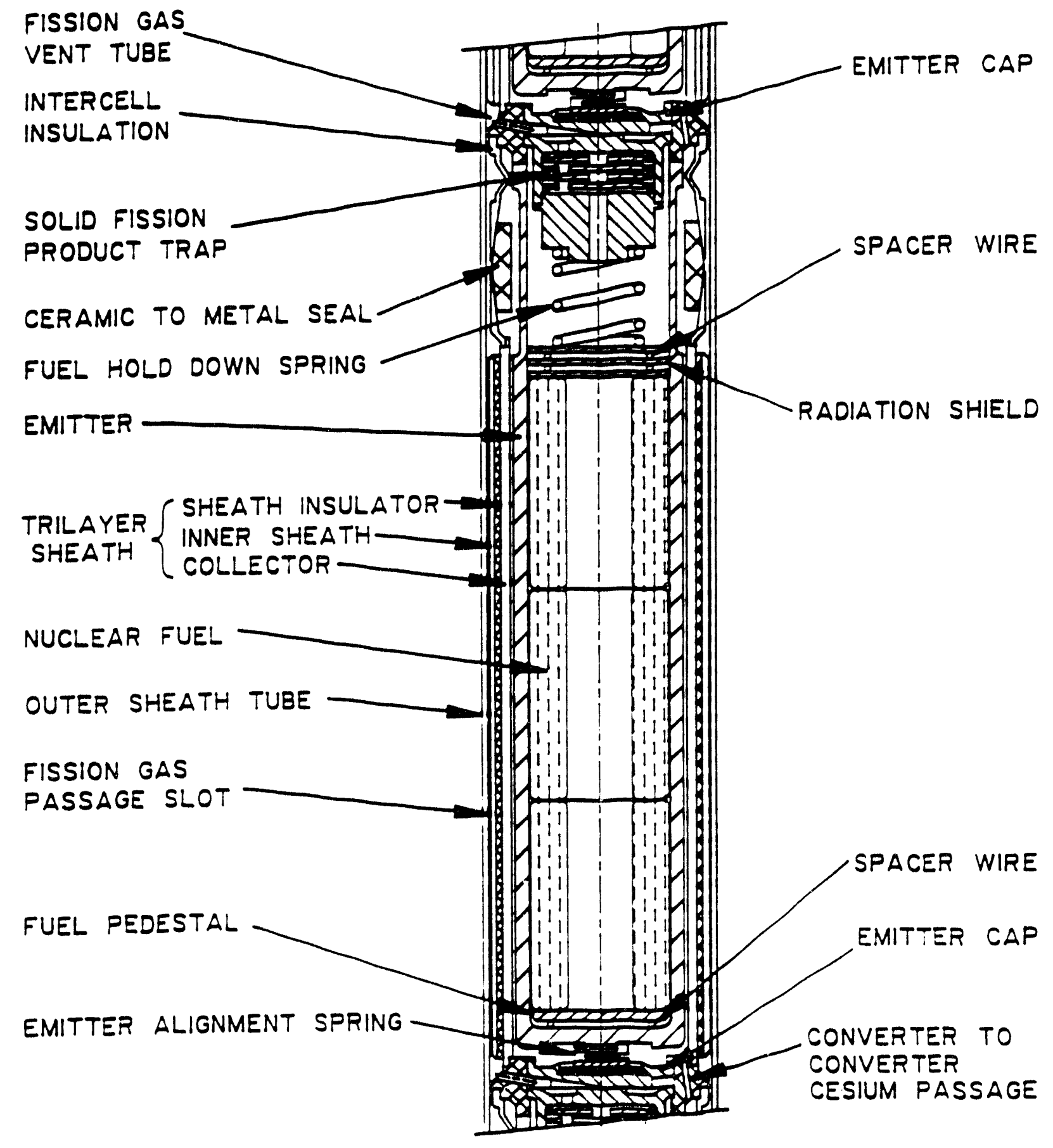

Figure 1-3. Thermionic Cell 


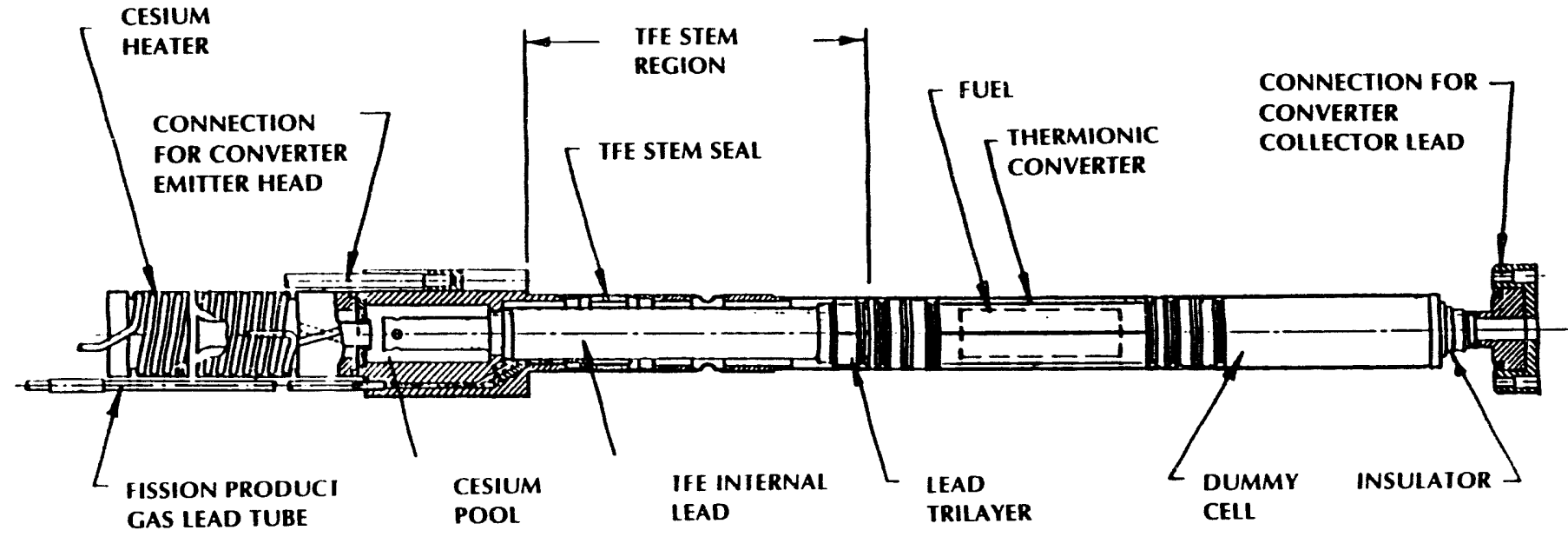

Figure 1-4. One Cell TFE Test in TFE Verification Program 
2) Materials evaluation and selection.

3) Performance testing.

4) Life testing, both accelerated and realtime.

In addition, performance models were developed for converter performance, fueled emitters and cesium reservoirs.

A brief description of each task is given below. For each of the component tasks, fabrication process specifications were developed and materials were chosen.

1.4.1 Conceptual Design. A TFE optimized for a $2 \mathrm{MW}$ (e) system was designed. Its scalability over the range of $500 \mathrm{~kW}$ to $5 \mathrm{MW}$ was demonstrated.

1.4.2 Converter Performance. The performance of converters of interest for megawatt class systems was measuredd and existing models on converter performance were refined.

1.4.3 Insulator Seals. The insulator seal isolates the space filled with gaseous fission products from the cesium filled interelectrode gap. It also assures that electrons flow from the collector of one cell to the emitter of an axially adjacent cell.

1.4.4 Sheath Insulators. The sheath insulator is a structure composed of 3 layers:

o The inner layer is the collector.

- The middle layer is an insulator electrically isolating the collector from the reactor coolant and structure. It also must conduct reject heat to the reactor coolant.

o The outer metallic layer assures the structural integrity of the sheath.

1.4.5 Fueled Emitter. The fueled emitter is the emitter component inside of which are the following components:

- $\mathrm{UO}_{2}$ fuel.

o Fuel holddown device to prevent damage to the cell during launch and ascent.

o Fission product trapping components to prevent solid and condensable fission products from exiting the cell.

o Heat shields to protect the upper and lower parts of the emitter from the high temperatures of the $\mathrm{UO}_{2}$ fuel. 


\subsubsection{Cesium Reservoir and Interconnective Components}

The cesium reservoir provides cesium vapor to the interelectrode gap. A graphite cesium reservoir was demonstrated in the program.

Interconnective components are those metal parts and insulators which are necessary to attach one cell in series with another.

\subsubsection{TFEs}

The TFE is an axial series of one or more cells. It also contains a cesium reservoir. TFEs with one, three and six cells were fabricated and tested.

The TFEs fabricated under the TFE Verification Program were designated the " $\mathrm{H}$ " series TFEs, being the next series following the "E", "F" and "G" series which were studied in the 1960s and 1970s. The E series TFEs had an emitter diameter of 0.625 inch; the F series, 1.1 inches; and the $\mathrm{H}$ series, 0.5 inches.

A specific TFE has a designation $x H y$, the " $x$ " being the number of cells in the TFE and the " $y$ " being the specific TFE in question. For example, the TFEs fabricated and tested in the program were:

TFE-1H1, the first of the 1-cell TFEs.

TFE-1H2, the second of the 1-cell TFEs.

TFE-1H3, the third of the 1-cell TFEs.

TFE-3H1, the first of the 3-cell TFEs.

TFE-3H5, the fifth of the 3-cell TFEs. Numbers 2, 3 and 4 were eliminated early in the program.

TFE-6H1, the first of the 6-cell TFEs.

\subsection{Semiannual Progress Reports}

Semiannual progress reports provide a running account of technical progress which reflects the work done at GA, TTC, RAI and SPI. These reports also summarize the status and results of the irradiation program at WHC, ANL-W and LANL.

Table 1-1 shows a complete list of all semiannual progress reports.

\subsection{Final Reports}

Final test reports give details on each of the major components outlined in Section 1.4. A list of these final reports is given in Table 1-2. It is assumed in these reports that the reader is familiar with thermionic technology and the structure and operation of thermionic fuel elements and their components. 
Table 1-1

SEMIANNUAL PROGRESS REPORTS

\begin{tabular}{||l|l|c||}
\hline \multicolumn{1}{|c|}{ Period Ending } & \multicolumn{1}{|c|}{ Date Issued } & Report Number \\
\hline March 31, 1987 & April 1987 & GA-A18780 \\
September 30, 1987 & March 1988 & GA-A19115 \\
April 30, 1988 & June 1988 & GA-A19269 \\
October 31, 1988 & January 1989 & GA-A19412 \\
April 30, 1989 & September 1989 & GA-A19666 \\
September 30, 1989 & March 1990 & GA-A19876 \\
March 31, 1990 & July 1990 & GA-A20119 \\
September 30, 1990 & January 1991 & GA-A20335 \\
March 31, 1991 & April 1991 & GA-A20493 \\
September 30,1991 & December 1991 & GA-A20804 \\
March 31, 1992 & April 1992 & GA-A20911 \\
September 30, 1992 & January 1993 & GA-A21210 \\
March 31, 1993 & May 1993 & GA-A21326 \\
September 30,1993 & January 1994 & GA-A21511 \\
\hline
\end{tabular}

Table 1-2

FINAL TEST REPORTS OF TFE VERIFICATION PROGRAM

\begin{tabular}{||l|c||}
\hline Report Title & Document No. \\
\hline Conceptual Design & GA-A21590 \\
Converter Peformance Final Test Report & GA-A21591 \\
Insulator Seal Final Test Report & GA-A21592 \\
Sheath Insulator Final Test Report & GA-A21593 \\
Fueled Emitter Final Test Report & GA-A21594 \\
Cesium Reservoir and Interconnective Components Final Test Report & GA-A21595 \\
TFE Performance Final Test Report & GA-A21596 \\
TFE Design Package & GA-A21597 \\
Fabrication Process Specifications & GA-A21734 \\
\hline
\end{tabular}

\subsection{Westinghouse Hanford Company Reports on Cesium Reservoirs}

WHC issued several reports dealing with the fabrication, testing at ${ }^{4}$ postirradiation examination of cesium reservoirs. These are listed in Table 1-3. The reader is referred to these reports for detail on the irradiation of cesium reservoirs and their subsequent postirradiation examination (PIE). 
WESTINGHOUSE HANFORD COMPANY REPORTS ON FUELED EMITTERS

Test Documentation

1. Engineering Test Plan for EBR-II Tests UFAC-1 and UFAC-2, HEDL-TC-2938, February 1987.

2. Experimental Description and Safety Analysis for EBR-II Tests UFAC-1 and UFAC-2, HEDL-TC-2948, March 1987.

3. Fabrication Master Data Package for EBR-II Tests UFAC-1 and UFAC-2, HEDLTC-2962, April 1987.

4. Engineering Test Plan for EBR-II Tests UFAC-2B and UFAC-3, WHC-SP-0469, May 1989.

5. Experiment Description and Safety Analysis for EBR-II Tests UFAC-2B and UFAC-3, WHC-SP-0470, July 1989.

6. Supporting Analysis for UFAC Tests in EBR-II, WHC-SD-SP-DA-002, December 1989.

7. Fabrication Master Data Package for EBR-II Tests UFAC-2B and UFAC-3, WHC-SDGN-TDD-303, November 1989.

Test Data Reports

1. B. J. Makenas, L. A. Lawrence and L. M. McWethy, "Interim Examinations of UFAC-1 and UFAC-2 Fueled Emitters", WHC-SP-0519, April 1990.

2. D. M. Paxton and L. A. Lawrence, "Irradiation and Examination of the UFAC-1B Fueled Emitters", WHC-SP-0698, September 1991.

3. L. A. Lawrence, "Irradiation and Examination of the UFAC-2 and UFAC-3 Fueled Emitters," WHC-SP-1059, September 1993. 


\section{OBJECTIVES OF THE TEST PROGRAM}

\subsection{Function of the Fueled Emitter}

The function of the fueled emitter is to act as the thermionic emitter and provide the heat necessary to drive the thermionic conversion process. The components of the fueled emitter are:

1) Emitter, including the emitter stem.

2) The nuclear fuel, typically $\mathrm{UO}_{2}$, contained within the emitter.

3) Solid fission product trap.

4) Fuel holddown spring.

5) Radiation shields.

6) Fuel pedestal.

7) Spacer wires.

These are shown on Figure 1-3.

\subsection{Requirements of the Fueled Emitter}

\subsubsection{Design Requirements}

The thermionics programs in the 1960s and 1970s demonstrated in-reactor lifetime sof one to two years for thermionic devices. Experience showed that the basic design of the fueled emitter should have the following characteristics:

1) Emitter material: tungsten.

2) Emitter fabrication process: chemical vapor deposition.

3) Fuel: $\mathrm{UO}_{2}$.

4) Emitter thickness to diameter ratio: .07 to .10 .

5) Emitter length-to-diameter ratio: 3 to 5 .

The optimum fuel emitter design for a megawatt class system is shown on Table 2-1. The test matrix covers parameters around the values shown in Table 2-1.

\subsubsection{Performance Requirements}

Emitter Distortion. Emitter distortion over the 7 year lifetime should be less than the interelectrode gap, which is typically in the range of 5 to 20 mils.

Thermo-chemical Interaction. Chemical reactions between emitter constituents should not cause loss of function. 


\section{OPTIMUM DESIGN PARAMETERS FOR MEGAWATT CLASS FUELED EMITTER}

\begin{tabular}{||l|l||}
\hline \hline Emitter & \\
\hline Material & Tungsten \\
Outside diameter, cm & 1.27 \\
Thickness, cm & 0.10 \\
Current density, a/cm & 7 \\
Nominal temperature, K & 1800 \\
Emitter length, cm & \\
& \\
Fuel & $\mathrm{UO}_{2}$ \\
Outside diameter, cm & 1.0 \\
Inside diameter, cm & Variable \\
Enrichment, \% U-235 & 93 \\
Fuel length, cm & 4.65 \\
Nominal fuel burnup, atom percent & 4.1 \\
Peak fuel burnup, atom percent & 5.3 \\
Nominal fast fluence, $10^{22}$ nvt & 2.7 \\
Peak fast fluence, 1022nvt & 3.5 \\
\hline
\end{tabular}

\subsection{Goals of the Test Program}

The goal of the fueled emitter test program was to design and demonstrate a fueled emitter which had a 7 year life. Parameters to be studied included:

1) Emitter thickness

2) Emitter material

3) Fuel design and material.

The major failure mechanisms to be studied were emitter distortion resulting from fission product buildup within the emitter and thermo-chemical interactions.

Ex-reactor testing was originally planned to study thermal ratcheting phenomena if initial studies indicated a potential performance problem area. However, as explained in Section 5.1, the ratchet effect does not appear to be a potential failure mode so no ex-reactor testing was conducted.

\subsection{Test Matrix}

Fueled emitters were tested in EBR-II, the test series being called Uninstrumented Fast Reactor Accelerated Component (UFAC) tests. Two batches of UFAC emitters were fabricated, as shown on Table 2-2. The real time emitters had a diameter of .5 inches, while accelerated 
TABLE 2-2

UFAC EMITTER IDENTIFICATION SCHEME

\begin{tabular}{|c|c|c|c|c|c|c|}
\hline $\begin{array}{c}\text { ID I } \\
\text { Real Time }\end{array}$ & $\begin{array}{l}\text { umber } \\
\text { Accelerated }\end{array}$ & Diameter & Thickness & $\begin{array}{c}\text { Design } \\
\text { Temperature }\end{array}$ & $\begin{array}{c}\text { Fuel } \\
\text { Design }\end{array}$ & Comments \\
\hline $\begin{array}{l}\text { SU2-1 } \\
\text { SU2-2 } \\
\text { SU2-3 }\end{array}$ & $\begin{array}{l}\text { SU1-4 } \\
\text { SU1-5 } \\
\text { SU1-6 } \\
\text { SU1-7 } \\
\text { SU1-8 } \\
\text { SU1-9 } \\
\text { SU1-10 }\end{array}$ & $\begin{array}{r}0.5 \\
0.5 \\
0.5 \\
0.25 \\
0.25 \\
0.25 \\
0.25 \\
0.25 \\
0.25 \\
0.25\end{array}$ & $\begin{array}{l}0.040 \\
0.050 \\
0.040 \\
0.020 \\
0.020 \\
0.020 \\
0.020 \\
0.020 \\
0.025 \\
0.025\end{array}$ & $\begin{array}{c}\text { UFAC BATCH-1 } \\
1800 \\
1800 \\
1800 \\
1700 \\
1800 \\
1900 \\
1800 \\
1900 \\
1800 \\
1900 \\
\\
\text { UFAC BATCH-2 } \\
\\
1800 \\
1800 \\
1800 \\
1800 \\
1800 \\
1800 \\
1800\end{array}$ & $\begin{array}{l}15 \% \text { void } \\
15 \% \text { void } \\
\text { Solid } \\
15 \% \text { void } \\
15 \% \text { void } \\
15 \% \text { void } \\
\text { Solid } \\
\text { Solid } \\
15 \% \text { void } \\
15 \% \text { void } \\
\\
\\
15 \% \text { void } \\
25 \% \text { void } \\
- \\
- \\
15 \% \text { void } \\
- \\
-\end{array}$ & $\begin{array}{l}\text { Reference design } \\
\text { Thick emitter } \\
\text { Solid fuel } \\
\text { Reference design/low temperature } \\
\text { Reference design } \\
\text { Reference design/high temperature } \\
\text { Solid fuel } \\
\text { Solid fuel/high temperature } \\
\text { Thick emitter } \\
\text { Thick emitter/high temperature }\end{array}$ \\
\hline
\end{tabular}


testing used a diameter of .25 inches. Fuel burnup in the accelerated specimen was accumulated at about 4.5 times faster than real time. The emitter thickness to diameter ratio was kept constant as the diameter was reduced so that the restraint to swelling pressures generated by the fuel was kept appropriately constant.

While CVD tungsten with $\mathrm{UO}_{2}$ fuel was the focus of most of the testing, two alternate fuel forms were evaluated: insulated fuel and wafered fuel. The insulated fuel had a thin rind of depleted $\mathrm{UO}_{2}$ surrounding a core of fully enriched $\mathrm{UO}_{2}$, the purpose being to increase the temperature of the fuel containing fission products and reduce its creep strength.

The wafered fuel had thin disks of tungsten located at several axial positions to better conduct heat from the center of the $\mathrm{UO}_{2}$ to the emitter. The average $\mathrm{UO}_{2}$ temperature would then be lowered and its tendency to swell reduced. 


\section{FABRICATION DEVELOPMENT}

\subsection{UFAC Batch 1 Fabrication}

Each fueled emitter test specimen is enclosed in a test capsule as shown in Figure 3-1. The test specimen contains the emitter, $\mathrm{UO}_{2}$ fuel, a fuel holddown spring, and a stand-off wire and shield at the bottom. The tungsten emitter is attached to a niobium structure at the top through a tantalum transition component.

The test specimen is completely surrounded by a niobium sleeve. The gap formed between the emitter and the niobium is filled with a helium/argon mixture which serves as the primary temperature control for the emitter. This assembly is attached to a closed tube that forms the plenum for the collection of the fission gases generated during irradiation. The size of the tube was chosen to maintain the fission gas pressure to a fraction of an atmosphere throughout the irradiation. These components are encased within a stainless steel outer secondary containment which forms the boundary with the EBR-II primary coolant sodium.

Figure 3-1 shows an accelerated test specimen in the test capsule, but a real time specimen would be similarly located.

Extensive heat transfer calculations were performed to evaluate the emitter temperatures based on the fabricated dimensions and gas composition. To bring these calculated emitter temperatures close to the design values, the inner diameter of the outer containment tube was individually honed to adjust the gap thickness. The final emitter temperature predictions of the as-fabricated test articles are shown in Table 3-1 along with the original design values.

Table 3-1

EMITTER TEMPERATURE - UFAC BATCH 1

\begin{tabular}{||c|c|c|c||}
\hline \hline & UFAC Capsule & Design Temperature & $\begin{array}{c}\text { Calculated As-Built } \\
\text { Temperature }\end{array}$ \\
\hline 1 & SU2-1 & 1800 & 1824 \\
2 & SU2-2 & 1800 & 1820 \\
3 & SU2-3 & 1800 & 1812 \\
4 & SU1-4 & 1700 & 1722 \\
5 & SU1-5 & 1800 & 1812 \\
6 & SU1-6 & 1900 & 1908 \\
7 & SU1-7 & 1800 & 1818 \\
8 & SU1-8 & 1900 & 1896 \\
9 & SU1-9 & 1800 & 1809 \\
10 & SU1-10 & 1900 & 1894 \\
\hline
\end{tabular}




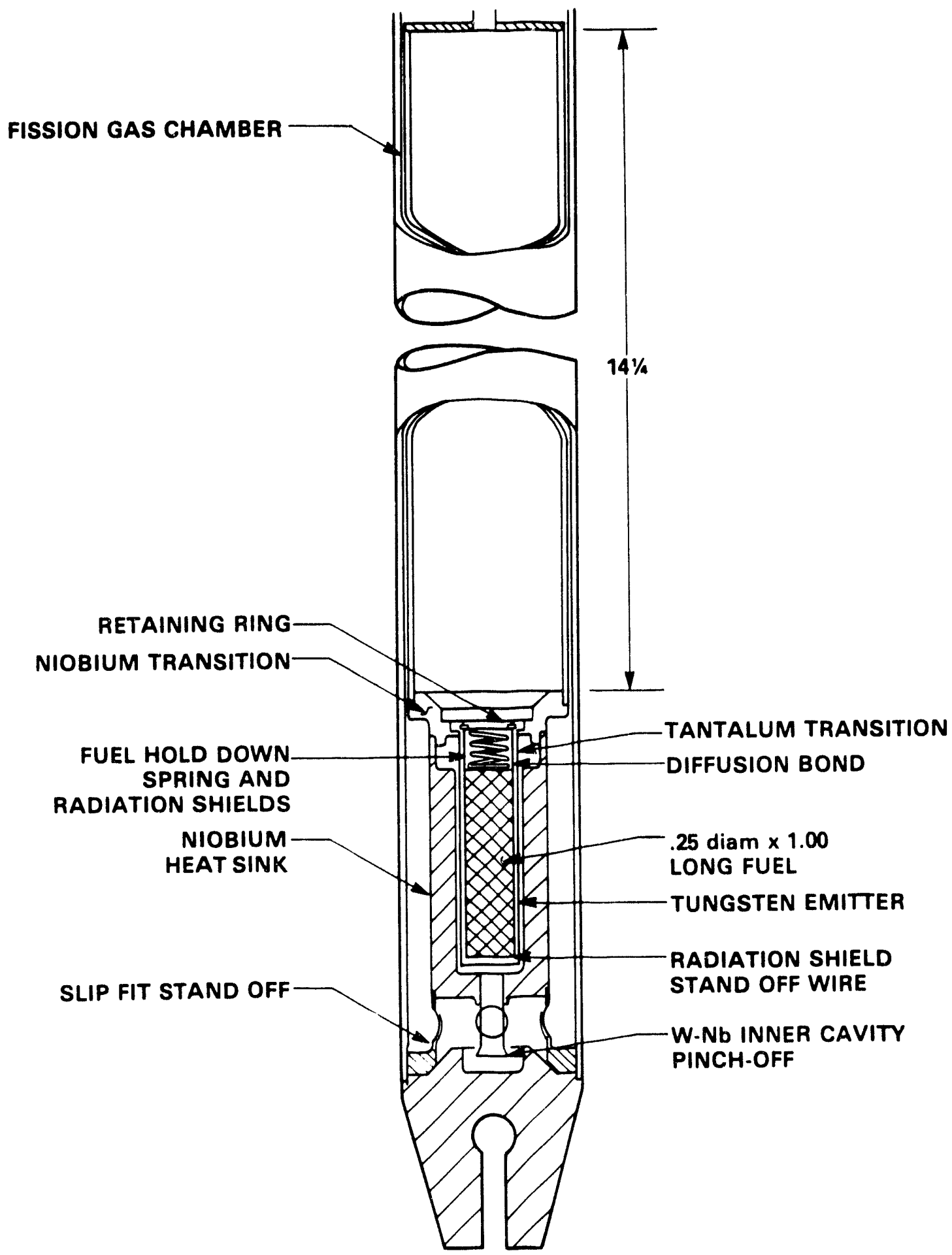

Figure 3-1. UFAC Fueled Emitter Test Capsule 
The uncertainties in the emitter temperature calculations have also been quantified, considering manufacturing tolerances, gas mixture and emissivity uncertainties, as well as variatic ns in EBR-II power and gamma heating. The results are summarized in Table 3-2. The uncertainties range from about 85 to $101 \mathrm{~K}$, when the errors are considered arithmetically, and between 35 and $39 \mathrm{~K}$, when considered statistically. These uncertainties, especially the statistical values, are very close to those that could be obtained if you could place a thermocouple close to the emitter.

The ten capsules of UFAC Batch 1 were assembled into the two test groups: UFAC-1 comprised the 7 small emitters for accelerated testing and UFAC-2 comprised the 3 emitters for realtime testing. Irradiation of UFAC-1 and UFAC-2 began on May 21, 1987.

\subsection{Bonding at the Tungsten-to-Tantalum Transition Joint}

The following Batch 1 test specimens were observed to experience a fracture shortly after irradiation began near the point where the tungsten was bonded to the tantalum transition piece:

Real time emitters: $\quad$ SU2-3

Accelerated emitters: SU1-6

SU1-7

SU1-10

The tantalum transition piece is necessary to accommodate the differential thermal expansion differences between the tungsten emitter and the niobium cell structure. 'The impact of this fracture on emitter performance is discussed in Section 4.2.

An examination of test conditions and the fabrication records showed the cause of the unexpected fractures to be:

1) The temperature at the bond during the irradiation testing was low, only about $1000^{\circ} \mathrm{C}$, increasing thermal stresses at the bond.

2) The bonding pressure during fabrication was at the low end of the acceptable range, particularly considering the low temperature during irradiation.

The corrective action for Batch 2 was twofold:

1) The test temperature at the bond was increased to $1200^{\circ} \mathrm{C}$ by relocating the $\mathrm{W} / \mathrm{Ta}$ joint closer to the heated emitter.

2) The fabrication bonding pressure was increased. 
TABLE 3-2

EMITTER TEMPERATURE UNCERTAINTY AT START OF TEST

\begin{tabular}{|c|c|c|c|c|c|c|c|c|c|c|c|c|c|}
\hline & \multicolumn{3}{|c|}{ Emitter Temperature } & \multicolumn{8}{|c|}{ Uncertainty (K) } & \multirow[b]{2}{*}{$\begin{array}{l}\text { Total } \\
( \pm X)\end{array}$} & \multirow[b]{2}{*}{$\begin{array}{r}\sqrt{\Sigma \Delta_{I}^{2}} \\
( \pm K)\end{array}$} \\
\hline & $\begin{array}{l}\text { Design } \\
\text { (K) }\end{array}$ & $\begin{array}{l}\text { Predicted } \\
\text { (K) }\end{array}$ & $\boldsymbol{\varepsilon}$ & $\begin{array}{l}\text { Gas Mix and } \\
\text { Emissivity }\end{array}$ & $\begin{array}{l}\text { Wr's } \\
\pm 20 \%\end{array}$ & $\begin{array}{l}\text { Power } \\
+3 \% \\
\end{array}$ & $\begin{array}{c}\text { Emitter } \\
\text { Eccentricity } \\
\text { (As Built) }\end{array}$ & $\begin{array}{l}\text { Collector } \\
\text { Eccentricity } \\
\text { (Maximum) }\end{array}$ & $\begin{array}{c}\text { Emitter } \\
\text { Gap } \\
\pm 0.0005\end{array}$ & $\begin{array}{l}\text { Collector } \\
\text { Gap } \\
\pm 0.0005\end{array}$ & $\begin{array}{c}\text { Stem } \\
\text { Loss } \\
+10 \% \\
\end{array}$ & & \\
\hline SU2-1 & 1800 & 1797 & -3 & 20 & 11 & 18 & 2 & 2 & 12.5 & 14 & 14 & 93.5 & 37.4 \\
\hline SU2-2 & 1800 & 1797 & -3 & 20 & 15 & 15 & 7 & 2 & 12.5 & 14 & 13 & 98.5 & 37.7 \\
\hline SU2-3 & 1800 & 1789 & -11 & 21 & 10 & 18 & 5 & 2 & 12.5 & 14 & 12 & 94.5 & 37.3 \\
\hline SU1-4 & 1700 & 1699 & -1 & 16 & 14 & 19 & 4 & 2 & 20.0 & 14 & 8 & 97.0 & 38.7 \\
\hline SU1-5 & 1800 & 1787 & -13 & 15 & 10 & 20 & 3 & 2 & 15.0 & 14 & 8 & 87.0 & 35.0 \\
\hline SU1-6 & 1900 & 1833 & -67 & 17 & 15 & 20 & 1 & 2 & 17.5 & 14 & 9 & 85.5 & 38.8 \\
\hline SU1-7 & 1800 & 1794 & -6 & 15 & 11 & 20 & 5 & 2 & 15.0 & 14 & 8 & 90.0 & 35.5 \\
\hline SU1-8 & 1900 & 1835 & -65 & 16 & 11 & 21 & 3 & 2 & 17.5 & 14 & 9 & 93.5 & 37.6 \\
\hline SU1-9 & 1800 & 1716 & -84 & 13 & 13 & 19 & 7 & 2 & 15.0 & 14 & 13 & 96.0 & 36.6 \\
\hline SU1-10 & 1900 & 1834 & -66 & 17 & 14 & 19 & 7 & 2 & 17.5 & 14 & 11 & 101.5 & 39.0 \\
\hline
\end{tabular}


This test experience does not affect the design of a reactor TFE, since test conditions, particularly thermal stresses at the bond location, are more severe than those of a typical reactor design.

\subsection{As-Built Operating Temperature}

The UFAC capsules were designed to operate at the temperature shown in Table 3-1. The surface temperature of the emitter rose to a level where the heat lost from the emitter surface equaled the heat generated by the fuel. Changes in the heat generation rate or the rate at which heat was transported from the emitter surface changed the emitter surface temperature.

Heat was transported from the emitter surface, by gas conduction, across a $\mathrm{He} / \mathrm{Ar}$ gas mixture. The "design" ratio of these gases was determined through thernal analysis. The PIE of emitters SU2-3, SU1-6, SU1-7, and SU1-10, which experienced fracture at the tungsten-tantalum bond early in their irradiation testing, showed that the ratio of $\mathrm{He} / \mathrm{Ar}$ gas was different than that specified by design. The actual helium/argon ratio, measured in PIE, is shown below in Table 3-3. Subsequent PIE of the UFAC-1B emitters (SU1-5, SU1-6, SU1-8, and SU1-9) revealed a similar discrepancy in He/Ar gas mixtures. The problem was traced to a conductivity gauge used in capsule fabrication and was easily corrected in the UFAC Batch 2 emitters. The effect of a lower $\mathrm{He} / \mathrm{Ar}$ ratio tended to increase the emitter surface temperature.

Table 3-3

MEASURED VS DESIGN He/Ar GAS RATIO

\begin{tabular}{||c|c|c||}
\hline Capsule & He/Ar Ratio "Design" & He/Ar Ratio Measured in PIE \\
\hline SU2-3 & 1.3 & 0.7 \\
SU1-4 & 11.3 & 6.0 \\
SU1-5 & 13.9 & 7.2 \\
SU1-6 & 9.0 & 4.6 \\
SU1-7 & 11.2 & 5.6 \\
SU1-8 & 7.6 & 4.2 \\
SU1-9 & 39.0 & 18.2 \\
SU1-10 & 6.9 & 3.6 \\
\hline
\end{tabular}

In addition, during the PIE of emitters SU2-3, SU1-6, SU1-7, and SU1-10, a burnup analysis revealed that the capsules had accumulated less burnup than anticipated. The reduced level of burnup meant that less fissioning occurred and therefore heat generation rates were less than design. This effect tended to lower the emitter surface temperature.

Based on actual heat generation rates and actual He/Ar gas mixtures, updated thermal 
analyses were performed. The revised emitter temperatures for the Batch 1 emitters used in the fueled emitter data base are presented below in Table 3-4.

Table 3-4

ACTUAL FUELED EMITTER OPERATING TEMPERATURE

\begin{tabular}{||c|c||}
\hline Capsule & $\begin{array}{c}\text { As-Operated Peak Emitter } \\
\text { Temperature (K) }\end{array}$ \\
\hline SU2-1 & 1810 \\
SU2-2 & 1840 \\
SU1-4 & 1640 \\
SU1-5 & 1717 \\
SU1-8 & 1815 \\
SU1-9 & 1680 \\
\hline
\end{tabular}

\subsection{Rhenium Fuel Pedestals and Heat Shields}

It was learned during the PIE of Batch 1 emitters that thermo-chemical reactions involving $\mathrm{Re}$ can cause emitter thinning. This is discussed in detail in Section 4.4. As a result, for Batch 2, the fuel pedestals and heat shields were fabricated of pure tungsten.

\subsection{UFAC Batch 2 Fabrication}

The emphasis of Batch 2 UFAC emitters was on advanced fuel configurations with the objective of increasing emitter lifetime/performance. As shown on Table 2-2, the matrix includes:

1) Batch 1 replicates for performance comparison. The emitters were:

- $\quad$ SU2-11, real time emitter.

- SU2-12, real time emitter with a high void volume.

- SU2-16, accelerated emitter.

2) Insulated fuel, to investigate the effect of a depleted layer of $\mathrm{UO}_{2}$ adjacent to the emitter. The depleted $\mathrm{UO}_{2}$ will result in a higher average temperature for the fissioning fuel. The emitters were:

- SU2-14, real time emitter.

- SU3-17, accelerated emitter.

3) Wafered fuel to investigate the effect of lower fuel temperature on emitter distortion. The emitters were:

- SU2-15, real time emitter.

- SU3-20, accelerated emitter. 
Figure 3-2 is a comparative illustration of the fueled emitter configurations for Batch 2.

In addition to the fuel form variations, the SU2-11 and SU2-12 emitters incorporated a solid fission product trap similar to that projected for the prototype emitter, and the SU2-12 and SU2-14 emitters featured a machined 0.020 in. thick region below the tungsten-totantalum bond intended as stress relief for the bond. This feature replicated the $\mathrm{H}$-series TFE emitter "stem" configuration in the region below the bond. Both the fission product trap and emitter stress relief are shown in Figure 3-2.

\subsubsection{Insulated Fuel Design}

The fuel for this concept consisted of an enriched solid pellet contained within a depleted annular "rind". The depleted layer was $0.8 \mathrm{~mm}$ thick in the realtime test and 0.5 $\mathrm{mm}$ thick in the accelerated test. The fission and gamma heat generated in the central pellet must be conducted through the depleted outer $\mathrm{UO}_{2}$ prior to rejection from the emitter. Because of the low thermal conductivity of the $\mathrm{UO}_{2}$ the temperature of the central zone will be high, resulting in low creep strength. The fission product induced swelling of the central zone will be opposed by the stronger, outer fuel rind as well as the tungsten emitter. Diametral distortion of the emitter should therefore be reduced.

\subsubsection{Wafered Fuel Design}

The fuel pellet for this concept was replaced by alternate wafers of fuel and tungsten. A 3 to 1 ratio of fuel-to-tungsten was chosen to minimize both the temperature and the gradient in the fuel. The lower fuel temperature should reduce fuel swelling and, thus, emitter distortion. The heat will flow axially to the tungsten wafers and then radially outward along the wafer for rejection out of the emitter. Once the fuel evaporates and redeposits on the emitter inner surface, the radial heat flow will further lower the fuel temperature. The fuel would therefore ideally operate only slightly above the emitter temperature of about $1800 \mathrm{~K}$.

\subsubsection{Thermal Modeling for Batch 2}

Thermal analysis of Batch 2 emitters was required to ensure the desired operating temperatures would be obtained. The calculations were two dimensional and took into account end losses, updated core configurations and the fission rate based on Batch 1 experience. The helium to argon gas ratio and the gas gap thickness were picked to give the desired emitter temperature.

\subsubsection{As-Fabricated Data}

Each emitter was carefully measured before assembly into the test capsule. Those dimensions and other data are shown on Table 3-5. 

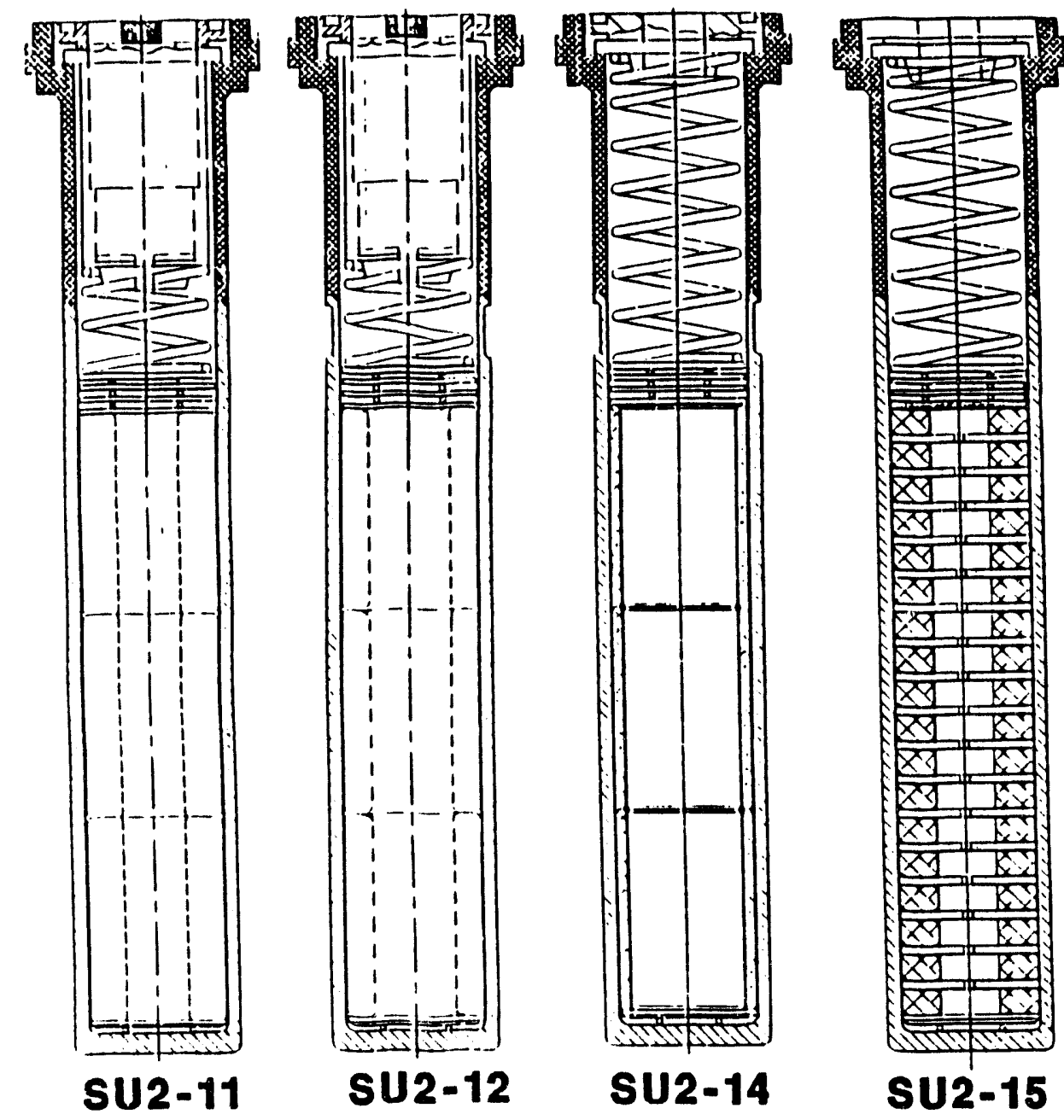
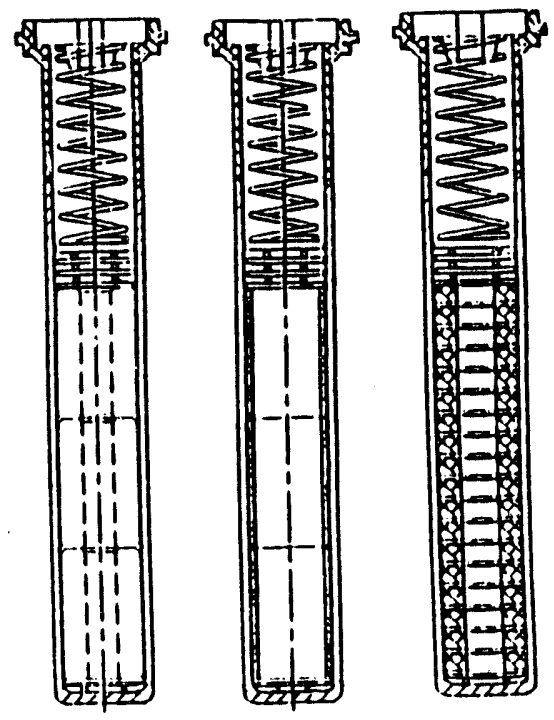

SU3-16,

Figure 3-2. UFAC Batch 2 Emitters 
Table 3-5

AS-FABRICATED DATA FOR BATCH 2

\begin{tabular}{||l|l|l|l|l|l|l|l|}
\hline \multicolumn{1}{|c|}{ Item } & SU2-11 & SU2-12 & SU3-16 & SU2-14 & SU3-17 & SU3-20 & SU2-15 \\
\hline Fuel enrichment, atomic weight \% & 9.1 & 8.6 & 29.5 & 9.1 & 36 & 36 & 12.54 \\
Tungsten emitter ID nominal, inch & 0.4220 & 0.4201 & 0.2106 & 0.4201 & 0.2111 & 0.2107 & 0.4202 \\
Tungsten emitter OD nominal, inch & 0.4999 & 0.5004 & 0.2502 & 0.5000 & 0.2502 & 0.2499 & 0.5001 \\
Niobium collector ID, fuel region, nominal, & & & & & & & \\
inch & 0.58 & 0.58 & 0.3105 & 0.58 & 0.3105 & 0.3105 & 0.58 \\
Niobium collector ID, sleeve region, nominal, & & & & & & & \\
inch & 0.58 & 0.58 & 0.3305 & 0.58 & 0.3305 & 0.3305 & 0.58 \\
Niobium collector OD, nominal, inch & 0.74 & 0.74 & 0.74 & 0.74 & 0.74 & 0.74 & 0.74 \\
Emitter to collector gap, nominal, inch & 0.0400 & 0.0398 & 0.0302 & 0.0400 & 0.0302 & 0.0303 & 0.0400 \\
Fuel pellet assembly length, inch & 1.825 & 1.827 & 0.955 & 1.819 & 0.997 & 1.023 & 1.879 \\
Fuel pellet/emitter diametral gap, nominal & 0.011 & 0.010 & 0.009 & 0.007 & 0.006 & 0.004 & 0.006 \\
Fuel pellet mass, g & 32.2 & 30.6 & 4.59 & 28.2 & 3.3 & 3.1 & 27.6 \\
Emitter to collector gas gap composition, & & & & & & & \\
nominal, \%He & 47.3 & 55.7 & 91.5 & 52.1 & 100 & 92 & 43.2 \\
Fuel (insulator) outside diameter, inch & 0.409 & 0.41 & 0.202 & 0.413 & 0.205 & 0.207 & 0.414 \\
\hline
\end{tabular}

\subsection{Advanced Materials}

Advanced emitter materials were considered for use in both real time and accelerated testing, the only requirement being that the materials have a significant data base such that a materials development program would not be necessary.

Tungsten hafnium carbide (WHfC) is such a material with a potentially significant lifetime improvement over CVD tungsten. The selection considered both a demonstrated mechanical strength advantage and an available fabrication technology. Westinghouse Advanced Energy Systems was identified as a potential supplier since they had recently completed a fabrication run for the Army's Picatinny Arsenal. Four bars of tungsten - 0.35 ha.nium - 0.025 carbon were ordered from Westinghouse, each approximately $1.9 \mathrm{~cm}$ in diameter and $38 \mathrm{~cm}$ long.

Westinghouse fabricated five ingots by vacuum arc melting to produce the four bars. The ingots were each about $5 \mathrm{~cm}$ in diameter by $10 \mathrm{~cm}$ long which would be extruded to the final dimensions. However, all attempts at this final extrusion proved to be only partially successful. During the extrusion, the ingot became stuck and solidified in the die damaging both the liner and the punch. Several steps taken to mitigate the problem were not successful. Two partially extruded round bars and one partially extruded flat bar were delivered to GA as part of this effort.

The problem with the extrusion allowed only a partial achievement of the goals for the advanced material. One area which proved to be successful was the fabricability of the material. Machining of the WHfC using electrical discharge methods and the subsequent grinding/honing to the finished product proved to be straightforward and easily 
accomplished. Also successful was diffusion bonding the material to tantalum, representative of the joint at the top of the emitter stem for attaching the emitter to the TFE.

As an advanced fuel material, $\mathrm{UO}_{2}$ doped with, for example $\mathrm{Nb}_{2} \mathrm{O}_{5}$ to enhance the creep rate, was considered, but the high $\mathrm{UO}_{2}$ operating temperatures appeared to preclude the realization of a higher creep rate.

Tungsten sponge or felt was also considered for insertion between the $\mathrm{UO}_{2}$ fuel and the tungsten clad (Ref. 3-1). This would act as a spring to absorb fuel distortion. However, it was difficult to get a low density tungsten material with an acceptable thermal conductivity. A processing concept which did appear to have an attractive thermal conductivity was considered too developmental for near term testing in EBR-II. 


\section{IN-REACTOR TESTING}

\subsection{Test Specimen Irradiations}

\subsubsection{Reactor Operation}

The irradiation of the UFAC fueled emitters was completed in January, 1992. The irradiation schedule in EBR-II is shown on Figure 4-1. The UFAC-1 specimens were the seven accelerated test specimens of Batch 1 shown on Table 2-2. The UFAC-2 specimens were the three real time specimens of Batch 1 to which the four real time specimens from Batch 2 were later added. UFAC-3 comprised the three accelerated specimens of Batch 2 .

The status of the test specimen groups is shown on Table 4-1. Periodically, an interim nondestructive examination was performed during which neutron radiographs (NR) were taken, and at that time the letter designation of the subassembly was changed, e.g., UFAC-1 to UFAC-1A, etc.

A road map showing the essential features of Table 4-1 is shown on Figure 4-2. The dates indicated in Figure 4-2 are approximate.

\subsubsection{Review of Test Specimen Performance}

Each specimen that was irradiated in EBR-II is briefly discussed below. In some cases, additional details are given in later sections of this report. A summary is given on Table 4-2.

SU2-1: This emitter remained in EBR-II for the full irradiation period. At the end, the capsule was bowed. Data are valid to the end of the irradiation.

SU2-2: The emitter was fractured at the end of the irradiation. Data are valid up to the NR before final discharge.

SU2-3: This emitter was fractured soon after beginning irradiation and was removed after the first irradiation interval. None of the data are valid. The impact of emitter fracture is discussed in Section 4.2.

SU1-4: This emitter was removed after achieving goal burnup of $3.8 \mathrm{a} / \mathrm{o}$. At the time of removal it was noted that there was a fracture at the W-Ta transition joint. Hence data are valid only up to the NR before final discharge.

SU1-5: This emitter was removed after achieving goal burnup of $3.8 \mathrm{a} / \mathrm{o}$. At the time of removal, it was noted that there was a breach of the emitter. Hence data are valid only up to the NR before final discharge. 


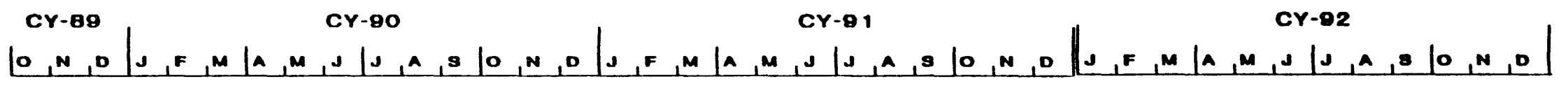

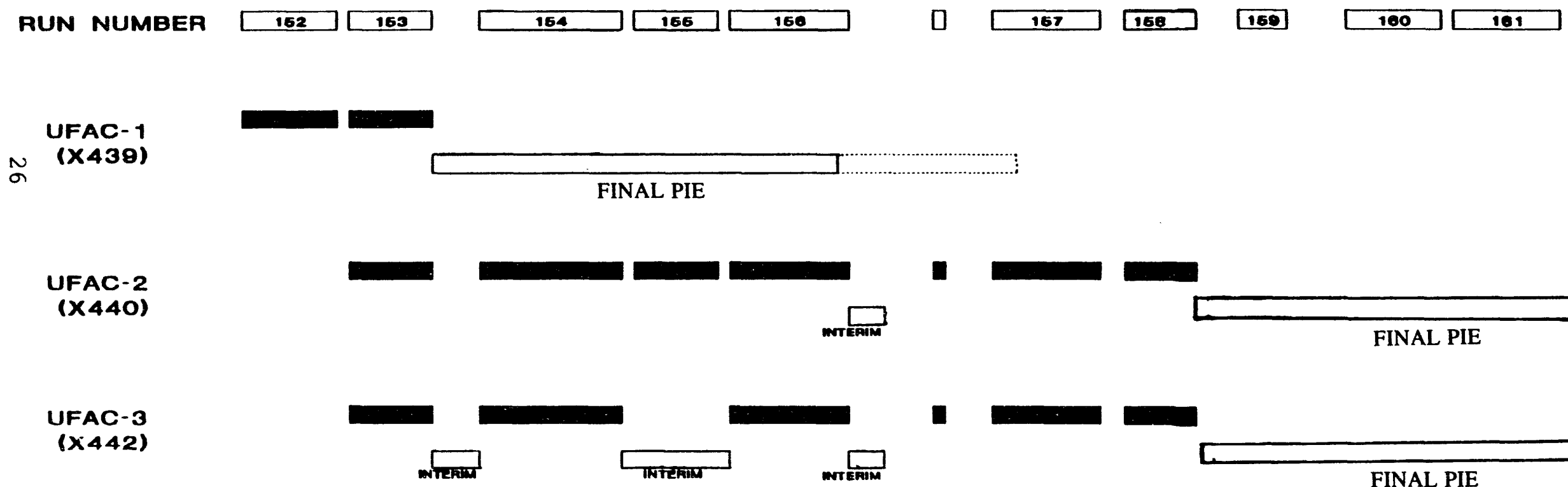

$\square \ldots$

wrLalय


Table 4-1

SUMMARY STATUS OF UFAC TEST SERIES IN EBR-II

\begin{tabular}{|c|c|c|c|c|c|c|}
\hline $\begin{array}{l}\text { Test } \\
\text { Desig- } \\
\text { nation }\end{array}$ & Test Content & Status & EFPD* & $\begin{array}{l}\text { Irradiation } \\
\text { Fast } \\
\text { Fluence } \\
\times 10^{22} \mathrm{n} / \mathrm{cm}^{2}\end{array}$ & $\begin{array}{l}\text { Peak } \\
\text { Burnup } \\
\text { (at. \%) }\end{array}$ & $\begin{array}{l}\text { Postirradiation } \\
\text { Examination } \\
\text { Status* }\end{array}$ \\
\hline UFAC-1 & 7 Batch-1 FEs & $\begin{array}{l}\text { Complete } \\
8-87\end{array}$ & 94.5 & 1.5 & 1.0 & $\begin{array}{l}\text { NDE } 7 \text { capsules } \\
\text { complete } 11-87\end{array}$ \\
\hline UFAC-1A & 7 Batch-1 FEs & $\begin{array}{l}\text { Complete } \\
4-88\end{array}$ & 221.5 & 3.6 & 2.1 & $\begin{array}{l}\text { NDE } 7 \text { capsules } \\
\text { complete } 7-88 \\
\text { DE } 3 \text { capsules } \\
\text { complete } 6-89\end{array}$ \\
\hline UFAC-1B & 4 Batch-1 FEs & $\begin{array}{l}\text { Complete } \\
4-90\end{array}$ & 518 & 7.6 & 4.3 & $\begin{array}{l}\text { NDE } 4 \text { capsules } \\
\text { complete } 6-90\end{array}$ \\
\hline UFAC-2 & 3 Batch-1 FEs & $\begin{array}{l}\text { Complete } \\
4-88\end{array}$ & 285 & 2.8 & 0.5 & $\begin{array}{l}\text { NDE } 3 \text { capsules } \\
\text { complete } 6-88 \\
\text { DE } 1 \text { capsules } \\
\text { complete } 6-89\end{array}$ \\
\hline UFAC-2A & 2 Batch-1 FEs & $\begin{array}{l}\text { Complete } \\
3-89\end{array}$ & 467 & 4.2 & 1.1 & $\begin{array}{l}\text { NDE } 2 \text { capsules } \\
\text { complete } 6-89\end{array}$ \\
\hline UFAC-2B & $\begin{array}{l}2 \text { Batch-1 FEs } \\
4 \text { Batch-2 FEs }\end{array}$ & $\begin{array}{l}\text { Complete } \\
4-91\end{array}$ & $\begin{array}{l}798 \\
331\end{array}$ & $\begin{array}{l}7.5 \\
2.9\end{array}$ & $\begin{array}{l}2.0 \\
.85\end{array}$ & $\begin{array}{l}\text { NDE } 6 \text { capsules } \\
\text { complete }\end{array}$ \\
\hline UFAC-2C & $\begin{array}{l}2 \text { Batch-1 FEs } \\
4 \text { Batch-2 FEs }\end{array}$ & $\begin{array}{l}\text { Complete } \\
1-92\end{array}$ & $\begin{array}{l}908 \\
441\end{array}$ & $\begin{array}{l}8.5 \\
4.1\end{array}$ & $\begin{array}{l}2.3 \\
1.1\end{array}$ & $\begin{array}{l}\text { NDE } 6 \text { capsules } \\
\text { complete }\end{array}$ \\
\hline UFAC-2D & 3 Batch-2 FEs & $\begin{array}{l}\text { Continue } \\
\text { FY-93 }\end{array}$ & 0 & 0 & 0 & $\begin{array}{l}\text { Continue test } \\
\text { FY }-93\end{array}$ \\
\hline UFAC-3 & 3 Batch-2 FEs & $\begin{array}{l}\text { Complete } \\
4-90\end{array}$ & 64 & 1.1 & 0.66 & $\begin{array}{l}\text { NDE } 3 \text { capsules } \\
\text { complete } 5-89\end{array}$ \\
\hline UFAC-3A & 3 Batch-2 FEs & $\begin{array}{l}\text { Complete } \\
9-90\end{array}$ & 172 & 2.9 & 1.73 & $\begin{array}{l}\text { NDE } 3 \text { capsules } \\
\text { complete } 11-90\end{array}$ \\
\hline UFAC-3B & 3 Batch-2 FEs & $\begin{array}{l}\text { Complete } \\
4-91\end{array}$ & 266 & 4.5 & 2.7 & $\begin{array}{l}\text { NDE } 3 \text { capsules } \\
\text { complete }\end{array}$ \\
\hline UFAC-3C & 2 Batch-2 FEs & $\begin{array}{l}\text { Complete } \\
1-92\end{array}$ & 376 & 6.2 & 3.5 & $\begin{array}{l}\text { NDE } 2 \text { capsules } \\
\text { complete. DE } \\
\text { planned. }\end{array}$ \\
\hline
\end{tabular}

* Equivalent full power days.

* NDE: nondestructive examinations: visual, dimensional, gamma-scan, neutron radiography.

* DE: destructive examinations: gas sampling, radiochemical burnup, metallography. 


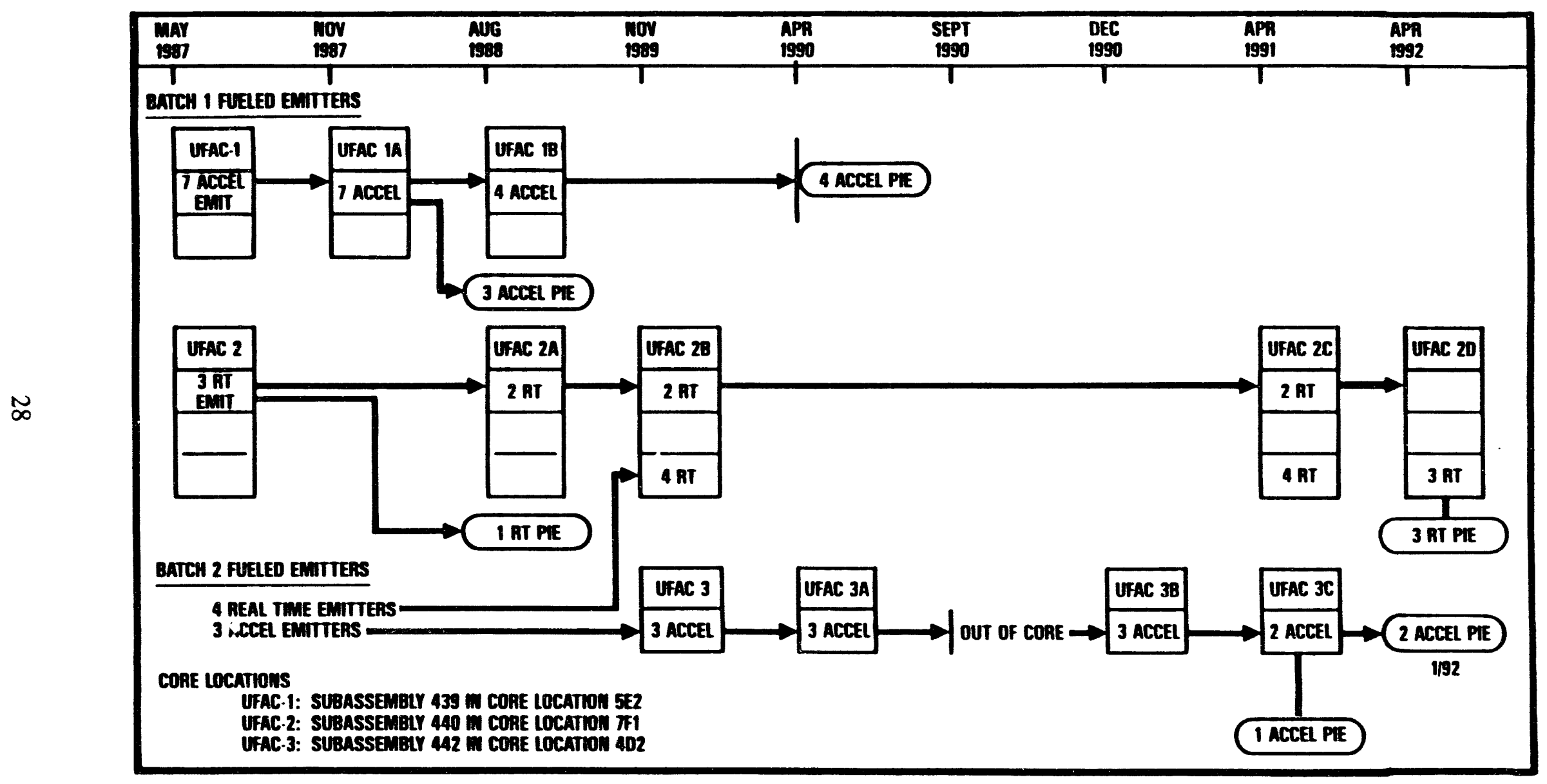

Figure 4-2. Road Map: Fueled Emitter Testing in EBR-II 
TABLE 4-2

\section{STATUS OF UFAC FUELED EMITTERS AT END OF IRRADIATION}

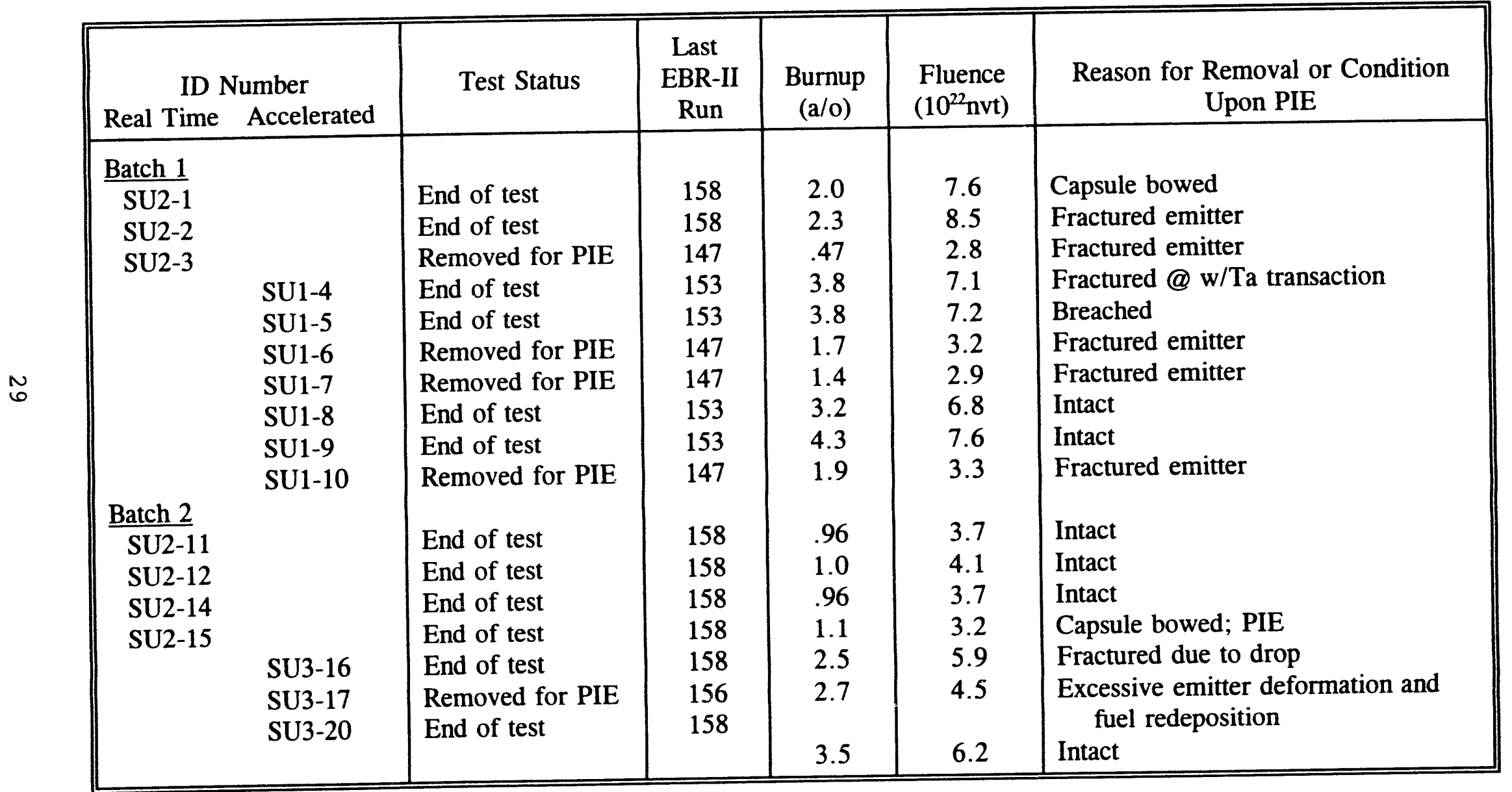


SU1-6: This emitter was fractured soon after beginning irradiation and was removed after the first irradiation period.

SU1-7: This emitter was fractured soon after beginning irradiation and was removed after the first irradiation period.

SU1-8: This emitter was removed after achieving goal burnup of $3.2 \mathrm{a} / \mathrm{o}$. Data are valid to the end of irradiation.

SU1-9: This emitter was removed after achieving goal burnup of $4.3 \mathrm{a} / \mathrm{o}$. Data are valid to the end of irradiation.

SU1-10: This emitter was fractured soon after beginning irradiation and was removed after the first irradiation period.

SU2-11: This emitter was removed at the end of the irradiation period; all of the data are valid.

SU2-12: This emitter was removed at the end of the irradiation period; all of the data are valid.

SU2-14: This emitter had insulated fuel. It was removed at the end of the irradiation period; all data appear valid.

SU2-15: This emitter had wafered fuel. It was removed at the end of the irradiation period. The capsule was bowed. The data appear valid.

SU2-16: This emitter was removed at the end of the irradiation period. It was dropped and cracked during intermediate neutron radiography taken in April, 1991. Data are valid up to this NR.

SU2-17: This emitter had insulated fuel. It was removed for PIE after 2.7 a/o burnup because of excessive emitter deformation.

SU2-20: This emitter had wafered fuel. It was removed at the end of the irradiation period. The data appear valid.

\subsection{Consequences of Emitter Fracture}

As discussed in Section 3.2, several test specimens experienced emitter fracture in the vicinity of the tungsten-to-tantalum transition joint. The effect of this fracture is to join the fission gas volume with the helium-argon gas gap volume.

An analysis of fission gas generation in specimens SU1-4, SU1-5, SU1-8 and SU1-9 
showed that for the average burnup of $3.8 \mathrm{a} / \mathrm{o}$, about $4.2 \mathrm{cc}$ of xenon and krypton should have been generated. The fission gas recovered in PIE was $3.5 \mathrm{cc}$. Hence almost all of the noble fission gases generated escaped from the fuel.

The composition of the gas recovered in PIE, which was about $4.1 \mathrm{cc}$, was:

XE 73 mole-percent

$\mathrm{Kr} 11$ mole-percent

He 12 mole-percent

Ar 2 mole-percent.

Hence, most of the gas in the gas gap after emitter fracture was fission gas.

For SU1-5, the gas conductivity and emitter temperature as a function of fission gas in the He/Ar gas mixture are shown on Figure 4-3. The conclusion is that an emitter fracture will cause the emitter temperature to rise by well over $500 \mathrm{~K}$. This temperature excursion will invalidate all emitter distortion data after the fracture occurs.

\subsection{Temperature Measurement Evaluations}

The UFAC test specimens were uninstrumented. The emitter temperature was calculated using as input the fission rate within the emitter and the as-built dimensions and materials of the test specimen. An instrumented fueled emitter irradiation test was considered in order to calibrate the uninstrumented tests but this was not done for the reasons outlined below.

As explained in Section 3, an uncertainty analysis of the test vehicle yielded an uncertainty in the emitter temperature of less than $40^{\circ} \mathrm{C}$. That is, when as-built data were used for the test vehicle together with best estimates of the actual fission rate, the emitter temperature could be calculated to within about $40^{\circ} \mathrm{C}$.

It was not possible to put a thermocouple directly on the emitter. It was felt that the use of thermocouples to measure temperatures on the test vehicle from which an emitter temperature could be calculated would not result in an improved temperature estimate for the emitter.

Passive temperature monitors were also considered, such as melt wires and miniature thermal expansion devices. However, further studies of available passive alternatives did not yield a workable scheme.

\subsection{Emitter Thinning}

It was postulated that a chemical reaction involving the Re could occur that would result in the creation of a corrosive liquid and cause erosion of the W emitter. Reaction with fission products was also considered possible. A schematic picture of the thinning observed in TFE-1H1 is shown on Figure 4-4. A complete survey of all emitters was made to 


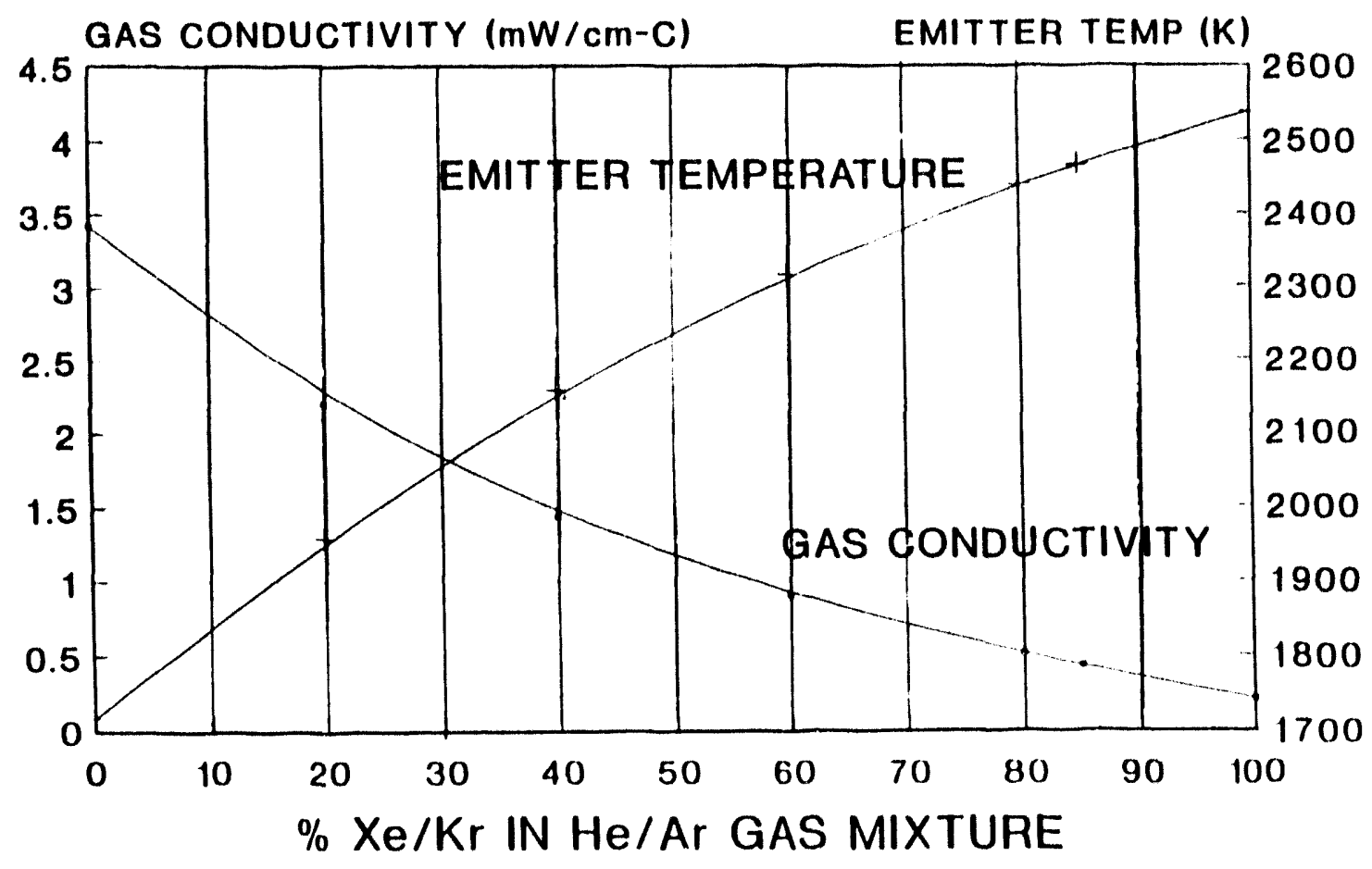

Figure 4-3. Fueled Emitter SU1-5 Gas Composition vs Emitter Temperature

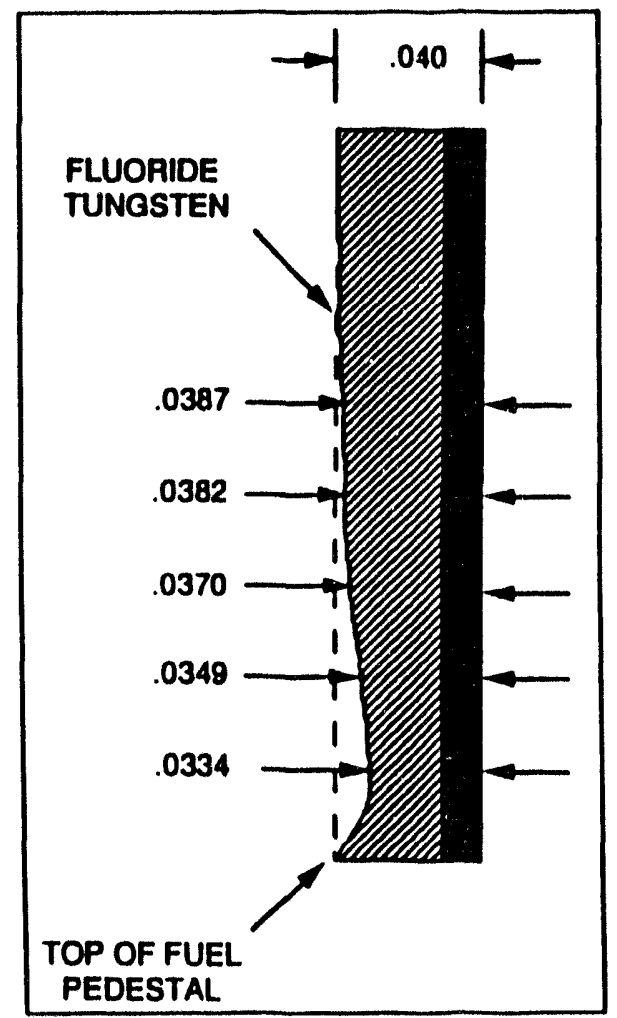

Figure 4-4. Emitter Thinning in TFE-1H1 
correlate emitter thinning with test article materials and irradiation parameters.

\subsubsection{Chemical Reactions Considered}

At high irradiation temperatures $(1800-2600 \mathrm{~K}), \mathrm{UO}_{2}$ will dissociate and liberate various vapor species, e.g., $\mathrm{U}(\mathrm{g}), \mathrm{UO}(\mathrm{g}), \mathrm{UO}_{2}(\mathrm{~g})$. During vaporization $\mathrm{UO}_{2+x}$ will preferentially lose oxygen until a congruently vaporizing composition is obtained. At this composition the $U$ aciivity may be sufficiently high to allow reaction with $R e$ in the fuel pedestal and top disc to form $\mathrm{URe}_{2}$. At irradiation temperatures, the $\mathrm{URe}_{2}$ will be liquid and quite mobile. Liquid $\mathrm{URe}_{2}$ and liquid $\mathrm{U}$-intermetallics in general, have the potential to corrode and thin the $\mathrm{W}$ emitter wall.

\subsubsection{Emitter Thinning in Test Articles}

To quantify emitter thinning, the axial dependence of emitter thickness was measured for several emitters. The maximum change in emitter thickness, i.e., the maximum thinning, was noted for each emitter. These data are summarized on Table 4-3 for those emitters that had a W/Re pedestal and on Table 4-4 for those emitters that had a W pedestal. These data are plotted vs burnup and irradiation time in Figures 4-5 and 4-6. The correlation between emitter thinning and he presence of Re in the pedestal is very strong.

This conclusion was reinforced by a microprobe analysis of SU1-4 performed during PIE at WHC. This is discussed in Section 4.5.

Table 4-3

EMITTER WALL THICKNESS CHANGE: EMITTERS WITH W/Re FUEL PEDESTALS

\begin{tabular}{||c|c|c|c|c||}
\hline Type & Designation & $\begin{array}{c}\text { Burnup } \\
\text { (at \%) }\end{array}$ & $\begin{array}{c}\text { Irradiation } \\
\text { Time (Hours) }\end{array}$ & $\begin{array}{c}\text { Change in Wall Thickness } \\
\text { (mils) }\end{array}$ \\
\hline TFE & $1 \mathrm{H} 1$ & 1.3 & 13,959 & -6.5 \\
& $1 \mathrm{H} 3$ & .7 & 7,217 & -4.7 \\
& $1 \mathrm{H} 2$ & .3 & 2,828 & 0 \\
& $3 \mathrm{H} 1$ & 1.0 & 14,162 & -5.9 \\
Batch 1, & SU1-4 & 3.8 & 12,449 & -4.9 \\
Accel & SU1-5 & 3.8 & 12,449 & -5.8 \\
& SU1-8 & 3.2 & 12,449 & -3.8 \\
& SU1-9 & 4.3 & 12,449 & -3.2 \\
Batch 1, & & & -5.6 \\
Real & SU2-1 & 2.0 & 21,792 & -2.5 \\
\hline
\end{tabular}




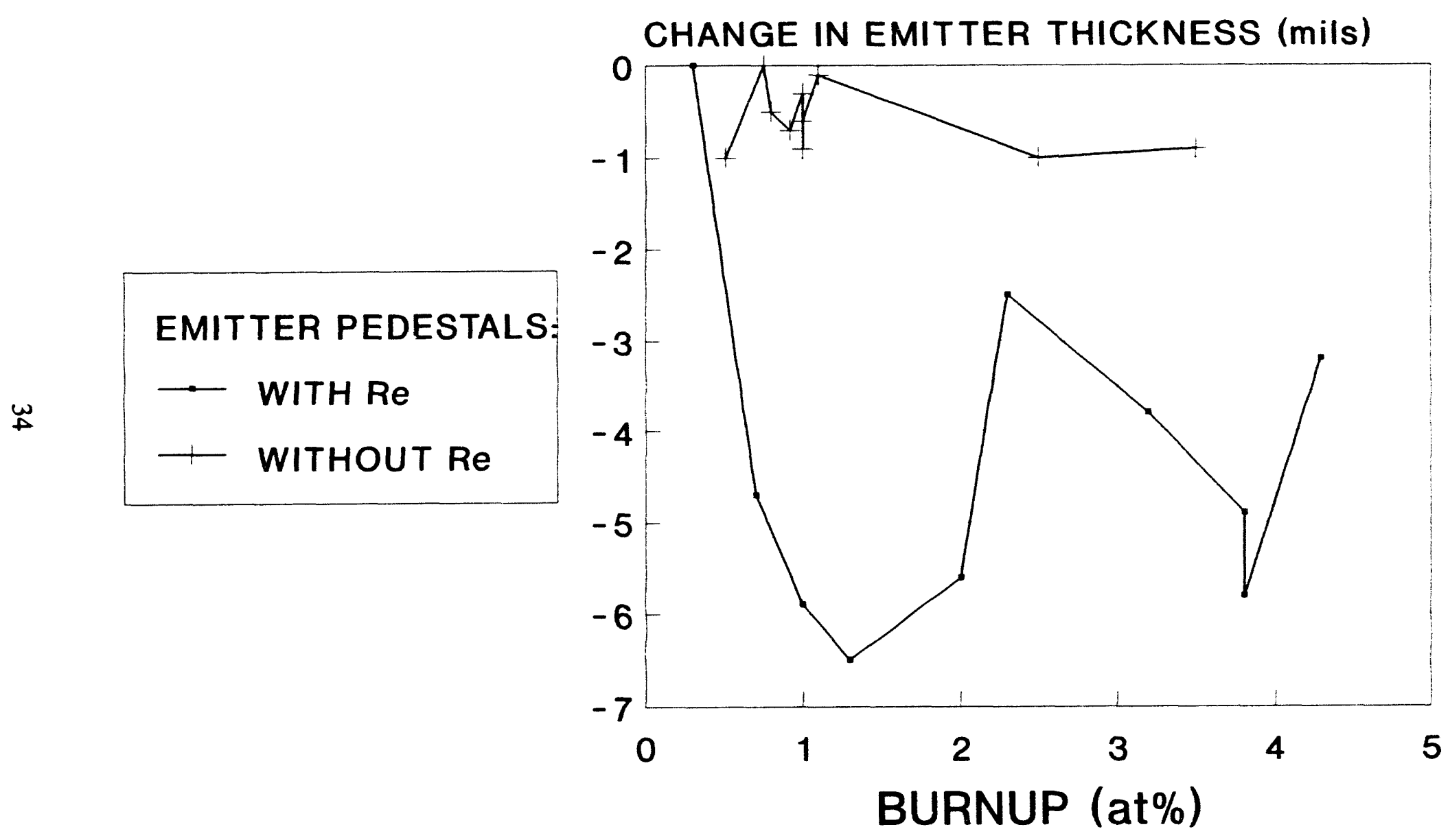

Figure 4-5. Emitter Thickness Change Effect of Re on Results 


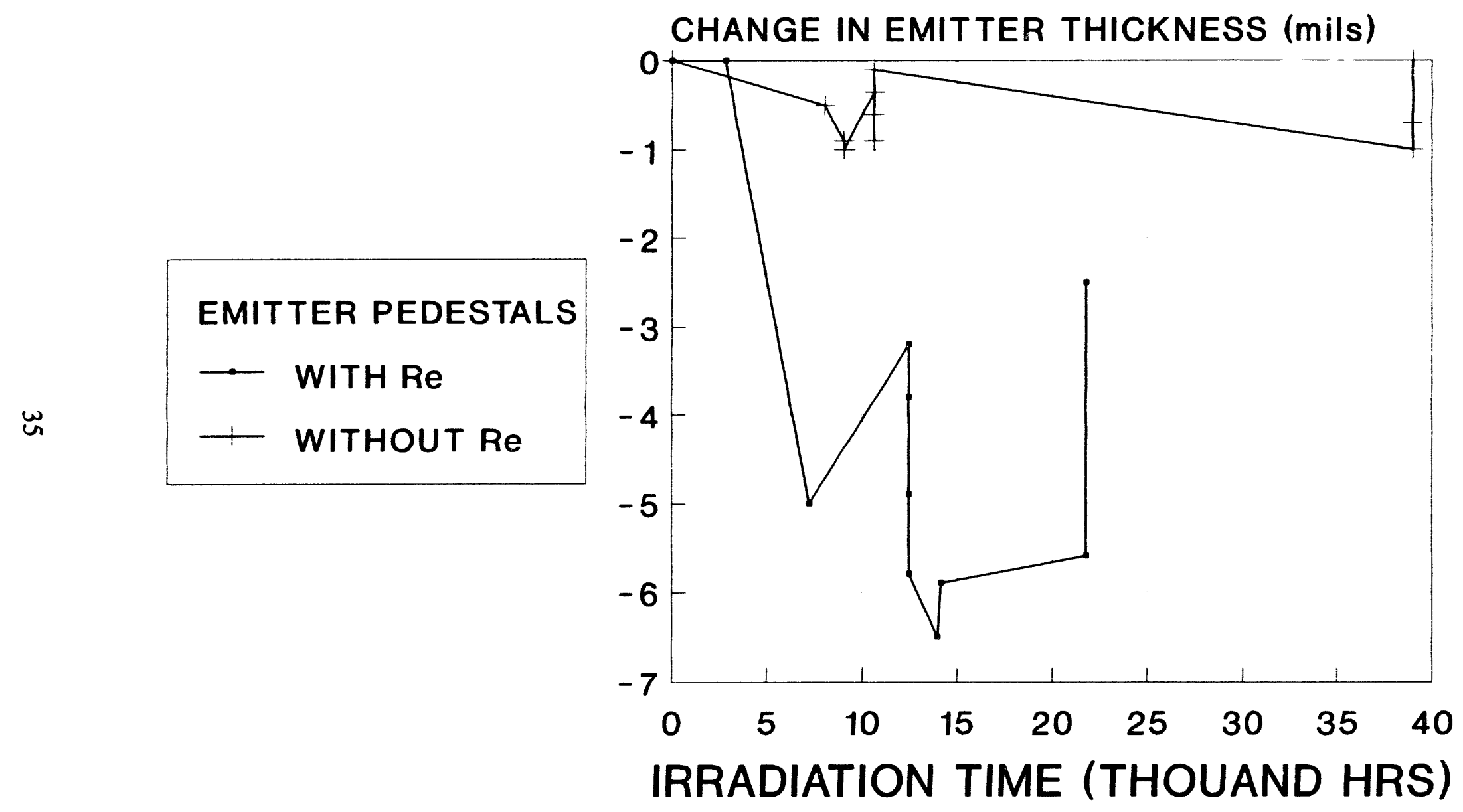

Figure 4-6. Emitter Thickness Change Effect of Re on Results 
Table 4-4

EMITTER WALL THICKNESS CHANGE: EMITTERS WITHW-ONLY FUEL PEDESTALS

\begin{tabular}{||c|c|c|c|c||}
\hline \hline Type & Designation & $\begin{array}{c}\text { Burnup } \\
\text { (at \%) }\end{array}$ & $\begin{array}{c}\text { Irradiation } \\
\text { Time (Hours) }\end{array}$ & $\begin{array}{c}\text { Change in Wall Thickness } \\
\text { (mils) }\end{array}$ \\
\hline Batch 2, & SU3-16 & 2.5 & 9,024 & -1.0 \\
Accel & SU3-20 & 3.5 & 9,024 & -0.9 \\
& & & & \\
Batch 2, & SU2-11 & 1.0 & 10,584 & -0.3 \\
Real & SU2-14 & 1.0 & 10,584 & -0.9 \\
& SU2-15 & 1.0 & 10,584 & -0.6 \\
TFE & $3 H 5$ & .8 & 10,584 & -0.1 \\
SP-100 & 2.1 & .51 & 3,041 & -0.5 \\
& 2.2 & .92 & 38,982 & -1.0 \\
& 2.3 & .75 & 38,982 & -0.7 \\
\hline
\end{tabular}

\subsection{UFAC-1 Metallography}

A metallographic examination of the accelerated emitters from Batch-1 was completed in late FY-91 by Westinghouse Hanford Company under a contract from the Air Force Phillips Laboratory. A brief summary of the metallographic examination is presented here.

Generally, examinations showed fuel structures consistent with the irradiation temperature. Extensive reactions occurred in the area of the lower W-26 Re alloy heat shields and to a lesser extent in the area of the upper heat shields. Similar interactions in the area of the heat shields were also seen in previous examinations at the interim burnup of 2 atom percent, but to a lesser extent. Examinations also showed $\mathrm{W} / \mathrm{UO}_{2}$ interaction characterized by an irregular $\mathrm{W}$ surface and an accumulation of metallic particles in the fuel. The metallic particles in the fuel are most likely $\mathrm{W}$. No interaction was seen at the $\mathrm{W} / \mathrm{UO}_{2}$ interface in the examinations of the lower burnup samples. The $\mathrm{W}$ contained extensive porosity also not seen in the lower burnup samples. Examinations of the breach section of SU1-5 suggest a post-breach high temperature, consistent with xenon and krypton contamination of the helium and argon heat transfer medium in the emitter-to-collector gas gap.

Observations for specific fueled emitters are given below. 


\subsubsection{Emitter SU1-4}

The fuel structure showed the normal mature columnar grain structures expected for the high surface temperature $\mathrm{UO}_{2}$. High magnification photographs of the $\mathrm{UO}_{2} / \mathrm{W}$ interface show intimate contact and definite interaction, with transport of metallic $\mathrm{W}$ into the fuel. The $\mathrm{W}$ also showed significant porosity.

Metallography examination showed extensive interaction in the lower heat shield region and observable emitter deformation. The appearance of metallic reaction products suggest a once molten eutectic formation with the emitter, heat shield material, fuel, and fission products.

The interaction at the bottom end, in the area of the heat shield, was seen to a lesser extent in the interim examinations at 2 a/o burnup. The examinations of companion emitters at $2 \mathrm{a} / \mathrm{o}$ did not show any interaction of the $\mathrm{UO}_{2}$ and $\mathrm{W}$ away from the heat shield and no porosity in the $\mathrm{W}$.

Examinations of samples at the top center of the fuel column showed similar $\mathrm{UO}_{2}$ and $\mathrm{W}$ interaction. Fuel grain structures at the top of the fuel column were very similar to those seen at approximately half the burnup.

\subsubsection{Emitter SU1-5}

Two metallography samples were studied from SU1-5. One surface exposed provided a unique perspective looking directly down the temperature gradient on the $\mathrm{UO}_{2}$ columnar grain structure in the outer region of the fuel. The $\mathrm{W}$ showed extensive porosity and interaction in the area of the lower heat shield, similar to that seen in SU1-4. The characteristics and extent of the interaction was very similar to that seen in SU1-4. Fuel structures were regular with no unusual structure formation. The extent of $\mathrm{UO}_{2} / \mathrm{W}$ interaction was also very similar to SU1-4.

The second sample showed the lower portion of the axial breach. The breach was very typical of an encapsulated pin breach where the capsule thermal bond was gas rather than liquid metal. The reduction in gap gas conductivity, due to the intrusion of the fission gases $\mathrm{Xe}$ and $\mathrm{Kr}$ into the $\mathrm{He}$ and $\mathrm{Ar}$ mixture, increased the emitter surface temperature and compounded the breach.

Since the fuel structures showed no evidence of fuel melting, fuel center temperatures were less than approximately $2700 \mathrm{~K}$. Therefore, fuel surface temperatures could be as high as $2300 \mathrm{~K}$ in the area of the breach. This corresponds to an approximate $500 \mathrm{~K}$ overtemperature in the vicinity of the breach.

The $\mathrm{UO}_{2}$ in the open breach area contained several metallic inclusions which may be the result of the over-temperature and not $\mathrm{UO}_{2} / \mathrm{W}$ interaction at normal operating 
temperatures. The $\mathrm{W}$ in the area of the breach showed a significant thinning and loss of material. This material loss may be the result of the over-temperature, or could be the result of some material loss during sample preparation.

\subsubsection{Emitters SU1-8 and SU1-9}

Metallography samples from the centers of the fuel columns showed large, well formed center voids with columnar grains extending to near the $\mathrm{UO}_{2} / \mathrm{W}$ interface, consistent with the previous samples examined. The $\mathrm{UO}_{2}$ showed the large concentration of metallic inclusions seen in the previous samples. The interaction at the $\mathrm{UO}_{2}-\mathrm{W}$ interface is similar to the previous samples examined. The emitter showed extensive porosity.

\subsubsection{Electron Microprobe Examination}

Shielded electron microprobe examinations of the SU1-4 samples were made at the intersection of the W emitter and lower W-26Re heat shield, and the area below the W-26Re heat shield. The major constituent, other than W and $\mathrm{Re}$, at the intersection of the heat shield with the emitter was $U$. A thin layer of $U$ was found on the bottom of the emitter, under the fuel pedestal. The metallic reaction product in this area was primarily $W$. There was no migration of $\mathrm{Re}$ out of the $\mathrm{W}-26 \mathrm{Re}$ heat shield. Fission products were not found in the area in signficant concentrations.

At the $\mathrm{W} / \mathrm{UO}_{2}$ fuel interface, the fuel and emitter were in firm contact. There were, however, metallic particles in the fuel. These particles were predominantly $W$ with a few percent Mo, most likely fission product Mo.

\subsubsection{Conclusions}

One emitter, SU1-5, breached during irradiation and limited exc ninations of the breach section suggest a local over-temperature in the vicinity of the breach.

All four emitters were fractured in the region of the W-Ta transition at the top of the emitter. Examinations of the fractures showed them to be very similar to the fractures that occurred in the emitters examined at about 2 a/o ournup. At high fluence, $W$ was very brittle at ambient temperatures and fractured in the fuel column during routine handling during the examination.

Metallography samples removed at the bottom of the fuel column showed extensive interaction of the $\mathrm{W}$. emitter with the $\mathrm{W}-\mathrm{Re}$ heat shield and the $\mathrm{UO}_{2}$ fuel. Postirradiation structures suggest that a low melting temperature eutectic was formed. A microprobe examination indicated uranium to be present at the intersection of the $\mathrm{W} / \mathrm{Re}$ heat shield and the emitter. W was found between the bottom of the heat shield and the bottom of the emitter. 
The $\mathrm{W}$ and Mo observed dispersed in the fuel probably resulted from the fabrication process. Milling materials contain W and Mo and it would not be surprising to have 50 to $100 \mathrm{ppm} \mathrm{W}$ or Mo introduced into the $\mathrm{UO}_{2}$.

Examinations, with the exception of the breach, did not show any evidence that the fueled emitter lifetimes were exceeded by irradiation to goal burnups of 4 atom percent. Postirradiation fuel structures were consistent with expected operating temperatures. The problem of interaction in the area of the $\mathrm{W}$ and the W-Re heat shields was eliminated by the replacement of W-Re with $\mathrm{W}$ as heat shield material for future designs.

\subsection{Fuel Burnup Prediction}

The PIE of capsules SU2-3 and SU1-6 showed that the measured burnup (fissions per initial metal atom) was less than had been predicted. The data are shown below:

Table 4-5

BATCH 1 FUELED EMITTER BURNUP: PREDICTED vs PIE

\begin{tabular}{||c|c|c|c|}
\hline \multirow{2}{*}{ Capsule } & \multicolumn{2}{|c|}{ Burnup, atom-percent } & \multirow{2}{*}{ Ratio } \\
\cline { 2 - 3 } & Predicted & PIE & \\
\hline SU2-3 & .515 & .478 & .90 \\
SU1-6 & 1.902 & 1.704 & .93 \\
\hline
\end{tabular}

The cause of the discrepancy could not be determined. Uncertainties in uranium isotopic composition,in-core flux estimates, tantalum impurity in the niobium collector, and other impurities which could depress the flux were considered but a satisfactory explanation was not found.

The lower measured burnup was assumed to mean that the fission rate in the sample was lower than projected. This would make the emitter temperature lower than projected. This factor was taken into account in evaluating emitter distortion.

\subsection{Emitter Distortion Analysis}

\subsubsection{Neutron Radiography}

Emitter distortion was measured in two ways: neutron radiography (NR) and actual physical measurement in PIE.

Experience has shown that changes in emitter diameter using neutron radiographs can be determined consistently to less than 0.0005 inches. This experience was initially determined by comparing NR results with (non-radioactive) standards. It was reaffirmed by 
comparing NR and PIE results. End-of-life neutron radiograph measurements were compared with PIE measurements for the UFAC-1 accelerated emitters. As shown on Table 4-6, the difference between the average PIE and neutron radiograph measurements was less than .0005 inches.

Table 4-6

PIE vs NEUTRON RADIOGRAPH MEASUREMENTS OF EMITTER DIAMETERS

\begin{tabular}{|l|c|c|c|c||}
\hline & SU1-4 & SU1-5 & SU1-8 & SU1-9 \\
\hline NR $^{*}$ & $.2581 "$ & $.2704^{\prime \prime}$ & $.2608 "$ & $.2544 "$ \\
\hline PIE $^{*}$ & $.2580^{\prime \prime}$ & $.270{ }^{\prime \prime}$ & $.2607^{\prime \prime}$ & $.2542 "$ \\
\hline & $.0001^{\prime \prime}$ & $.0004^{\prime \prime}$ & $.0001^{\prime \prime}$ & $.0002 "$ \\
\hline
\end{tabular}

*Average of all orientations measured.

The distortion data derived from neutron radiography are presented in the appendix. The analyses presented below are based on these data.

\subsubsection{Reference Fueled Emitters}

Most of the fueled emitters had reference fuel and emitter designs. However, insulated fuel and wafered fuel designs were also studied, and the results are presented in Section 4.7.3.

The major goal of the fueled emitter irradiation was to determine fueled emitter distortion as a function of burnup and temperature. Meaningful data were generated at only two emitter temperatures: $1700 \mathrm{~K}$ and $1800 \mathrm{~K}$. However, significant data were obtained on the dependence of emitter distortion upon burnup.

Figure 4-7 summarizes the extent of the data base. As indicated in Section 4.1, and as shown on Figure 4-7, not all of the data obtained are valid. Several Batch 1 emitters suffered fractures in the region of the tungsten-to-tantalum transition joint, allowing fission products to enter the He/Ar gas volume. In emitters SU2-3, SU1-6, SU1-7 and SU1-10 broken stems were noticed in the first interim neutron radiograph and these emitters were removed from the EBR-II core. Because of the temperature excursion, the emitter distortion data of these fueled emitters were not considered valid.

Some emitters appeared intact in initial neutron radiographs, but showed fracture in the stem in subsequent radiographs. SU2-2, SU1-4, SU1-5, for example, appeared to be intact in radiographs taken at intermediate burnups, but at subsequent radiographs the emitter stem appeared fractured. In these cases, the fueled emitter measurements prior to the fracture are considered valid and are used in the fueled emitter distortion data base. Emitter measurements after the fracture are not valid. 


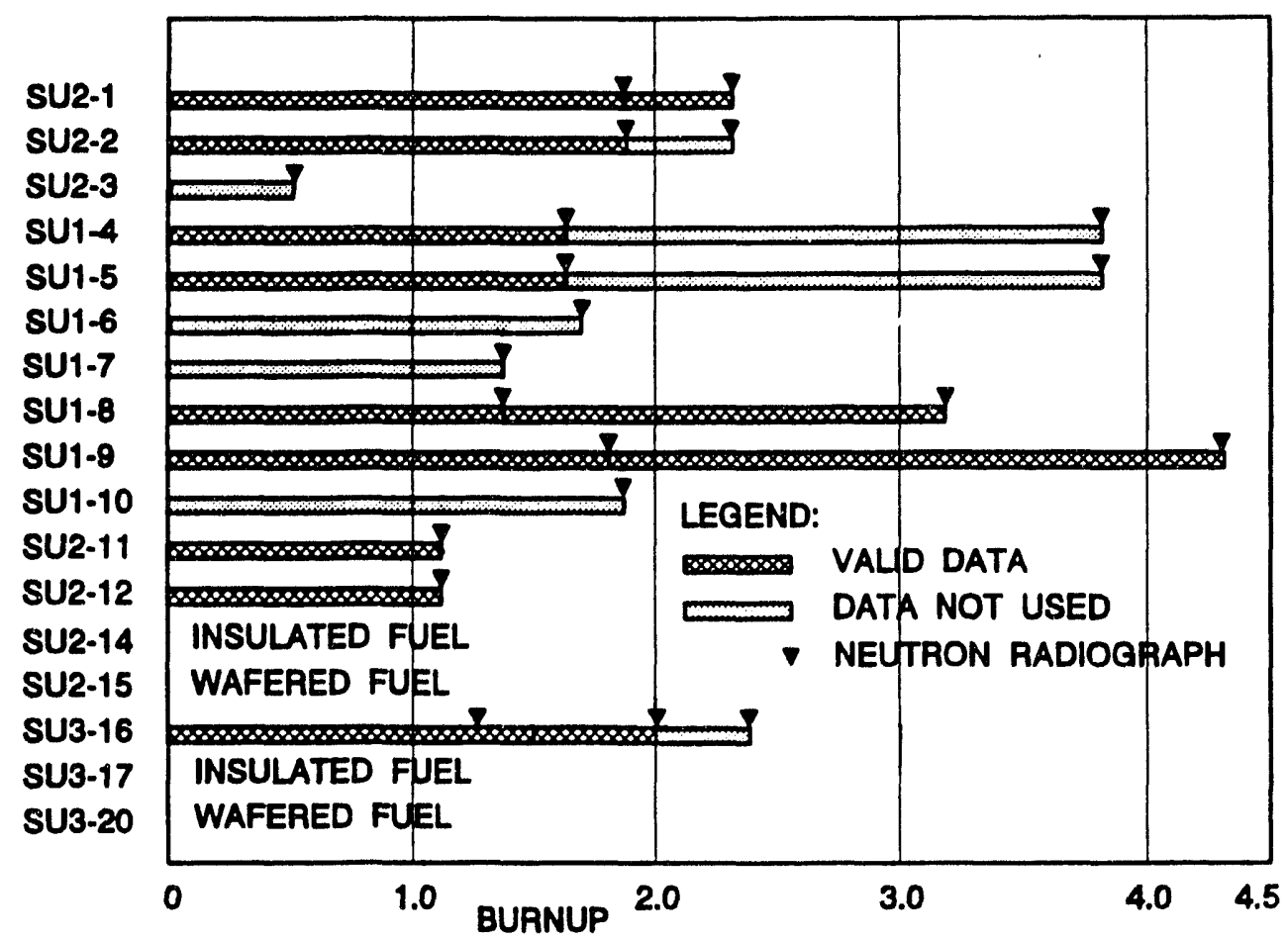

Figure 4-7. UFAC Fueled Emitter Data Base

Figures 4-8 and 4-9 show the emitter distortion data which are considered valid for emitter temperatures of $1800 \mathrm{~K}$ and $1700 \mathrm{~K}$, respectively. There is good agreement between the accelerated fueled emitter of SU1-8 and the remaining real time emitters. For equivalent burnups, the emitter distortion at $1700 \mathrm{~K}$ appears to $\mathrm{k} z$ about half of the distortion measured at $1800 \mathrm{~K}$. There is a consistent base of data out to about $2 \mathrm{a} / \mathrm{o}$ burnup.

\subsubsection{Advanced Fueled Emitters}

As reviewed in Section 3.5, two types of advanced fueled emitters were tested in Batch 2: insulated fuel (SU2-14 and SU3-17) and wafered fuel (SU2-15 and SU3-20).

The distortion of the emitters with insulated fuel were excessive. Both realtime and accelerated emitter specimens showed excessive deformation. As shown in Figure 4-10 emitter deformation was $3 \%(\Delta \mathrm{D} / \mathrm{D})$ at $1 \%$ burnup and $14 \%(\Delta \mathrm{D} / \mathrm{D})$ at $2.7 \%$ burnup.

For the wafered fuel, both specimens yielded promising data out to about $1.7 \%$ burnup, as shown in Figure 4-11, with emitter deformation less than $2 \%$. The accelerated specimen, SU3-10, continued irradiation out to $3.5 \%$ burnup. Emitter deformation increased markedly after $1.7 \%$ burnup, producing $9 \%$ deformation at $3.5 \%$ burnup.

The deformation of both advanced fuel concepts are plotted against the standard fuel data base characterized by SU1-8 in Figure 4-12. Both the standard fuel and the wafered fuel give comparable results. The insulated fuel concept does not appear worthy of further consideration. 

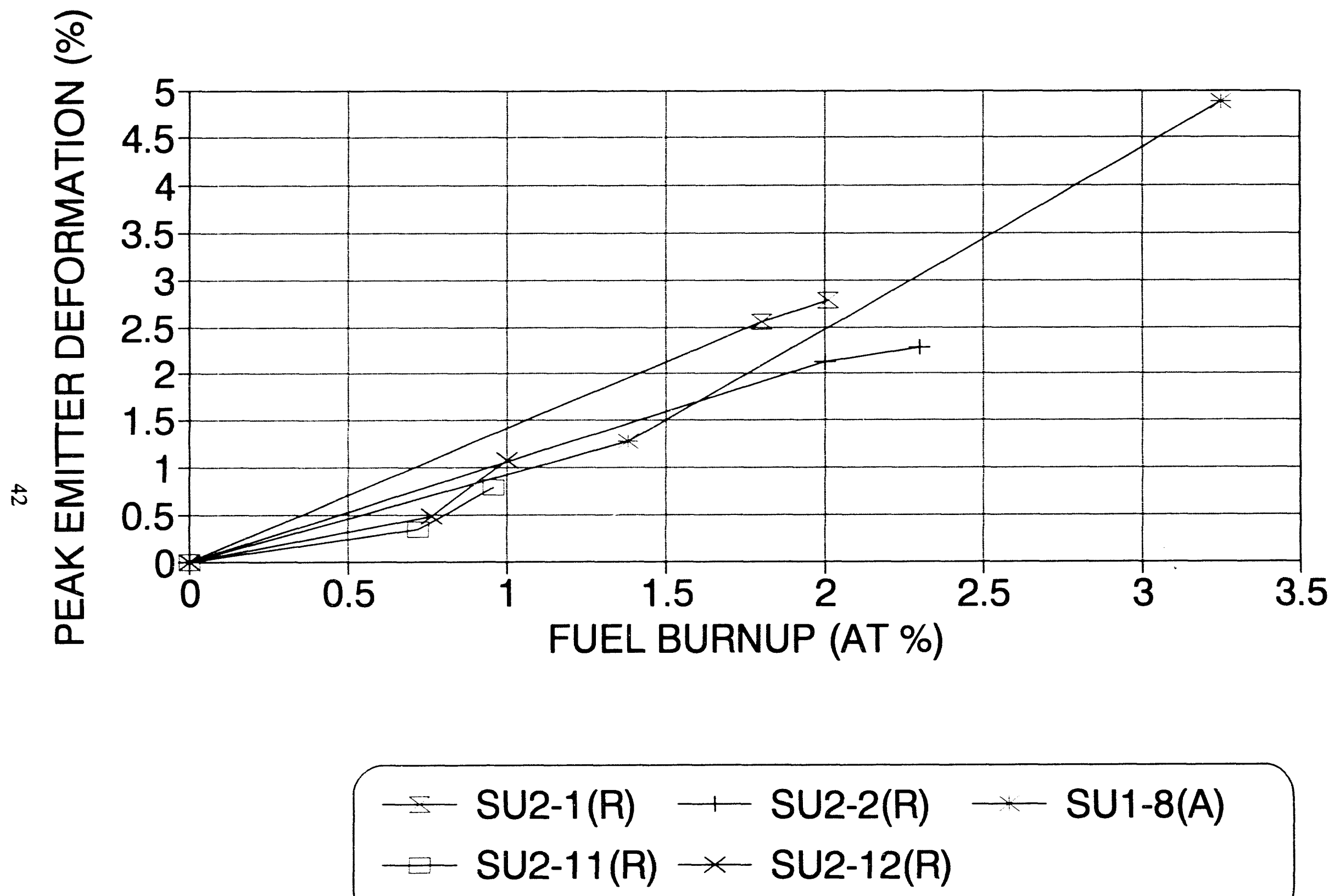


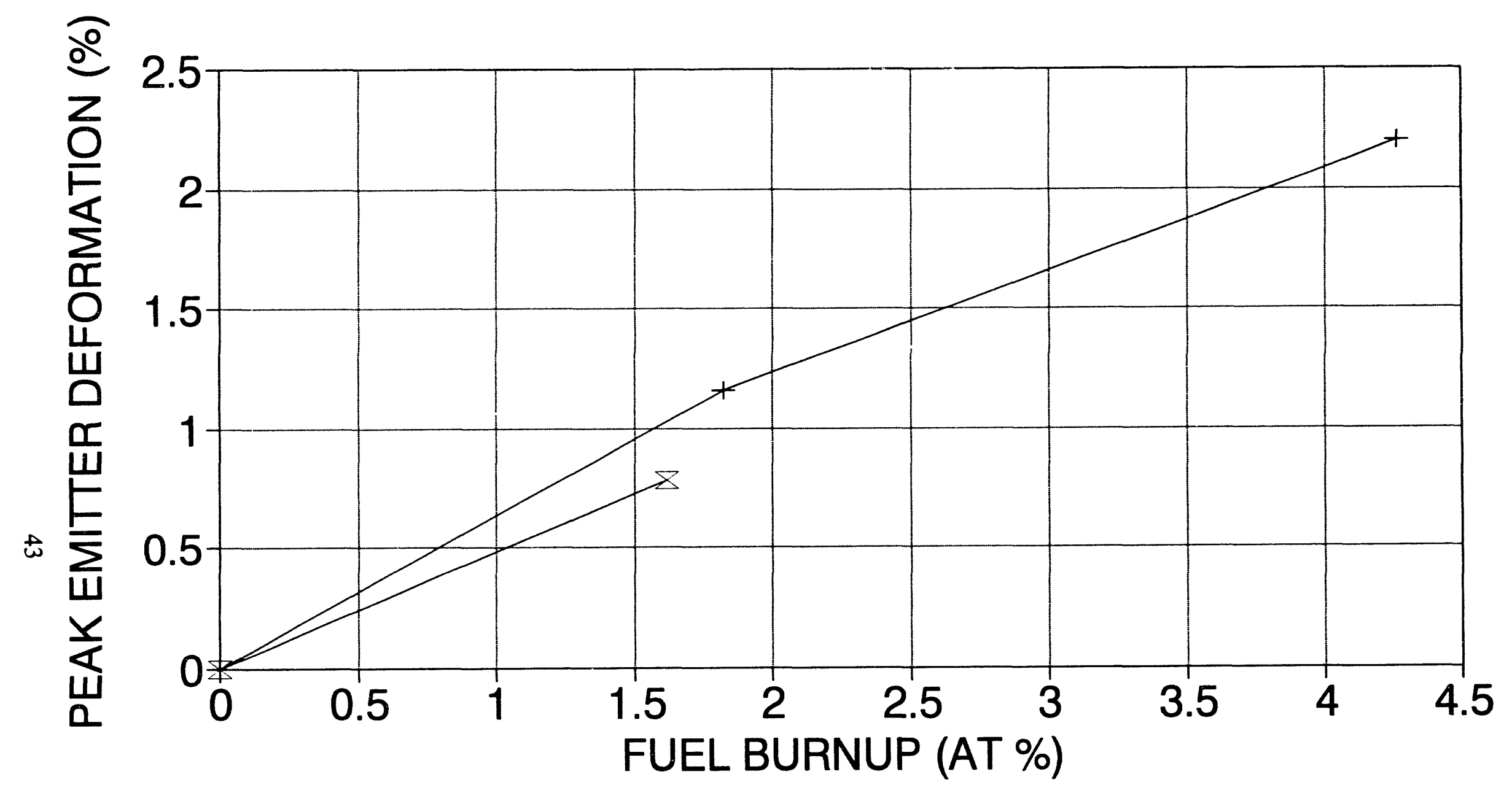

$$
\mp \text { SU1-5 — SU1-9 }
$$

Figure 4-9. Fueled Emitter Deformation Standard Fuel in Fast Flux @ $1700 \mathrm{~K}$ 


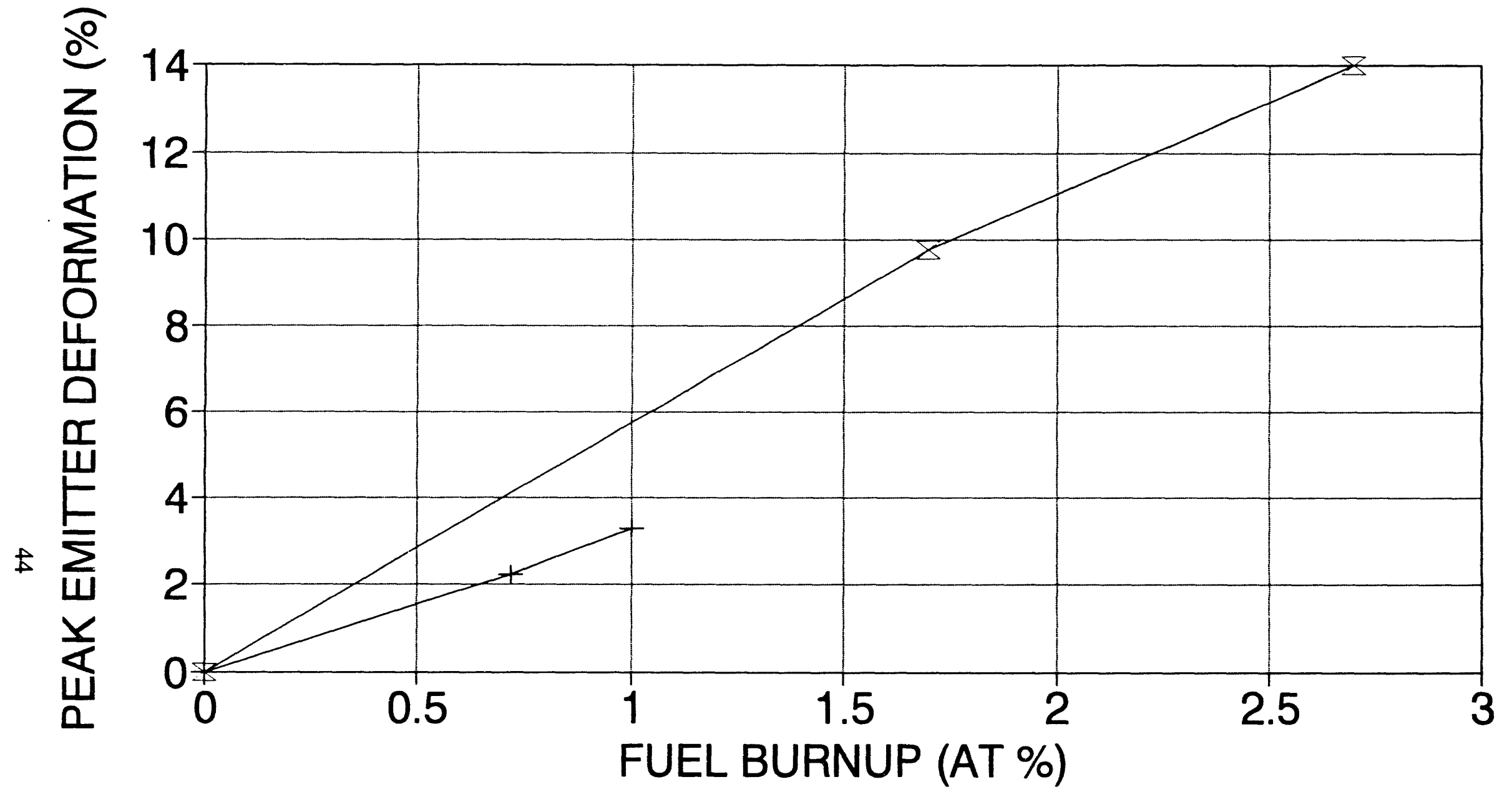

\section{$\mp$ SU3-17(A) + SU2-14(R)}

Figure 4-10. Fueled Emitter Deformation Insulated Fuel in Fast Flux @ $1800 \mathrm{~K}$ 


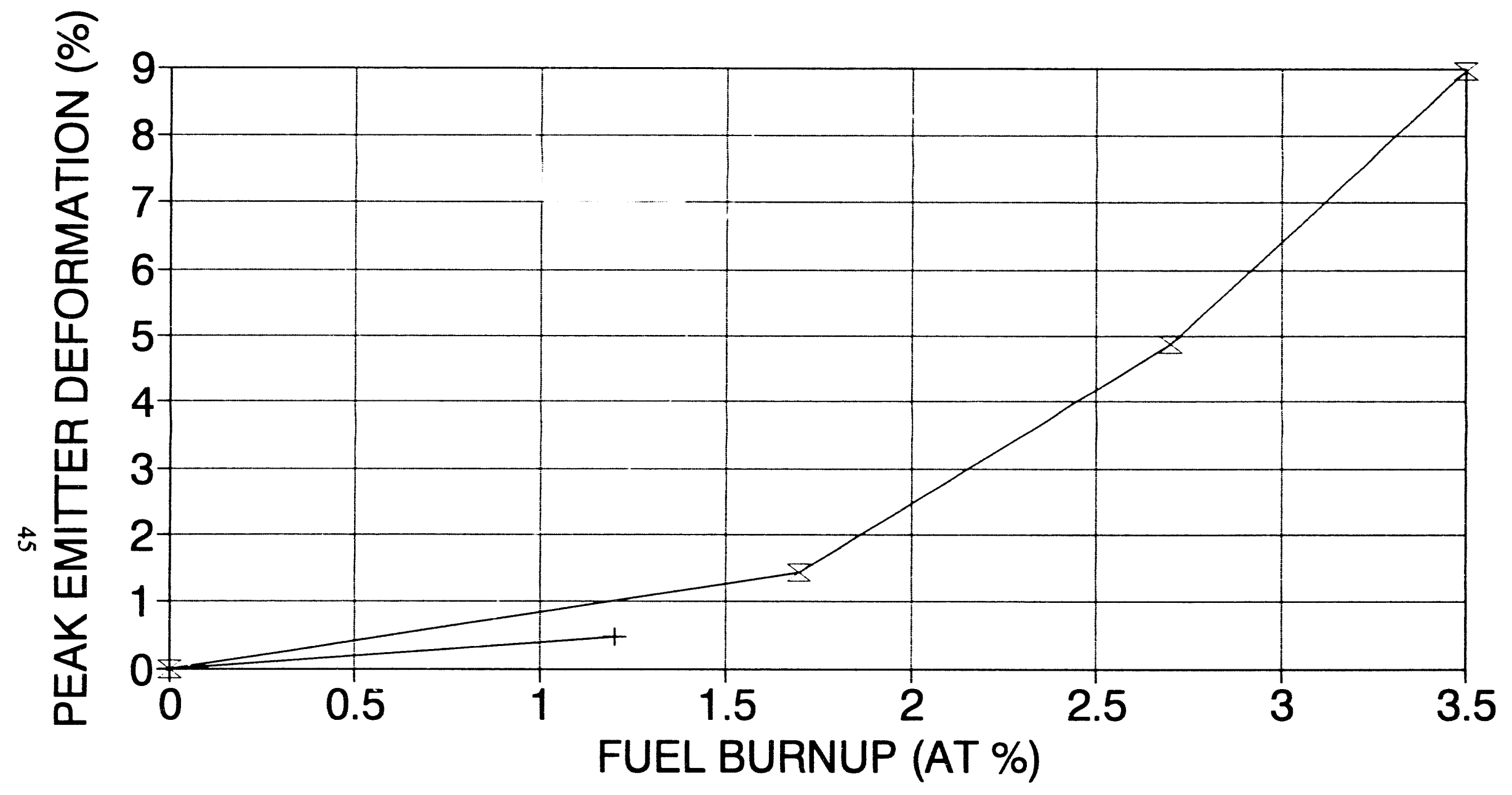

\section{$=\operatorname{SU} 3-20(\mathrm{~A})+\mathrm{SU} 2-15(\mathrm{R})$}

Figure 4-11. Fueled Emitter Deformation Wafered Fuel in Fast Flux @ $1800 \mathrm{~K}$ 


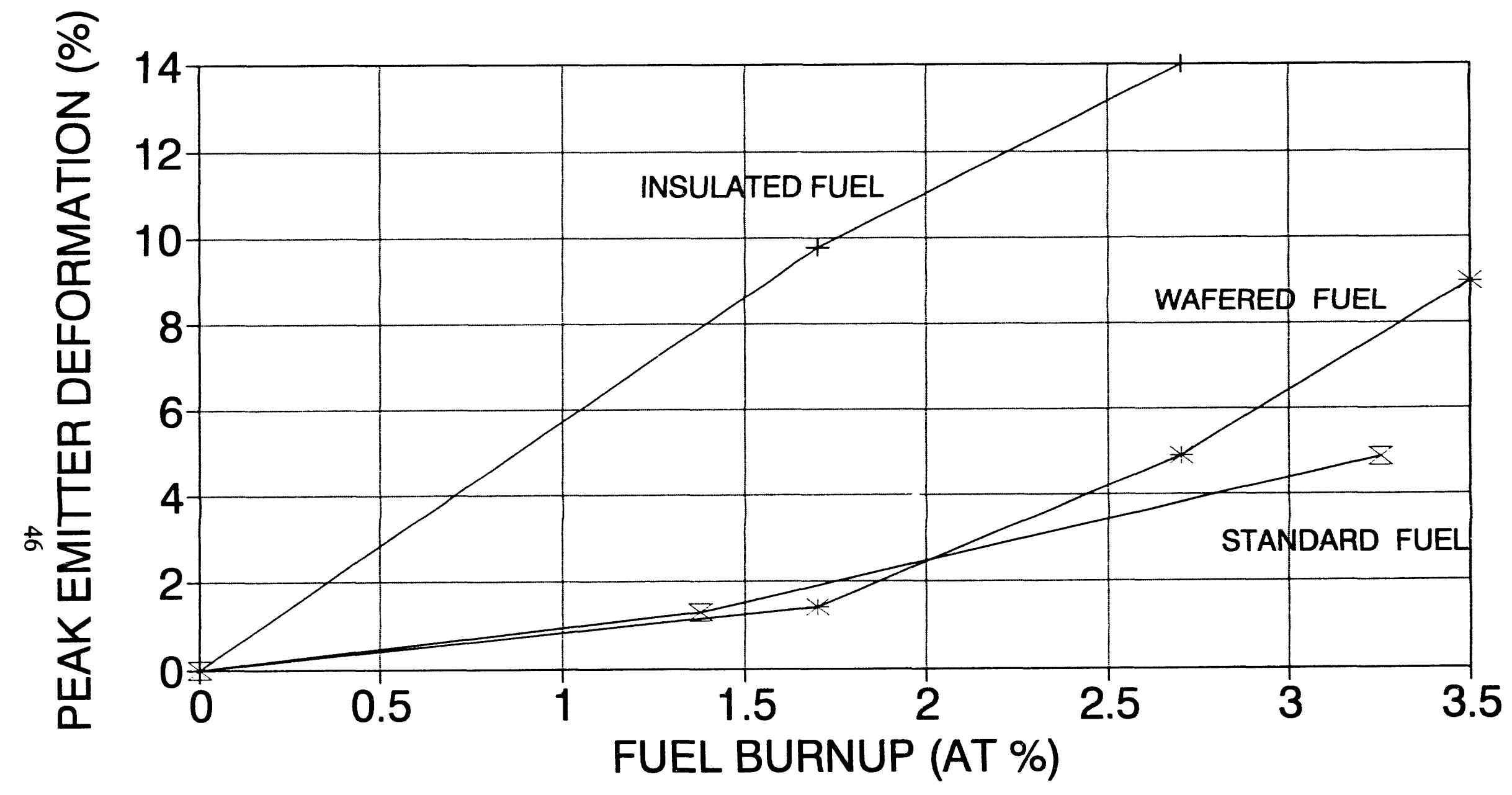

\section{$\approx$ SU1-8 $\div$ SU3-17 * SU3-20}

Figure 4-12. Fueled Emitter Deformation Alternate Fuel Forms: Fast Flux @ $1800 \mathrm{~K}$ 


\section{FUELED EMITTER MODEL DEVELOPMENT}

\subsection{Ratchet Effect in Emitter Distortion}

Figure 5-1 shows the cross section of a typical cylindrical emitter used in a space nuclear power system with $\mathrm{UO}_{2}$ fuel contained within the emitter cavity. The underlying cause of the potential ratchet effect involves the different coefficients of thermal expansion between the $\mathrm{UO}_{2}$ fuel and the tungsten emitter. Figure 5-2 shows the thermal expansion vs temperature for the two materials. Because the fuel expands at a faster rate than the emitter, the potential exists that repeated thermal cycling could cause the fuel to push the emitter outward during each cycle. The emitter deformation may "ratchet" outward at each of these thermal cycles (Ref. 5-1).

When the fuel is fabricated, its OD is smaller than the ID of emitter to allow for the differential thermal expansion between the fuel and emitter upon initial startup. As the fuel temperature increases, it expands and may or may not come into contact with the cooler emitter. Heat transfer into the emitter is accomplished by a combination of radiation and interface pressure-induced thermal conduction. As the emitter is brought up to operating temperature, the vapor pressure of the hotter fuel causes it to vaporize and redeposit itself onto the ID of the cooler emitter. In time, the entire fuel volume will redeposit itself within the emitter cavity. The initial annular volume between the fuel and emitter will be displaced into a void which forms in the center of the fuel.

At a later time, if the power level is reduced, the contracting fuel will tend to initially break away from the emitter leaving a gap. Continued operation at the reduced power will, however, tend to cause the high temperature fuel to expand back into the gap, once again establishing firm contact with the emitter. A subsequent rise in power level could then cause an outward pressure on the emitter and potentially contribute to emitter distortion.

Calculations indicated that the possible distortion resulting from a power cycle between $100 \%$ and $50 \%$ power is about .04 mils. Hence, over 20 such cycles would be necessary to contribute an emitter distortion of $1 \mathrm{mil}$. Since this mode of operation is very unlikely, the ratchet effect was not considered to be a significant contributor to performance degradation, and it was not studied further.

A related phenomenon is the possible buildup of fission gases within a central volume in the $\mathrm{UO}_{2}$ and the subsequent pressure on the emitter from such a buildup. However, TRIGA tests showed that fission product gases are not retained but migrate out of the fuel into the fission gas plenum. A nearly linear relationship between pressure in the fission gas plenum and burnup has been measured, with most of the noble fission gases escaping from the fuel within a relatively short time. Hence the steady buildup of pressure within an emitter is not expected. 


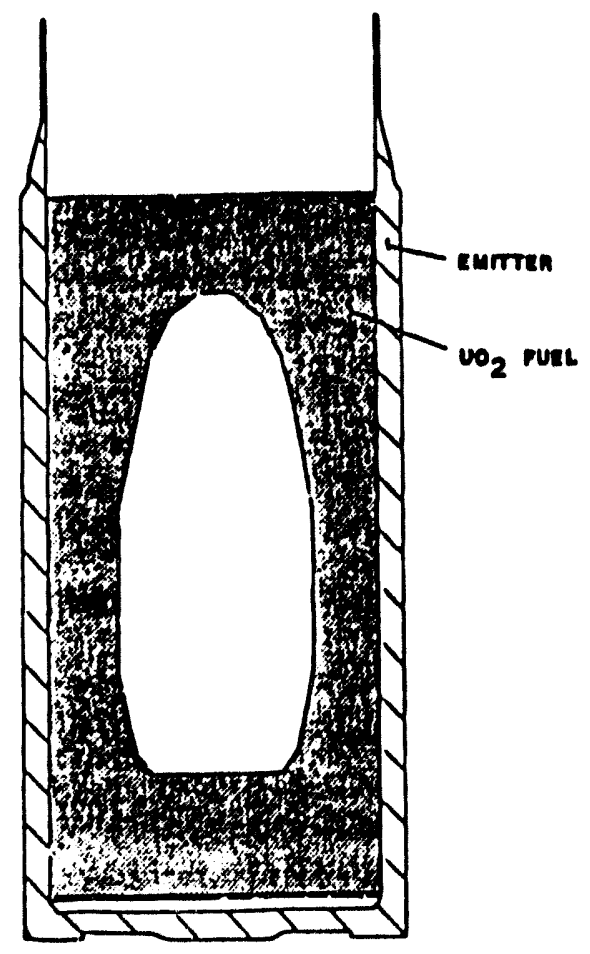

Figure 5-1. Emitter/Fuel Cross Section

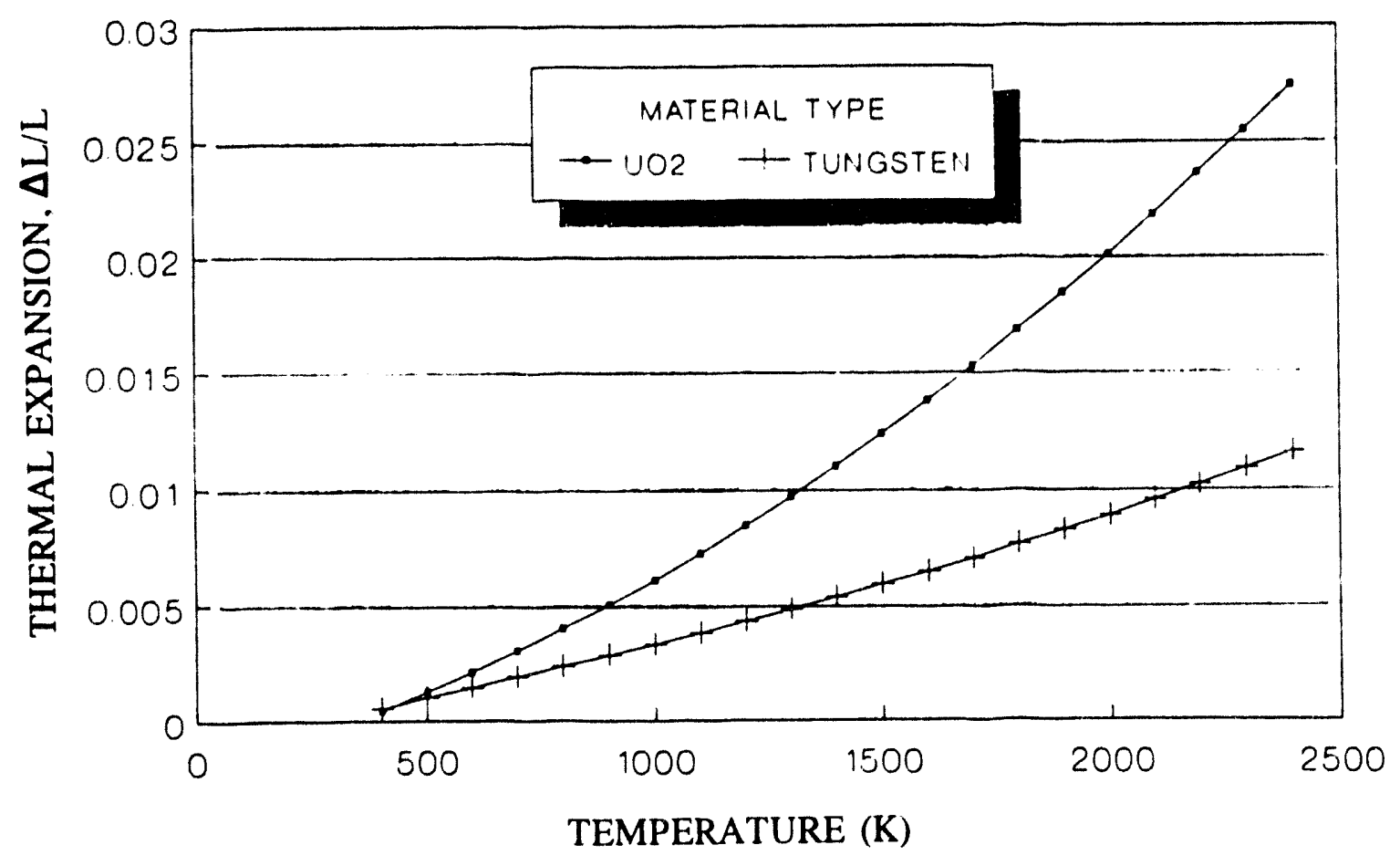

Figure 5-2. Thermal Expansion - $\mathrm{UO}_{2}$ vs Tungsten 


\subsection{LIFE-4 Code Development}

Fuel emitter modeling was primarily directed toward modification of the LIFE-4 code so that it can be used by the reactor designer in predicting fueled emitter lifetime in TFE assemblies. It was also used in estimating emitter distortion in both accelerated and realtime irradiation testing as a function of temperature, power density, fuel configuration, and cladding strength.

The LIFE-4 code was adapted for use in the TFE Verification Program at LANL (Refs. 5-2 and 5-3).

\subsubsection{Background}

The LIFE code was originally developed for predicting behavior of mixed oxide fuel pins in liquid metal fast-breeder reactors (LMFBR; Refs. 5-4 and 5-5). The code evolved through several versions, including LIFE-3, LIFE-4, Revision 0, and LIFE-4, Revision 1. The starting point for developing a code for fueled emitters was LIFE-4, Revision 0.

Considerable effort was expended by the developers to use "first principles" modeling. However, they recognize that fuel pin behavior is exceedingly complex, and empirical relations were used as appropriate to provide "adjustable constants". Revision 0 was selected for analyses of emitter deformation because of its emphasis on first principles modeling; such a code would probably extrapolate better to TFE conditions than would empirically based methods.

The application to fueled emitters is similar to that for which the LIFE code was originally developed. A TFE is basically a uranium dioxide $\left(\mathrm{UO}_{2}\right)$ fuel element clad by the emitter, generally chemical vapor deposited (CVD) tungsten. In addition to the cladding, the TFE differs from LMFBR fuel pins primarily in that emitter temperatures, and thus outer fuel temperatures, are much higher than usual for LMFBR fuel pins as shown in Table 5-1.

Table 5-1

COMPARISON OF LIFE-4 APPLICATIONS

\begin{tabular}{|l|l|l|}
\hline \multicolumn{1}{|c|}{ Feature } & \multicolumn{1}{c|}{ TFE } & \multicolumn{1}{c|}{ LMFBR } \\
\hline Temperature (K) & 1700 to 1900 & 650 to 700 \\
Power Density $\left(\mathrm{W} / \mathrm{cm}^{3}\right)$ & 50 to 200 & $900-2000$ \\
Burnup & & \\
Environment & Vacuum (Cs) & Helium \\
\hline
\end{tabular}

Emitter temperatures are generally on the order of 1700 to $1900 \mathrm{~K}$. In contrast, LMFBR cladding temperatures are on the order of 650 to $700 \mathrm{~K}$. In addition, TFE power densities 
are much lower than LMFBR power densities 50 to $200 \mathrm{~W} / \mathrm{cm}^{3}$ versus 900 to $2000 \mathrm{~W} / \mathrm{cm}^{3}$. Burnups of ultimate interest are similar. Finally, TFEs are normally manufactured and operate in a vacuum, unlike fuel pins, which are backfilled with helium. Thus, on initial operation heat transfer resistance between fuel and emitter is certain to be much higher than for the usual fuel pin. Because of these differences, which are well outside the original calibration, it can be expected that adjustments are needed to the constants for the LIFE-4 submodels.

In the early 1980s, a broad spectrum of tests was analyzed, including some of Zimmerman's (Ref. 5-6) basic unrestrained $\mathrm{UO}_{2}$ experiments, some Battelle experiments (Ref. 5-7) for various clad high-temperature alloys, and severai early TFE tests conducted by General Atomics (Ref. 5-8). As a result of these analyses, it was decided to use Revision 0 of the code over the existing Revision 1 version (although the differences of results between versions were quite small), and a set of changes to code constants was determined as an initial "space" calibration. This work is documented informally in Ref. 5-3.

\subsubsection{Data Base for Evaluating LIFE-4 Code Predictions}

The data base used in evaluating LIFE-4 code predictions comes from fueled emitter irradiations in TRIGA (see Refs. 1-2, 1-3 and the early Semiannual Progress Reports as referenced in Section 1.5) and from fuel emitter irradiations in EBR-II. The TRIGA irradiations involved 6 test specimens, as shown in Tables 5-2 and 5-3, below.

Table 5-2

FUELED EMITTER TEST DATA FROM TRIGA IRRADIATIONS

\begin{tabular}{|c|c|c|c|c|c|c|}
\hline \multirow[b]{2}{*}{ Capsule } & \multirow[b]{2}{*}{ Cell } & \multicolumn{2}{|c|}{ Emitter } & \multicolumn{3}{|c|}{ Operating Conditions } \\
\hline & & $\begin{array}{l}\text { O.D. } \\
\text { (in.) }\end{array}$ & $\begin{array}{l}\text { Thickness } \\
\text { (mils) }\end{array}$ & $\begin{array}{l}\text { Power Density } \\
\left(\mathrm{W} / \mathrm{cm}^{3}\right)\end{array}$ & $\begin{array}{l}\text { Emitter Temperature } \\
(\mathrm{K})\end{array}$ & $\begin{array}{l}\text { Burnup } \\
\text { (at.\%) }\end{array}$ \\
\hline 1 & 2 & 1.1 & 110 & 53.0 & 1852.0 & 0.29 \\
\hline 2 & 2 & 1.1 & 70 & 51.9 & 1791.1 & 0.55 \\
\hline 2 & 3 & 1.1 & 70 & 40.2 & 1758.8 & 0.39 \\
\hline 3 & 1 & 1.1 & 40 & 42.0 & 1780.8 & 0.32 \\
\hline 3 & 2 & 1.1 & 70 & 51.5 & 1769.1 & 0.38 \\
\hline 3 & 3 & 1.1 & 70 & 49.2 & 1772.8 & 0.40 \\
\hline
\end{tabular}

Data from 6 fueled emitters in EBR-II were: 
Table 5-3

FUELED EMITTER TEST DATA FROM EBR-II IRRADIATION

\begin{tabular}{|c|c|c|c|c|c|c|}
\hline \multirow[b]{2}{*}{ Test } & \multicolumn{2}{|c|}{ Emitter } & \multirow{2}{*}{$\begin{array}{l}\text { Fuel I.D. } \\
\text { (in.) }\end{array}$} & \multicolumn{3}{|c|}{ Operating Conditions } \\
\hline & $\begin{array}{l}\text { O.D. } \\
\text { (in.) }\end{array}$ & $\begin{array}{l}\text { Thickness } \\
\text { (mils) }\end{array}$ & & $\begin{array}{l}\text { Power Density } \\
\qquad\left(\mathrm{W} / \mathrm{cm}^{3}\right)\end{array}$ & $\begin{array}{l}\text { Emitter Temperature } \\
(\mathrm{K})\end{array}$ & $\begin{array}{l}\text { Burnup } \\
\text { (at.\%) }\end{array}$ \\
\hline SU2-1 & 0.50 & 40 & 0.188 & 194.6 & 1867.0 & 0.70 \\
\hline SU2-2 & 0.50 & 50 & 0.188 & 210.7 & 1849.7 & 0.76 \\
\hline SU1-4 & 0.25 & 20 & 0.079 & 642.4 & 1584.3 & 1.77 \\
\hline SU1-5 & 0.25 & 20 & 0.079 & 661.9 & 1565.7 & 1.79 \\
\hline SU1-8 & 0.25 & 20 & 0.080 & 563.5 & 1700.0 & 1.53 \\
\hline SU1-9 & 0.25 & 25 & 0.079 & 722.1 & 1502.9 & 1.99 \\
\hline
\end{tabular}

\subsubsection{LIFE-4 Predictions}

The latest LIFE-4 model predictions are shown on Table 5-4. The average absolute relative error on emitter deformation for the current calibration is $33 \%$, with a standard deviation about the average error of $19 \%$.

The code predicts a knee in the curve of emitter distortion versus burnup at about $1 \mathrm{a} / \mathrm{o}$ burnup. However, the knee is not pronounced, there being a constant positive slope to the curve above the knee.

Table 5-4

ANALYSIS OF FUELED EMITTER EXPERIMENTS

\begin{tabular}{||c|c|c|c|c||}
\hline \multirow{2}{*}{ Test } & \multicolumn{2}{|c|}{ Emitter Deformation } & \multicolumn{2}{c||}{ Fission Gas Release } \\
\cline { 2 - 5 } & $\begin{array}{c}\text { Measured } \\
(\%)\end{array}$ & $\begin{array}{c}\text { Calculated } \\
(\%)\end{array}$ & $\begin{array}{c}\text { Measured } \\
(\%)\end{array}$ & $\begin{array}{c}\text { Calculated } \\
(\%)\end{array}$ \\
\hline SU2-1 & 0.63 & 0.56 & $\mathrm{n} / \mathrm{a}$ & 57.7 \\
SU2-2 & 1.05 & 0.22 & $\mathrm{n} / \mathrm{a}$ & 67.2 \\
SU1-4 & 0.77 & 0.58 & $\mathrm{n} / \mathrm{a}$ & 78.3 \\
SU1-5 & 0.84 & 0.52 & $\mathrm{n} / \mathrm{a}$ & 82.1 \\
SU1-8 & 0.96 & 0.78 & $\mathrm{n} / \mathrm{a}$ & 81.7 \\
SU1-9 & 0.92 & 0.46 & $\mathrm{n} / \mathrm{a}$ & 82.6 \\
CAP1/CELL2 & 0.31 & 0.36 & $\mathrm{n} / \mathrm{a}$ & 46.5 \\
CAP2/CELL2 & 1.60 & 0.95 & 93.9 & 61.4 \\
CAP2/CELL3 & 0.78 & 1.05 & 99.5 & 46.2 \\
CAP3/CELL1 & 2.66 & 1.54 & 90.8 & 48.2 \\
CAP3/CELL2 & 0.67 & 0.79 & $\mathrm{n} / \mathrm{a}$ & 52.4 \\
CAP3/CELL3 & 0.71 & 0.88 & 59.8 & 53.5 \\
\hline
\end{tabular}




\section{FUELED EMITTER SPECIFICATION}

\subsection{Reference Materials}

o Fuel: $\quad \mathrm{UO}_{2}$

o Emitter: CVD tungsten

- Emitter body: W from $\mathrm{WF}_{6}$

- Emitter surface: W from $\mathrm{WCl}_{6}$

o Heat shields: Tungsten

o Fuel pedestal: Tungsten

o Tungsten-to-niobium transition: Tantalum

o Emitter thickness:

- $\quad 0.50$ in. fuel diameter: $\geq .040$ inches

- Fuel diameter/emitter diameter: $\leq 12.5$

o Typical emitter temperature: $1800 \mathrm{~K}$

\subsection{Advanced Emitter Materials}

- Single crystal tungsten or tungsten alloy

o Tungsten-hafnium-carbide

\subsection{Advanced Fuel}

- Wafered $\mathrm{UO}_{2}$ 


\section{REFERENCES}

1-1 General Atomics Report GA-C18062, GES Baseline System Definition and Characterization Study, Final Report for the Period December 1984 through July 1985; Prepared under JPL Contract 956472, August 9, 1985.

1-2 General Atomics Report GA-A18182 (1985), SP-100 Thermionic Technology Program Annual Integrated Technical Progress Report for the Period Ending September 30, 1985, by GA Technologies, Rasor Associates Inc., Space Power, Inc. and Thermo Electron Corporation, November 1985.

1-3 General Atomics Report GA-A18915 (1987), Thermionic Irradiations Program Final Report, General Atomics, San Diego, CA.

1-4 Cone, V. P. and J. Dunlay (1987), Thermionic Technology Program Fiscal Year 1986 and Final Technical Report, Thermo Electron Report No. TE4400-227-87.

1-5 Hatch, G.L. (1988), Thermionic Technology Program: Thermionic Converter Performance Final Report, NSR-25-25, E-533-003-B053188 (DOE Contract No. DE-ACO3-86SF15954).

3-1 Trujillo, V., M. Merrigan and W. Ranken (1988), "Characterization of Compliant Thermal Conductive Tungsten Material for Thermionic Element Application", Proceedings $23^{\text {rd }}$ IECEC Conference, Denver, CO.

5-1 "Fueled Emitter Deformation: Ratchet Effect", Space Power Incorporated Report, SPI-17-4, May 1988.

5-2 Baars, Ralph, "Modeling Emitter Deformation for Thermionic Fuel Elements Using the LIFE Code: Interim Report", LANL Report LA-CP-91-2, August 5, 1991.

5-3 Baars, Ralph, "Application of LIFE-4 to SP-100", Los Alamos National Laboratory Document LA-UR-85-1657, May 1985.

5-4 Roth, T., Ed., "LIFE-4 (Rev. 0) Programmers Manual", Westinghouse Advanced Energy Systems Report, October 1982.

5-5 Sundquist, B. E. and T. S. Roth, "LIFE-4 (Rev. 1) Validation Report", Westinghouse Advanced Energy Systems Report, January 1990.

5-6 Zimmerman, H., "Investigations on Swelling and Fission Gas Behavior in Oxide Fuels Under Neutron Irradiation", Nuclear Research Center Karlsruhe Report KfK 2467, June 1977. 
5-7 "Progress on Development of Fuels and Technology for Advanced Reactors During July 1969 through June 1970 and July 1971 through September 1971 Annual Reports", Battelle Memorial Institute Reports BMI-1886, July 1970 and October 1971.

5-8 "Development of a Thermionic Reactor Space Power System Final Summary, " Gulf General Atomic Report A12608, June 30, 1973. 


\section{APPENDIX}

EMITTER DISTORTION DATA DERIVED FROM

NEUTRON RADIOGRAPHY MEASUREMENTS 


\section{SU2-1 EMITTER DEFORMATION 1.8 AT\% BURNUP, 798 EFPD's}

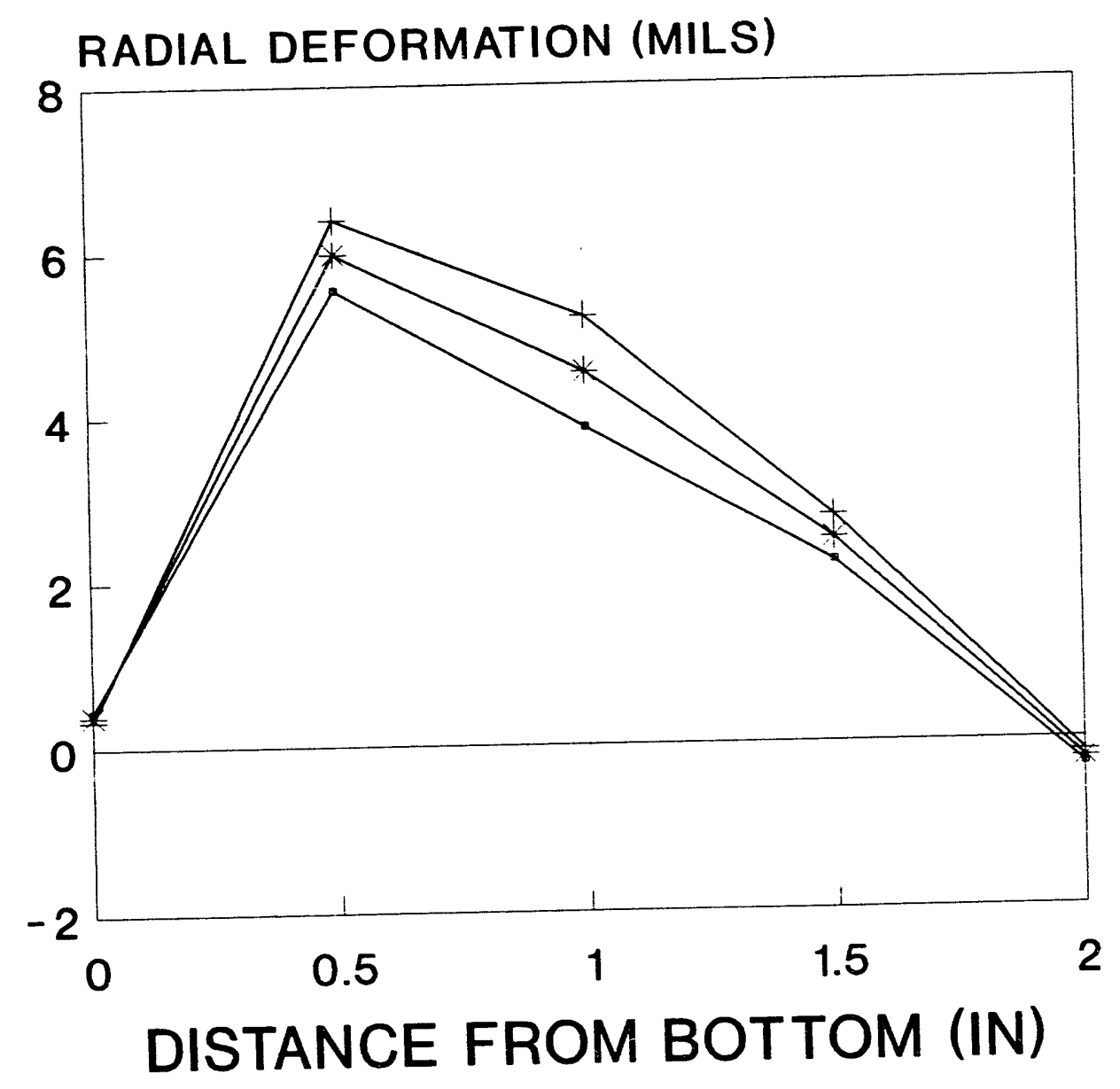




\section{SU2-1 EMITTER DEFORMATION 2.01\% BURNUP, 908 EFPD's}

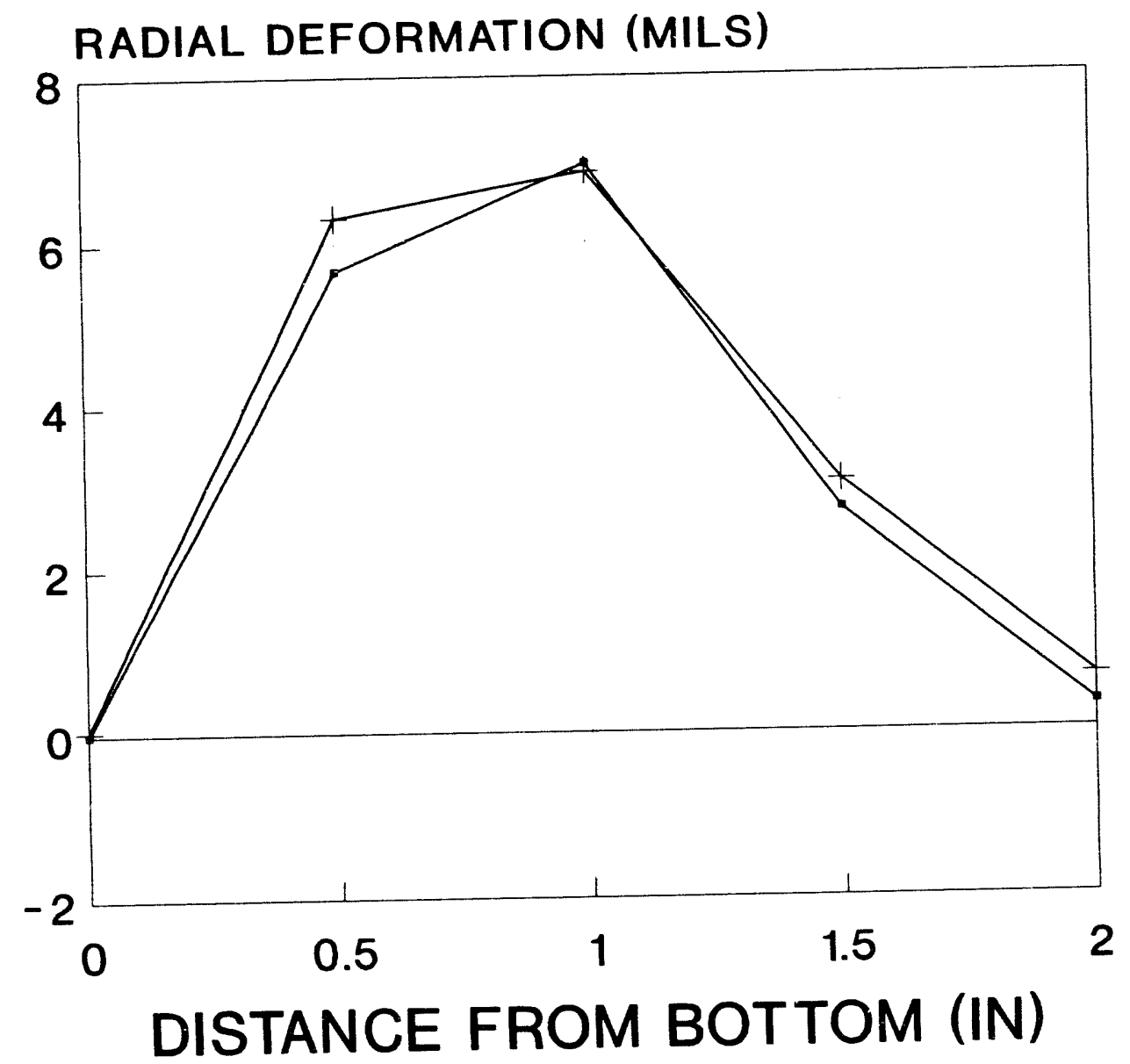

I3450\SU2-1B 


\section{SU2-2 EMITTER DEFORMATION 2.0 AT\% BURNUP, 798 EFPD's}

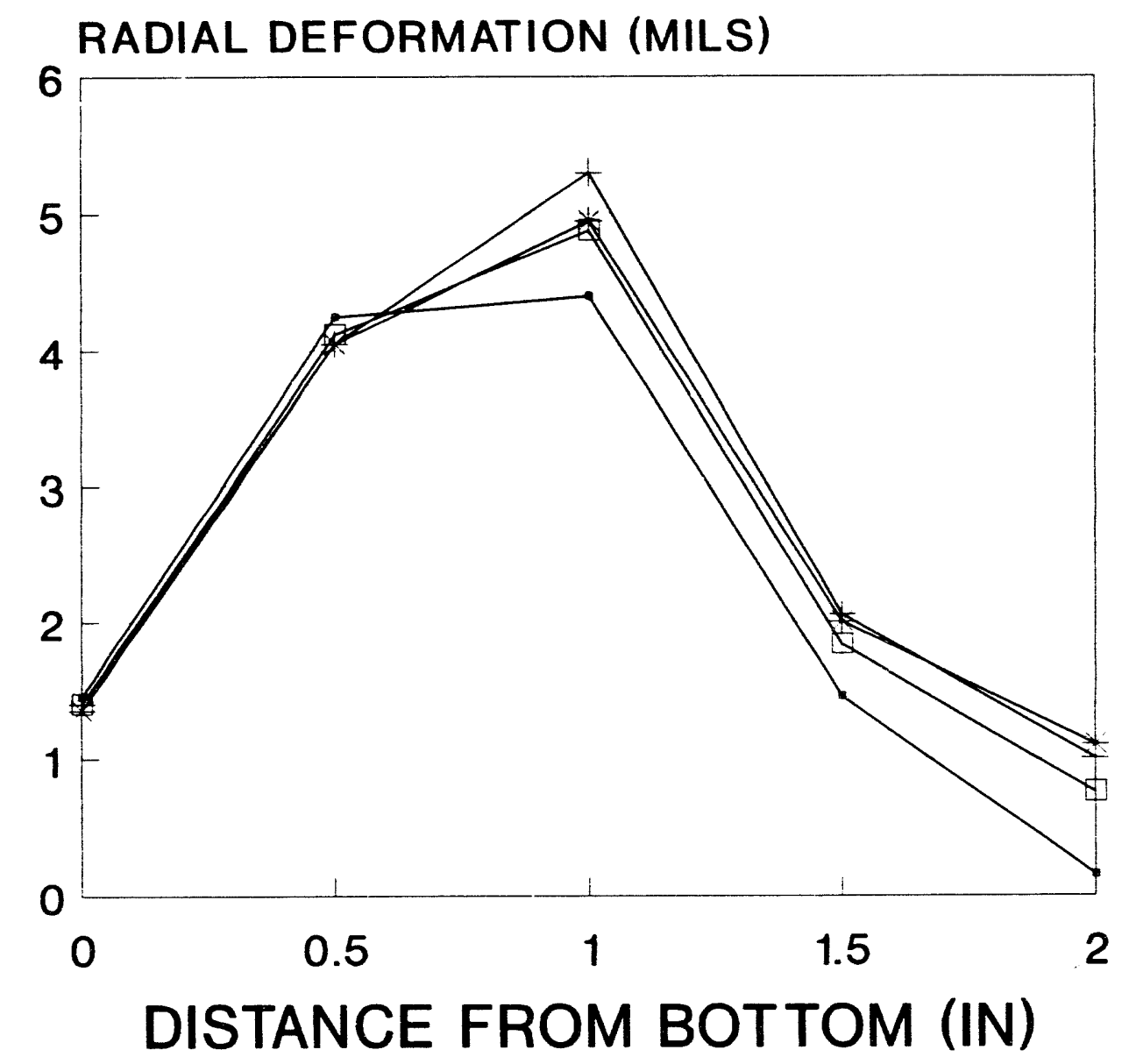




\section{SU2-2 EMITTER DEFORMATION 2.3 AT\% BURNUP, 908 EFPD's}

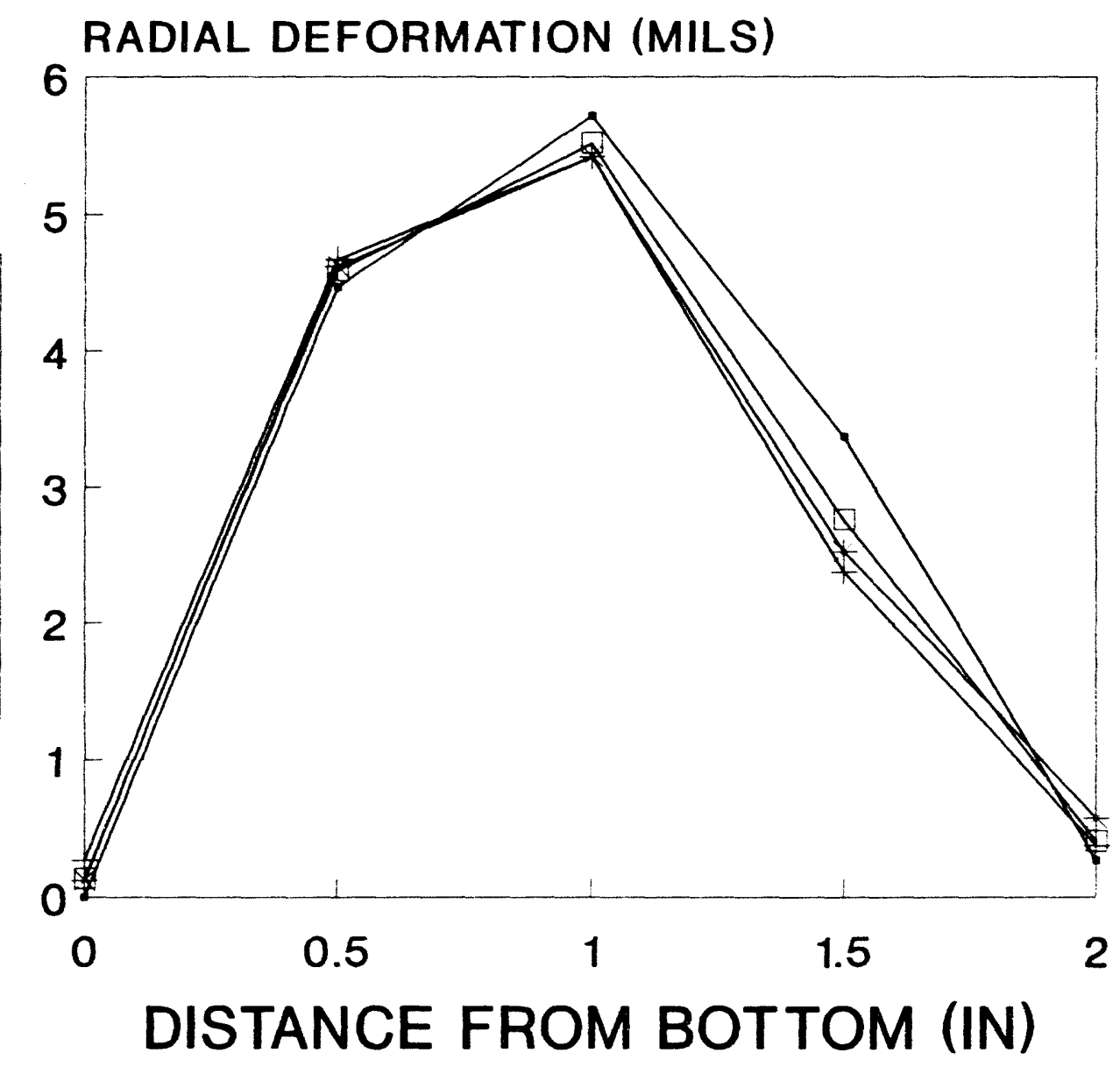




\section{SU1-8 EMITTER DEFORMATION 1.28 AT\% BURNUP}

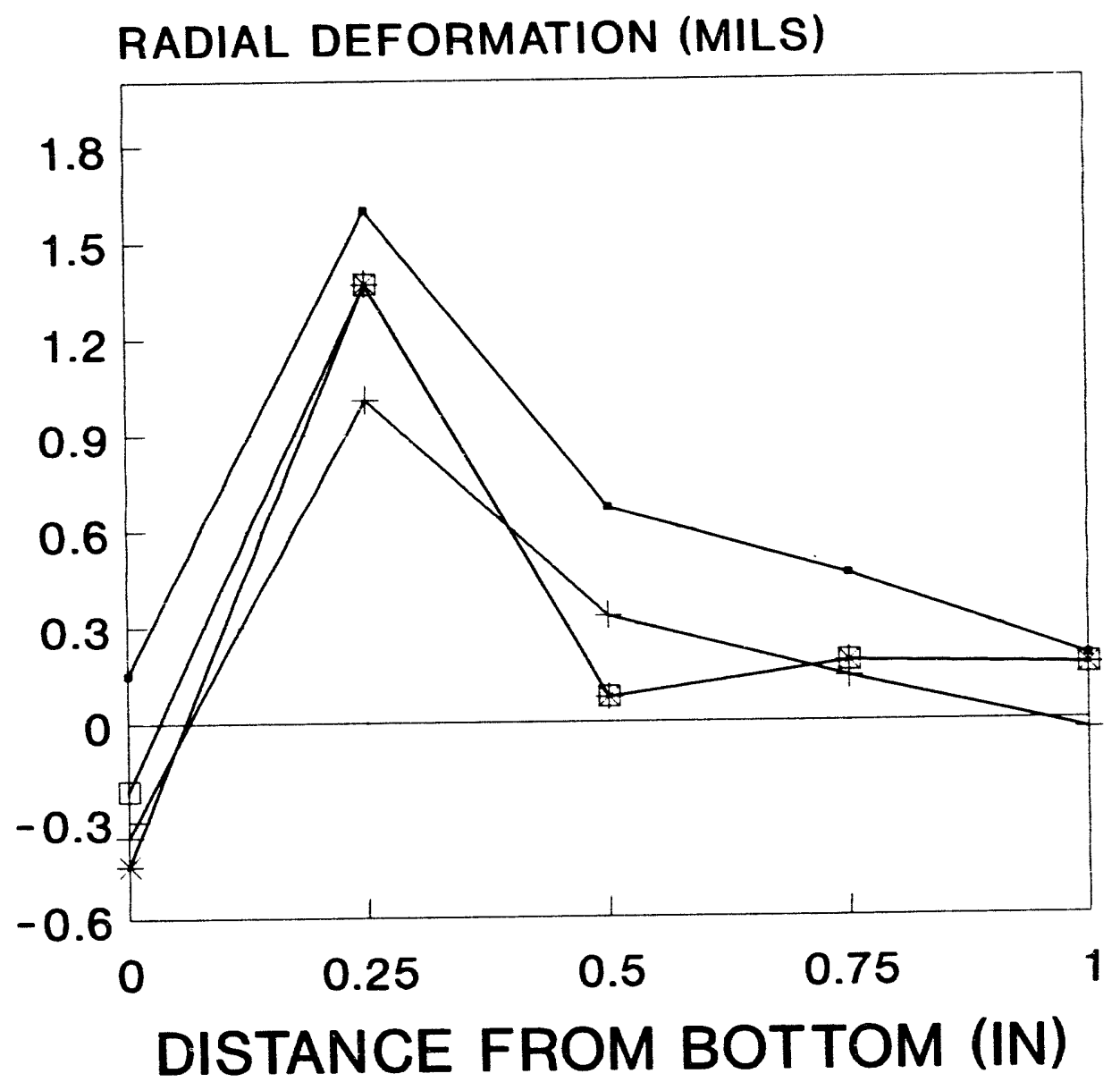




\section{SU1-9 EMITTER DEFORMATION 1.75 AT\% BURNUP}

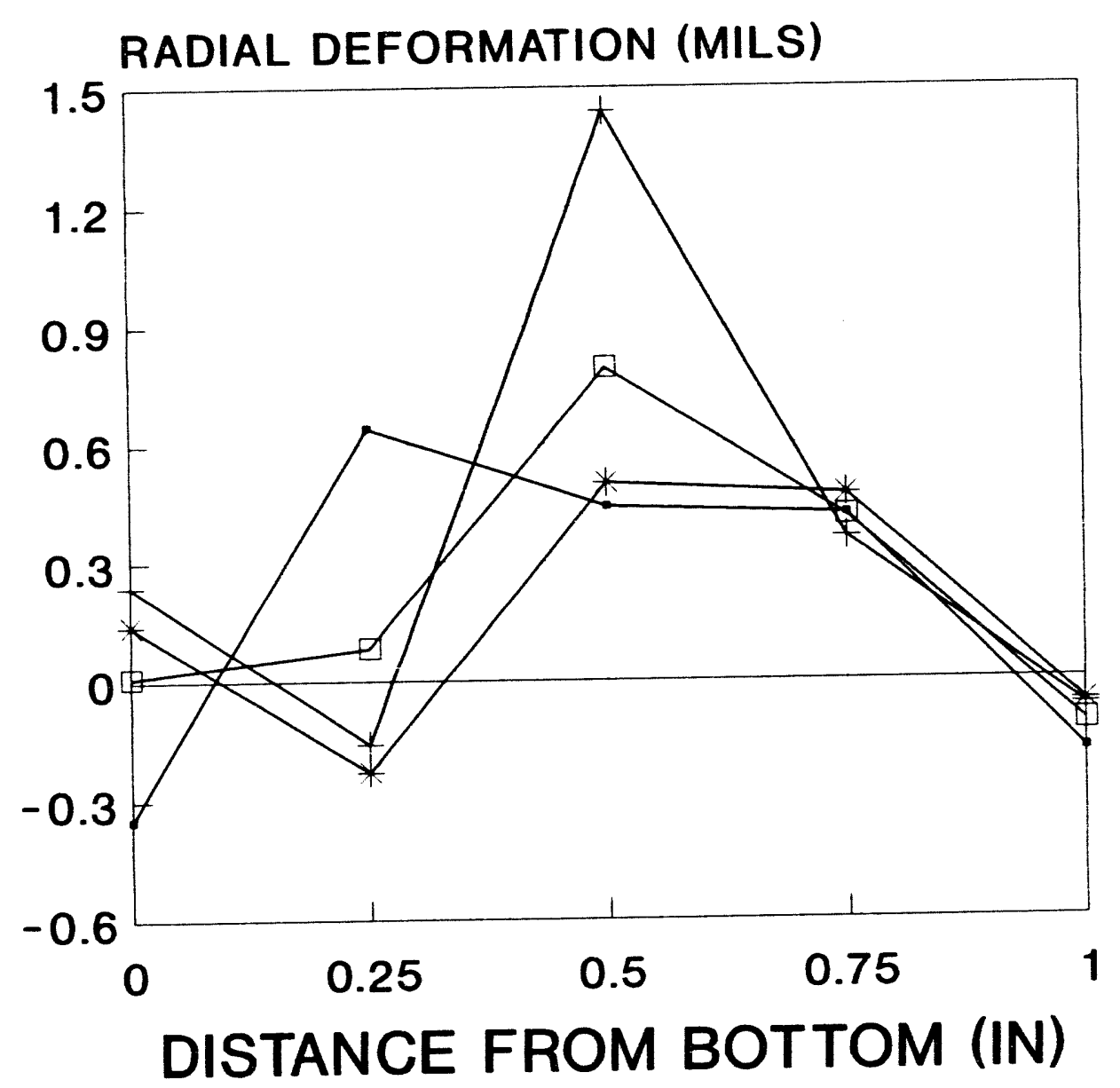




\section{SU2-11 EMITTER DEFORMATION 0.72 AT\% BURNUP, 331 EFPD}

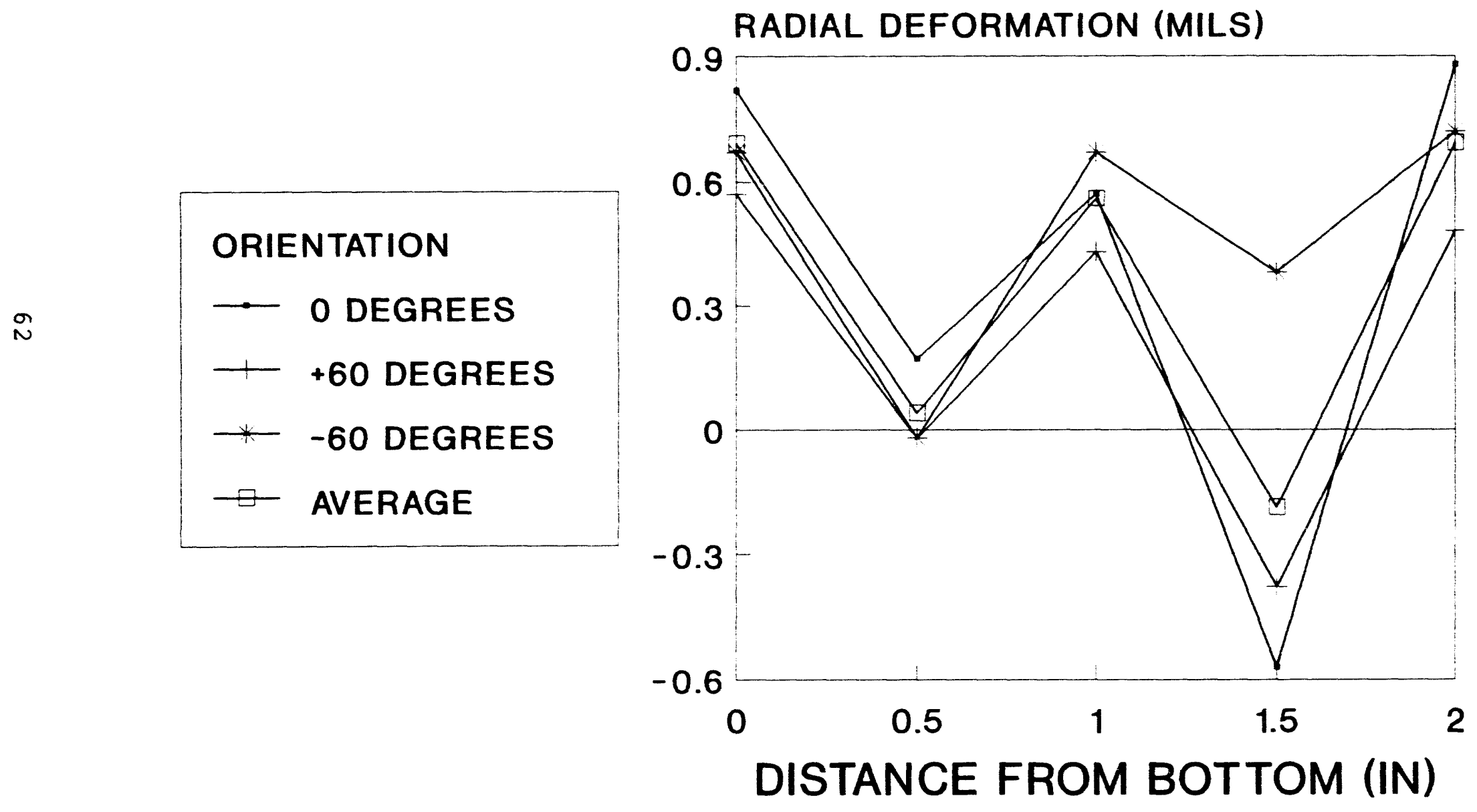




\section{SU2-11 EMITTER DEFORMATION 0.96 AT\% BURNUP, 441 EFPD}

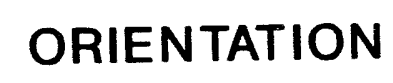

ORIENTATION

- 0 DEGREES

+ +60 DEGREES

* -60 DEGREES

$\square$ AVERAGE

RADIAL DEFORMATION (MILS)

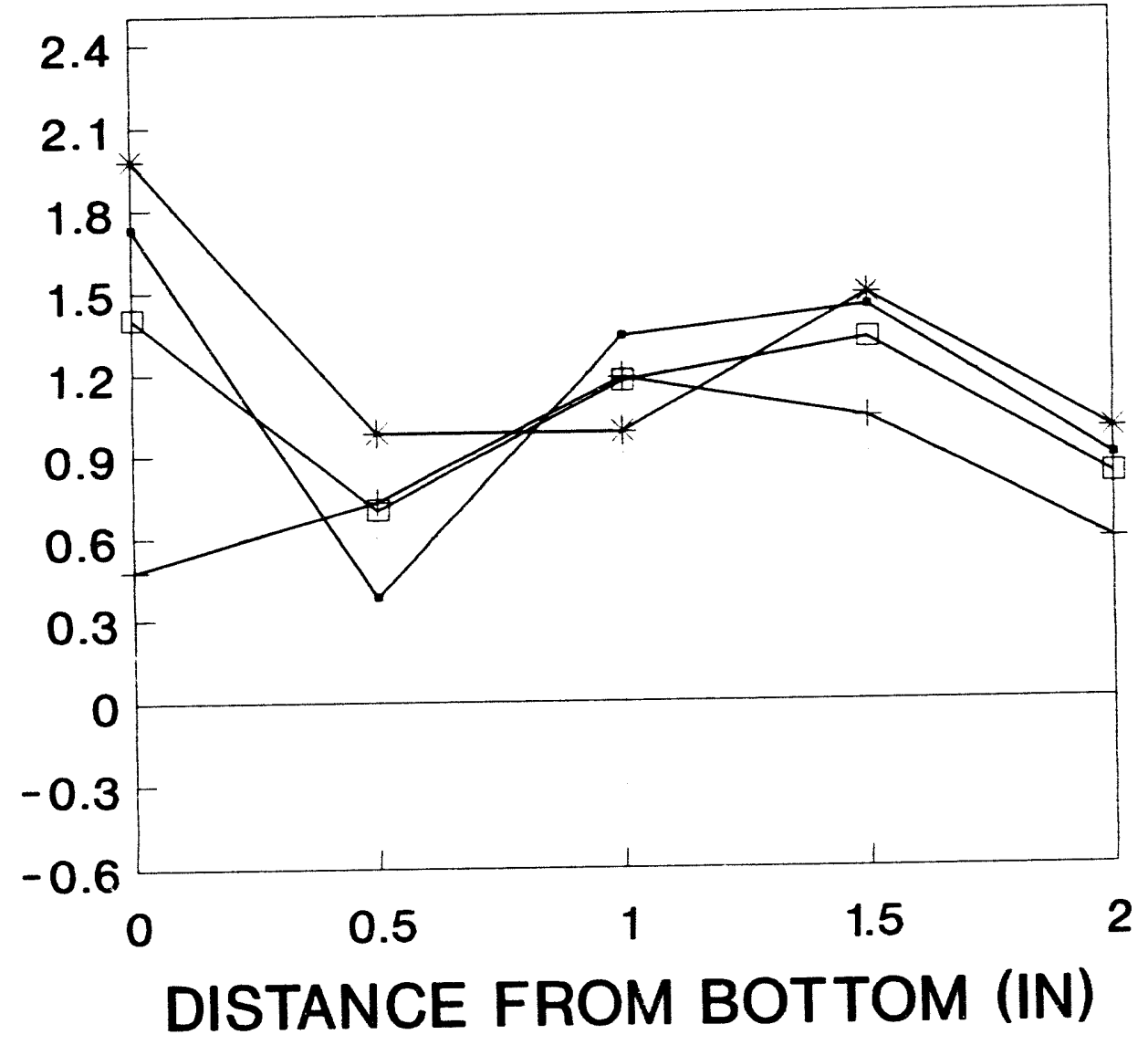




\section{SU2-12 EMITTER DEFORMATION 0.76 AT\% BURNUP, 331 EFPD}

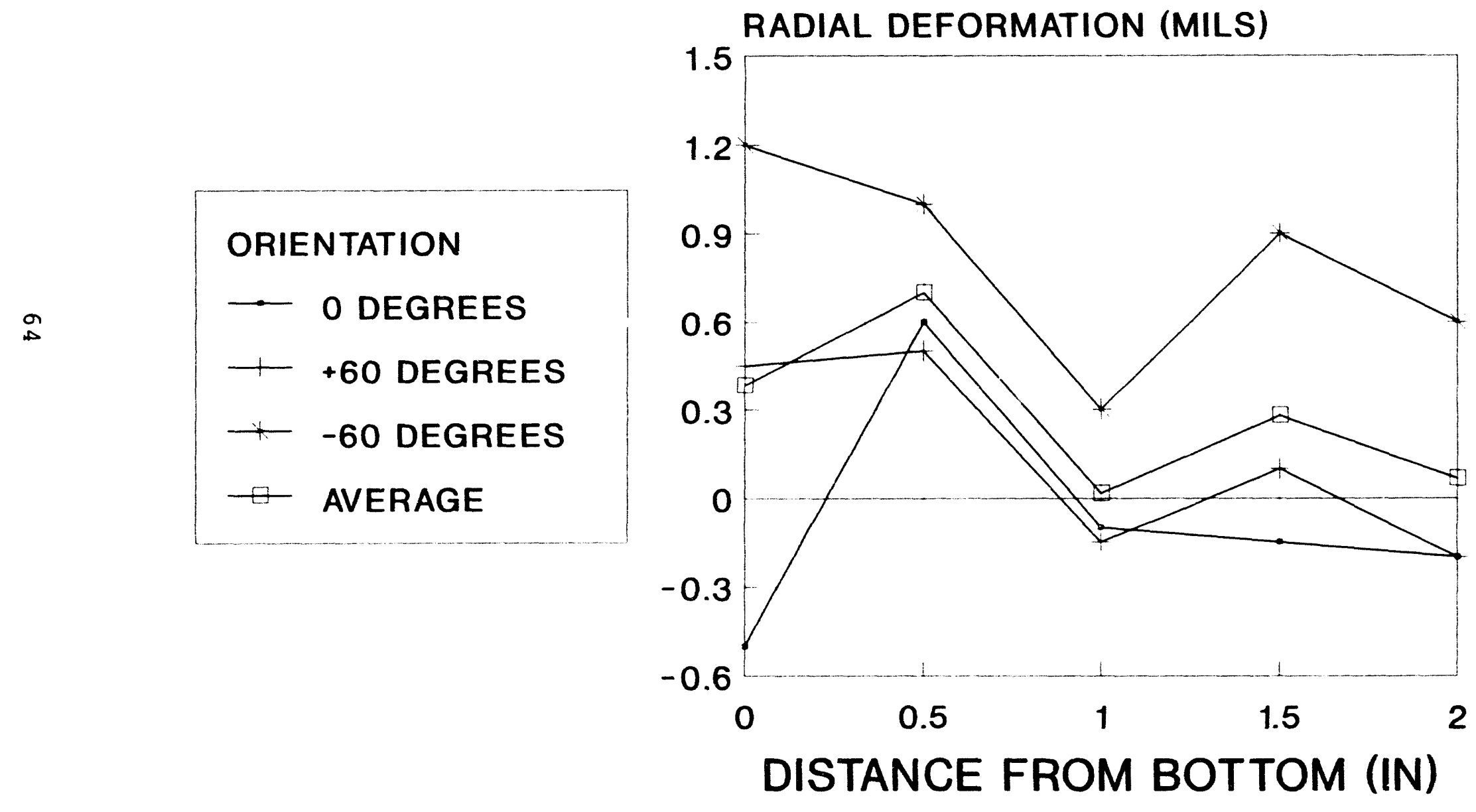

\3450\SU2-12A 


\section{SU2-12 EMITTER DEFORMATION 1.01 AT\% BURNUP, 441 EFPD}

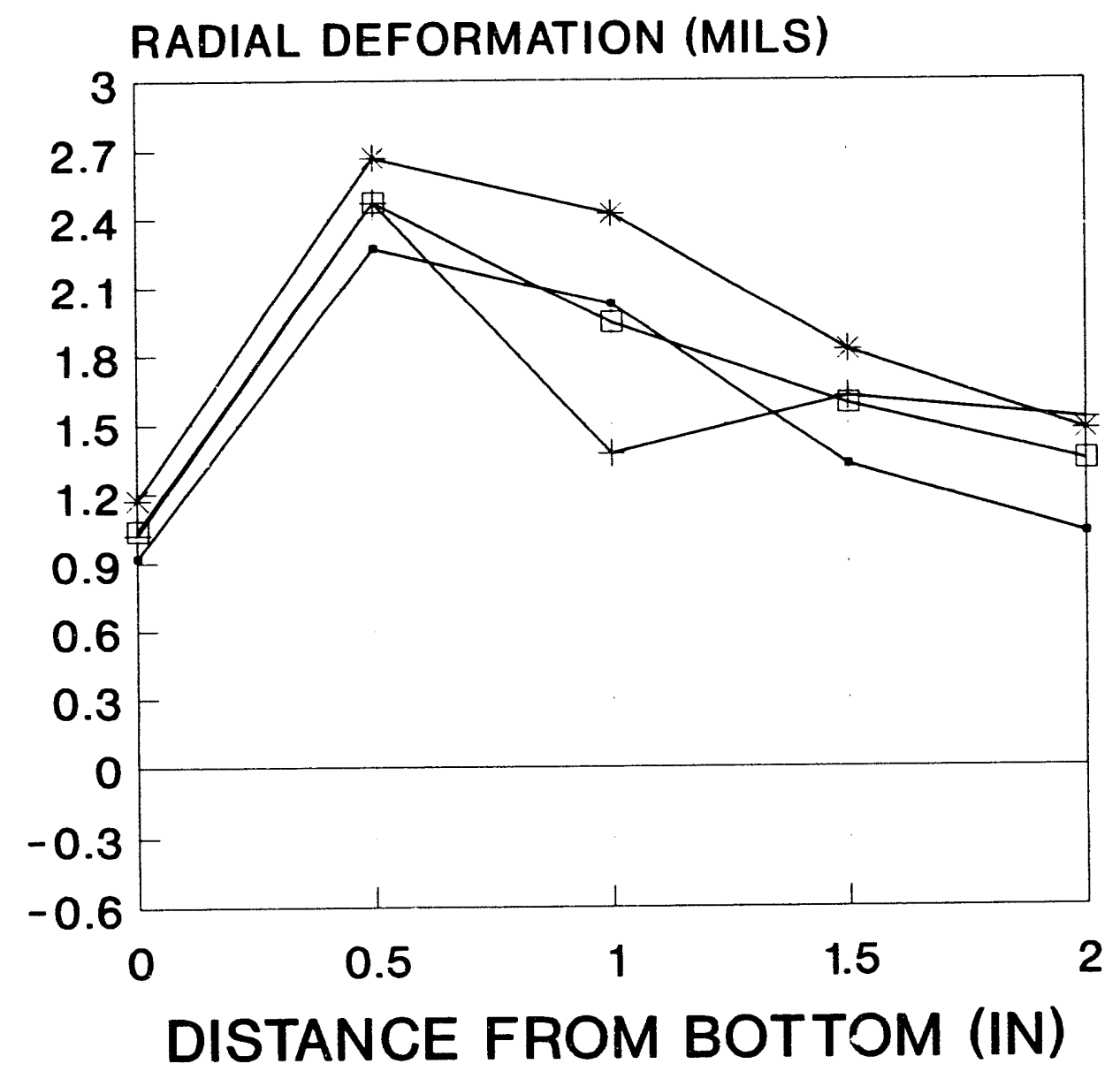




\section{SU2-14 EMITTER DEFORMATION 0.72 AT\% BURNUP, 331 EFPD}

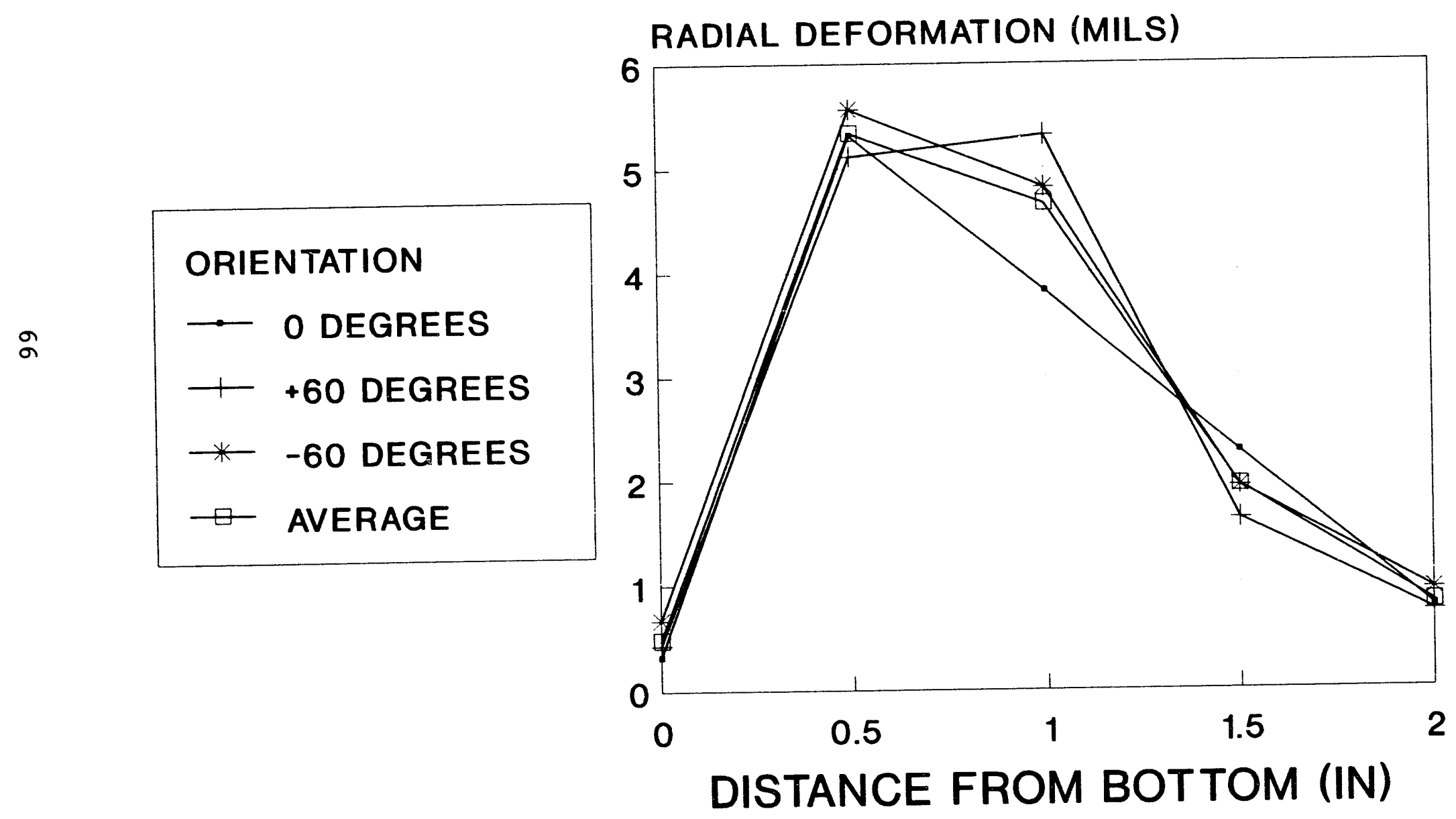




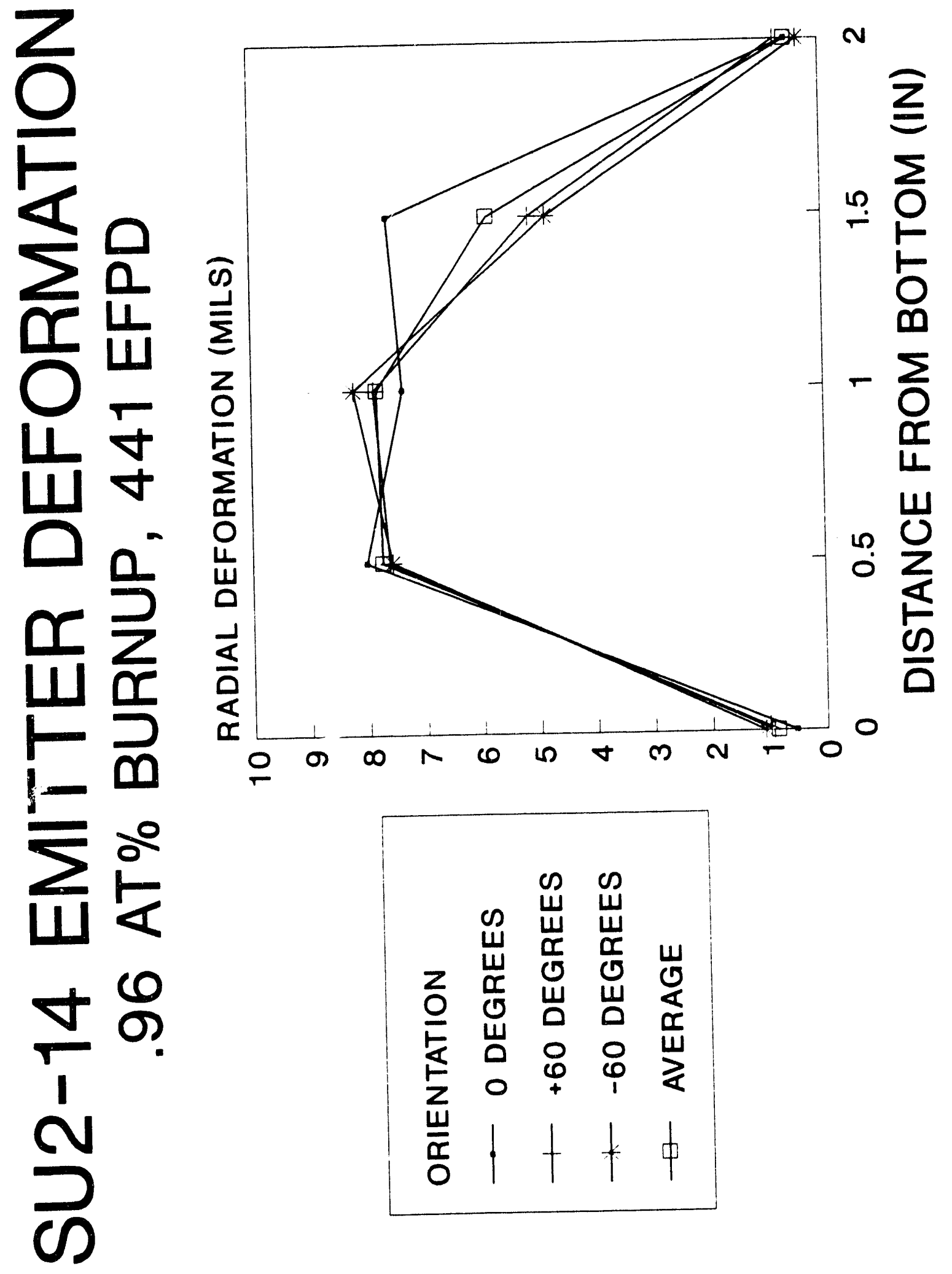

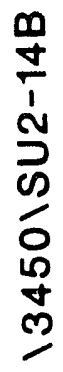




\section{SU2-15 EMITTER DEFORMATION 0.85 AT\% BURNUP, 331 EFPD's}

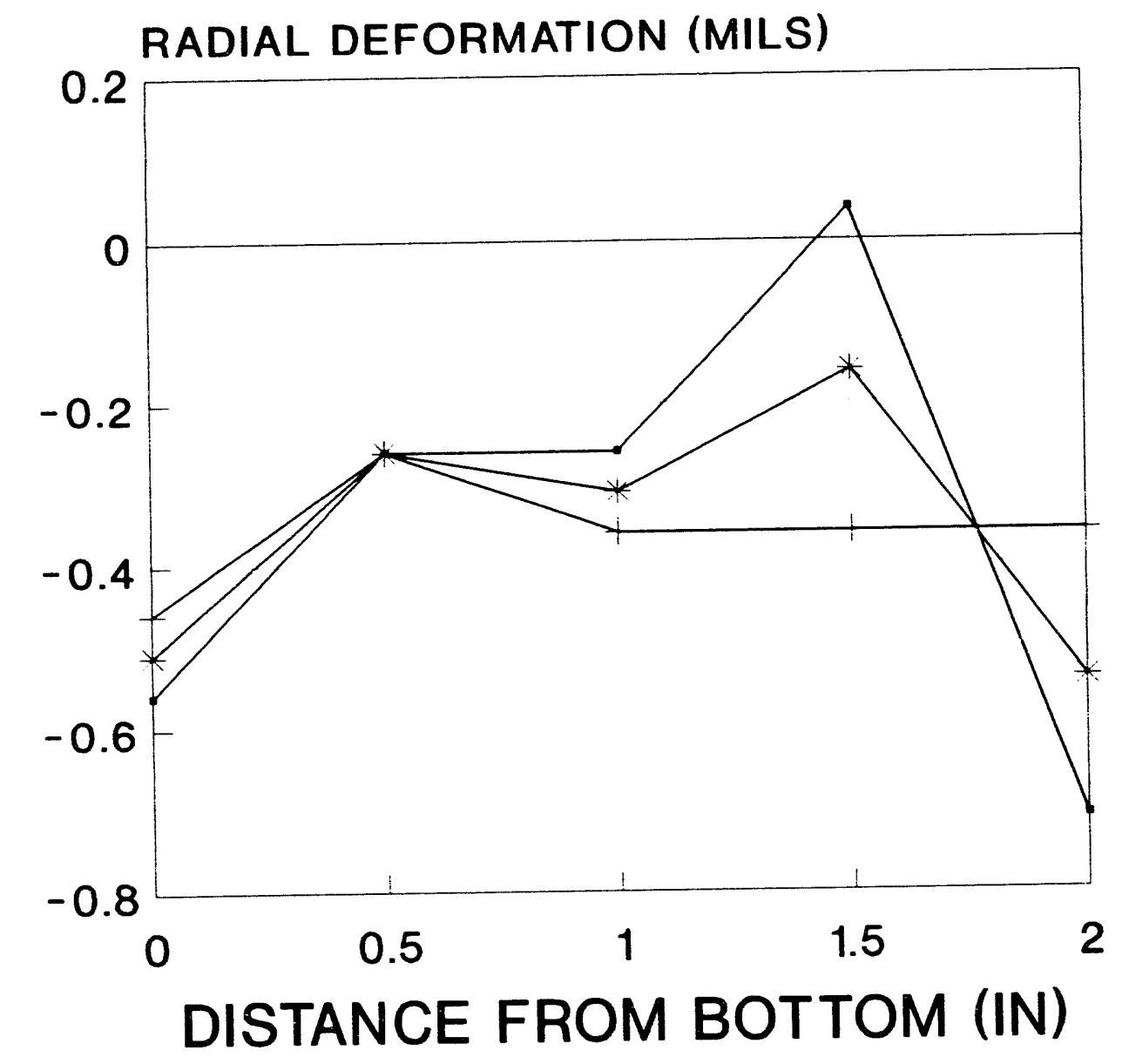




\section{SU2-15 EMITTER DEFORMATION 1.13 AT\% BURNUP, 441 EFPD's}

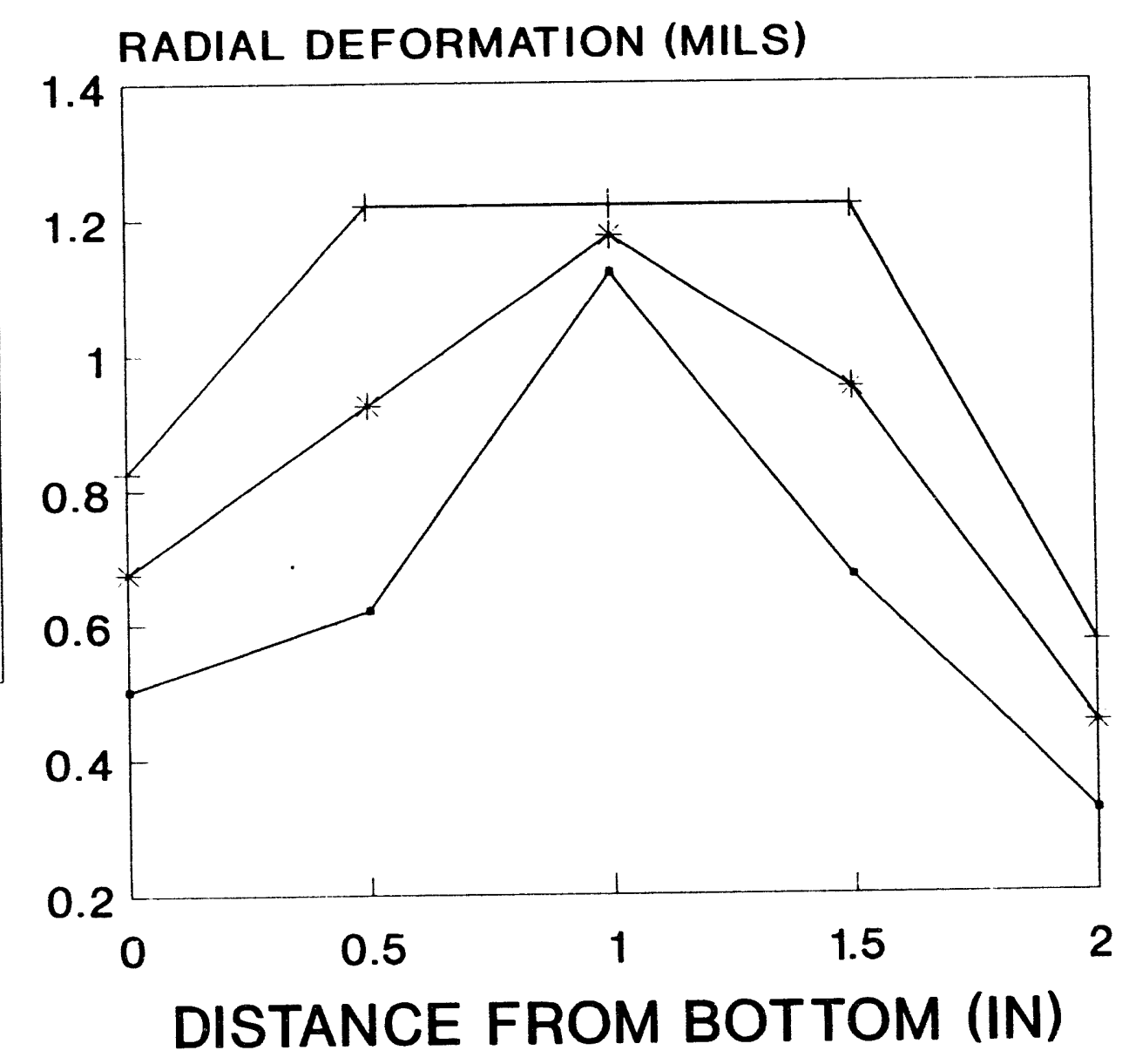




\section{SU3-16 EMITTER DEFORMATION 1.3 AT\% BURNUP, 172 EFPD's}

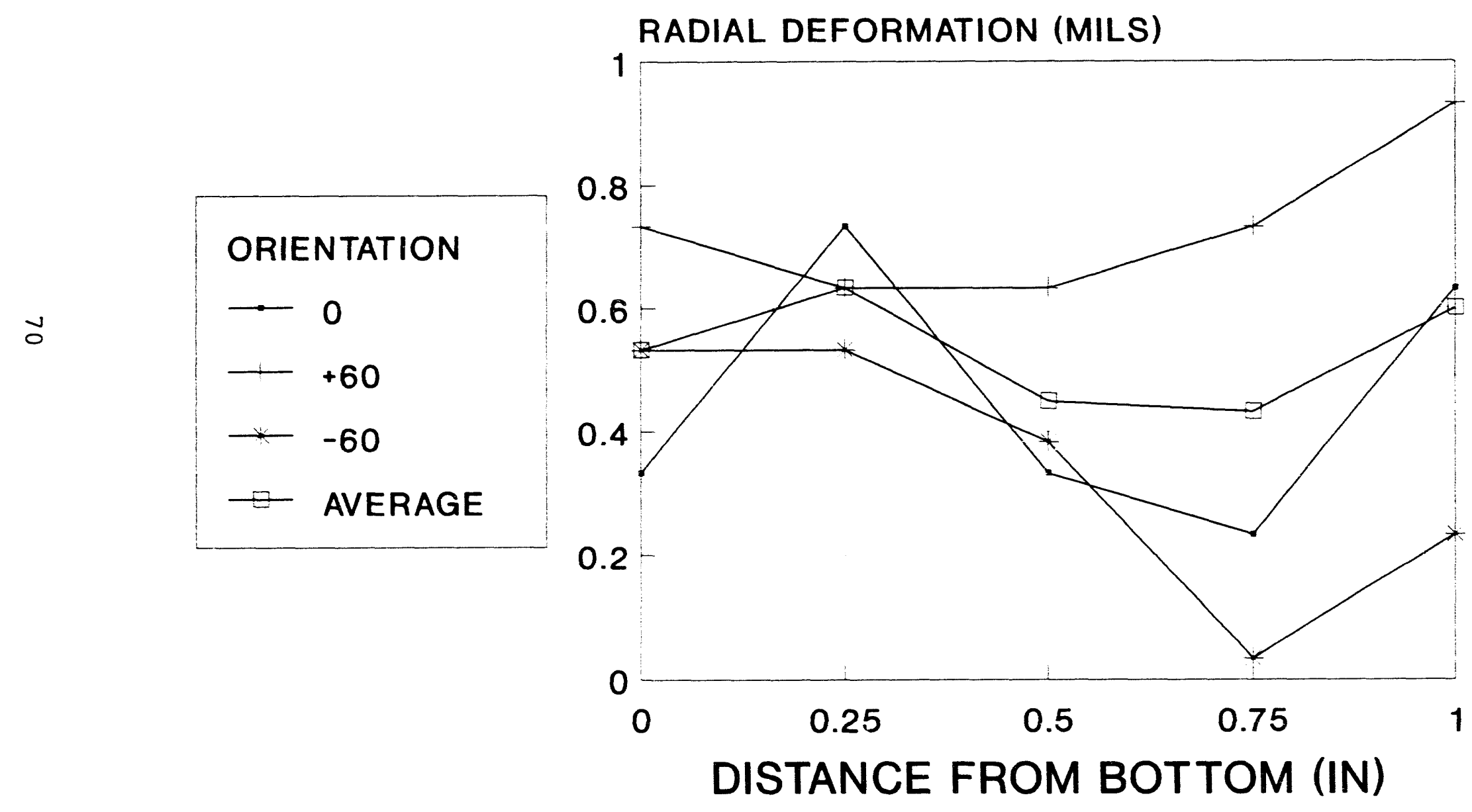




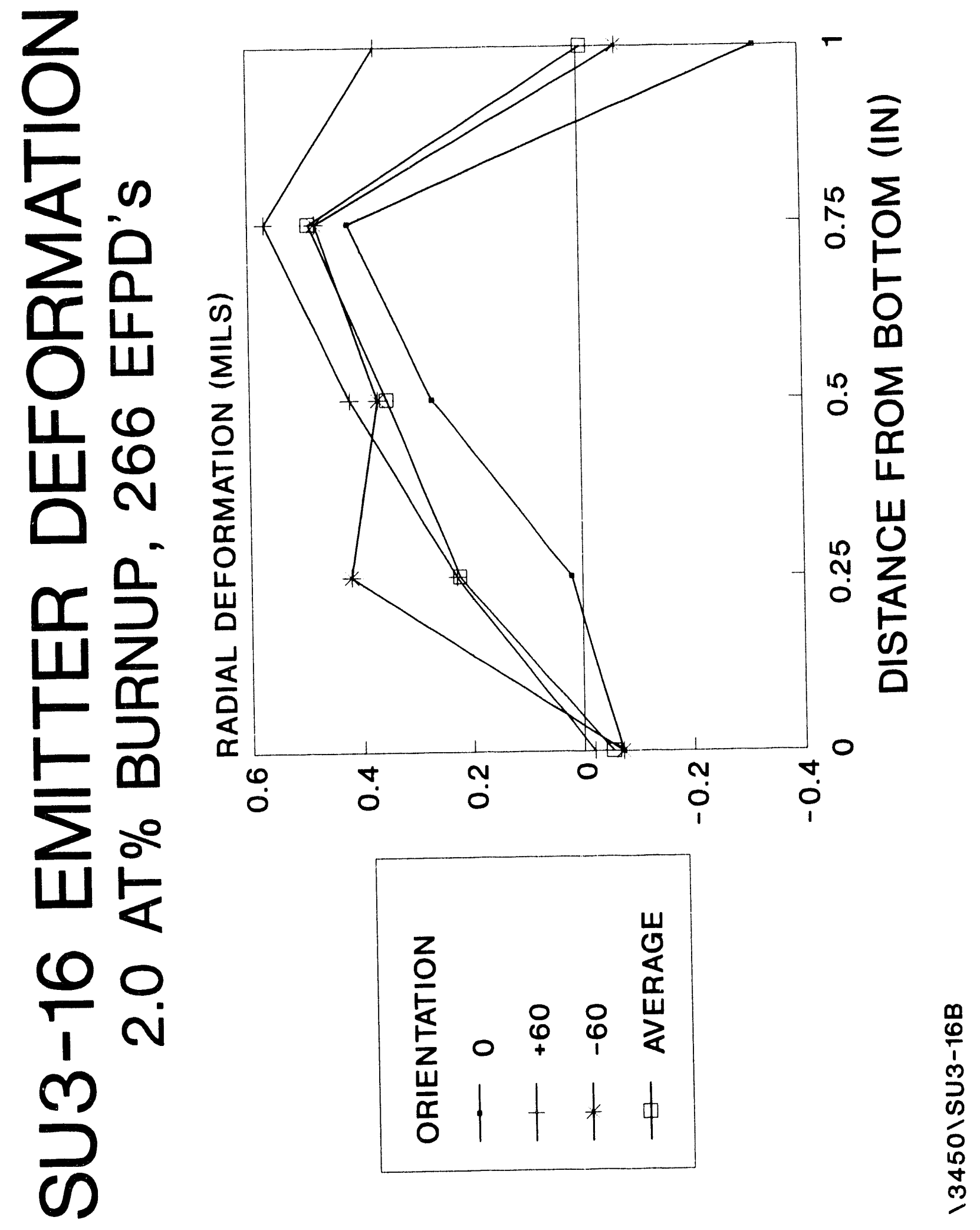




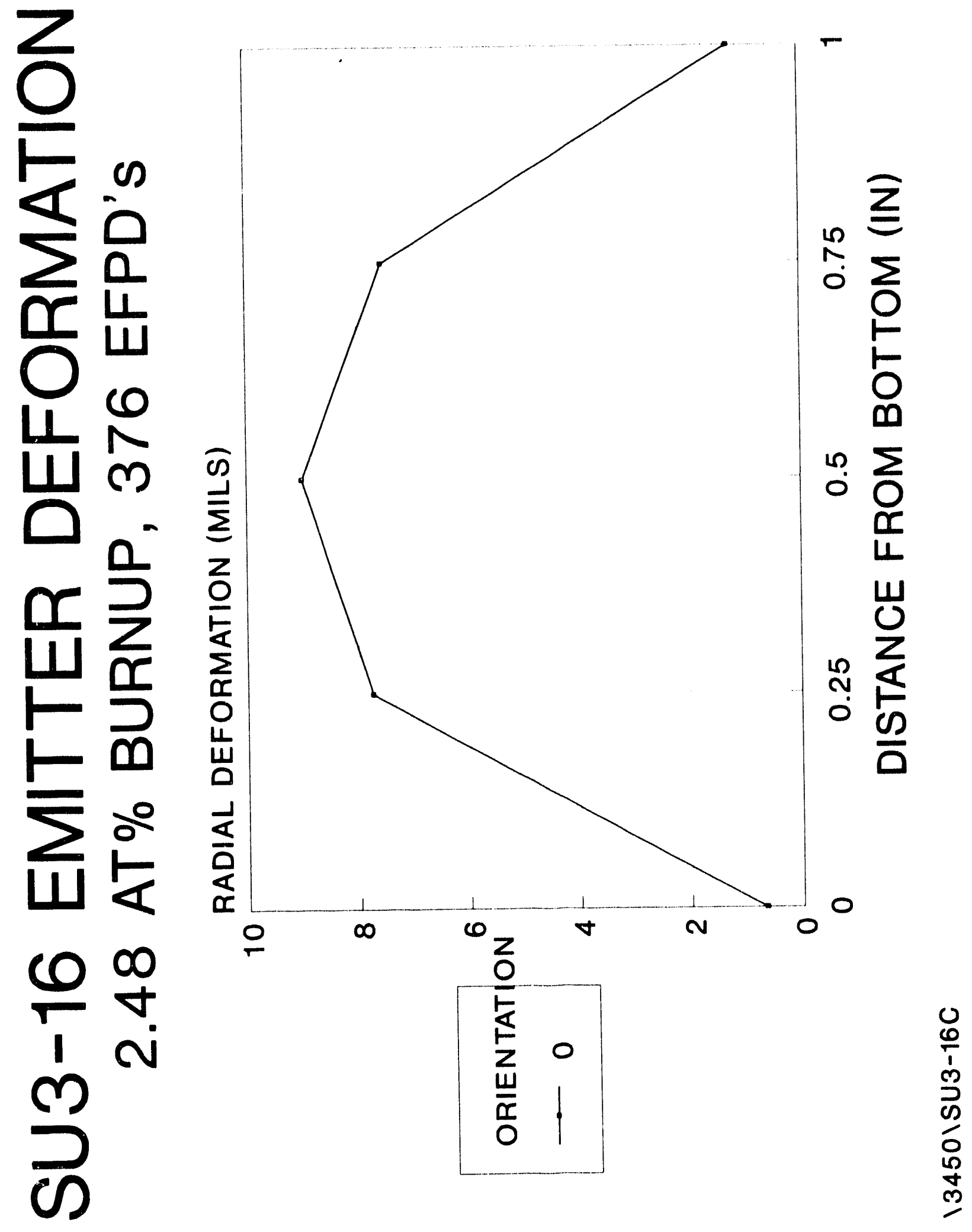




\section{SU3-17 EMITTER DEFORMATION 1.7 AT\% BURNUP, 172 EFPD's}

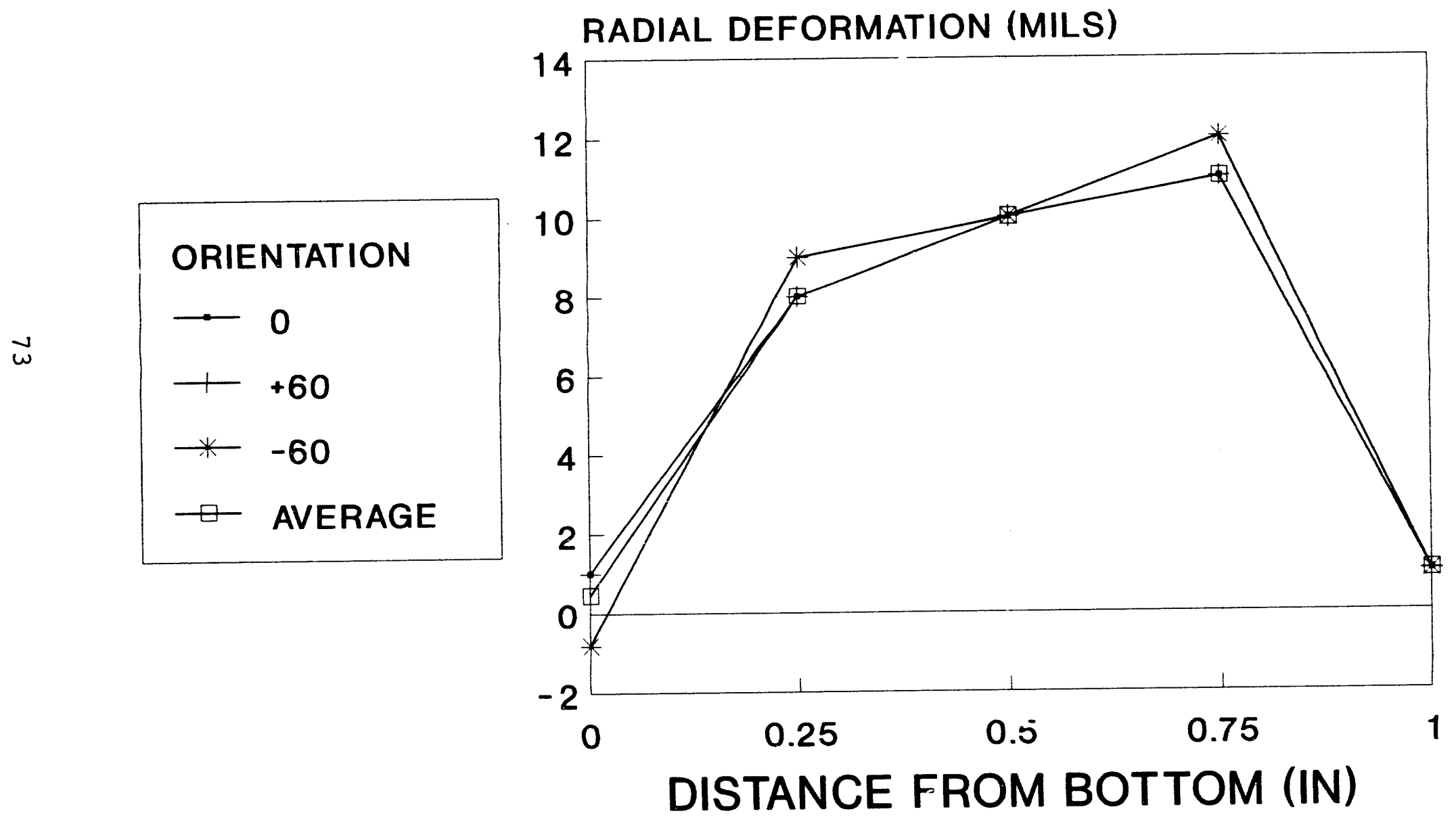

\3450\SU3-17A 


\section{SU3-17 EMITTER DEFORMATION 2.7 AT\% BURNUP, 266 EFPD's}

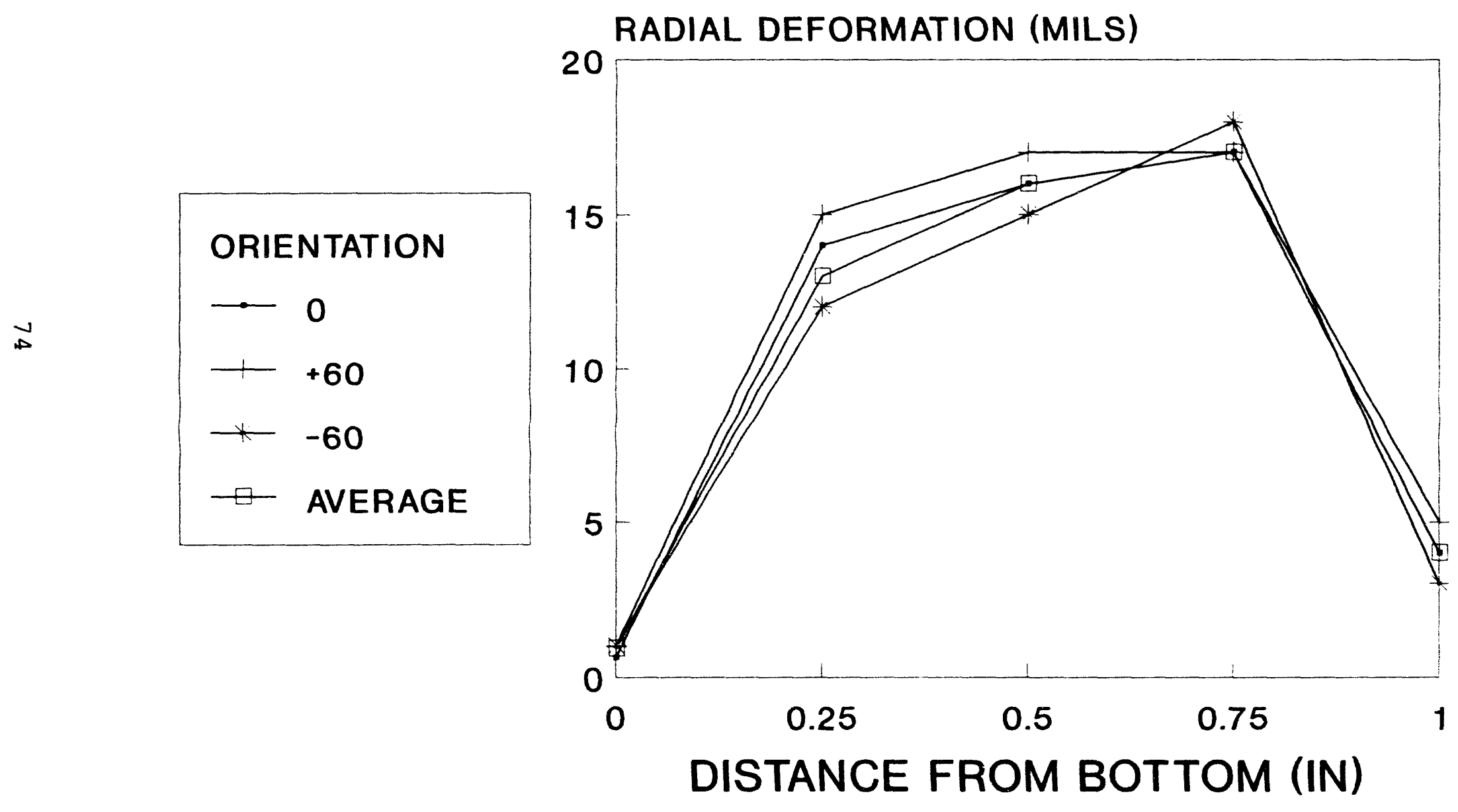




\section{SU3-20 EMITTER DEFORMATION 1.7 AT\% BURNUP, 172 EFPD's}
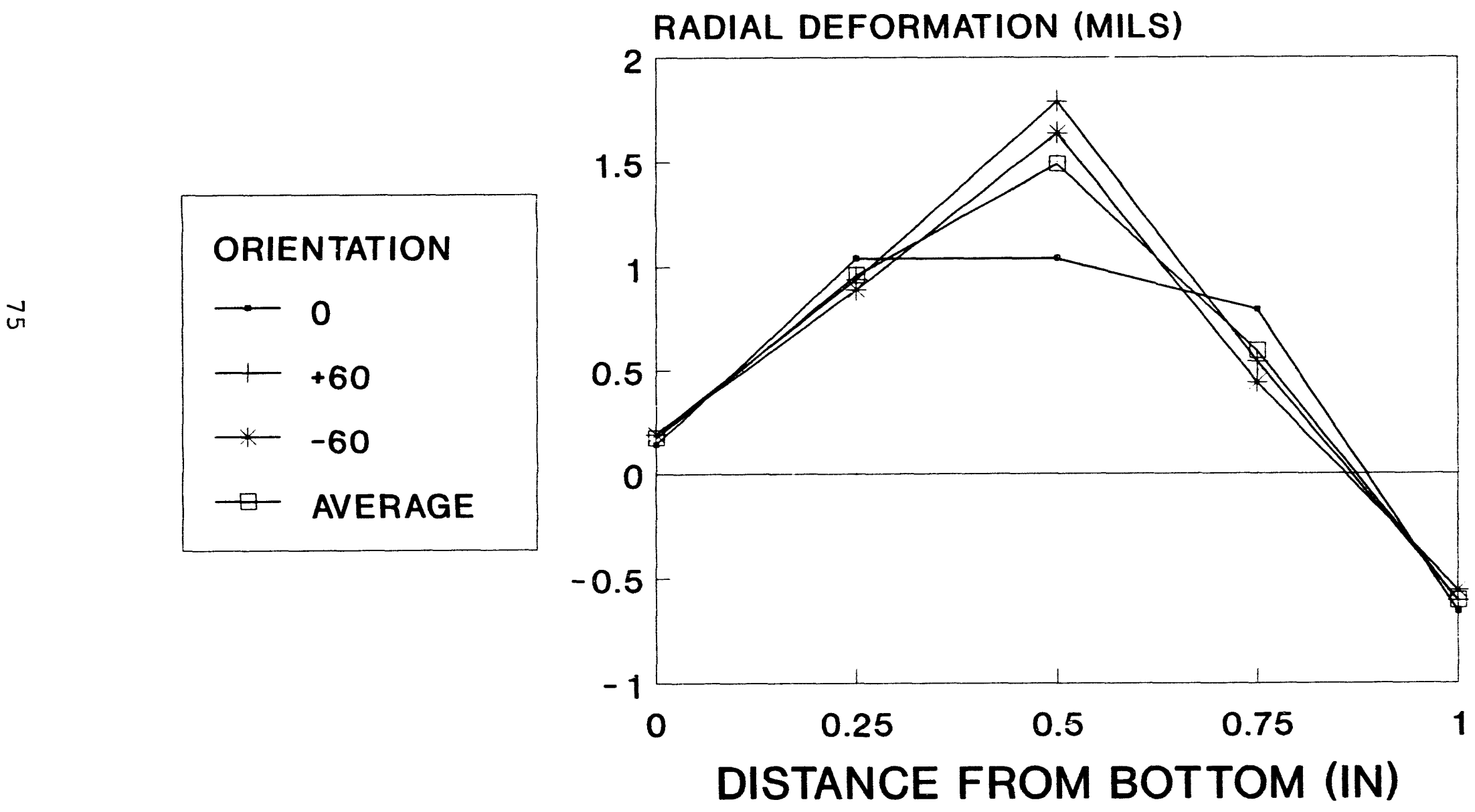


\section{SU3-20 EMITTER DEFORMATION 2.7 AT\% BURNUP, 266 EFPD's}

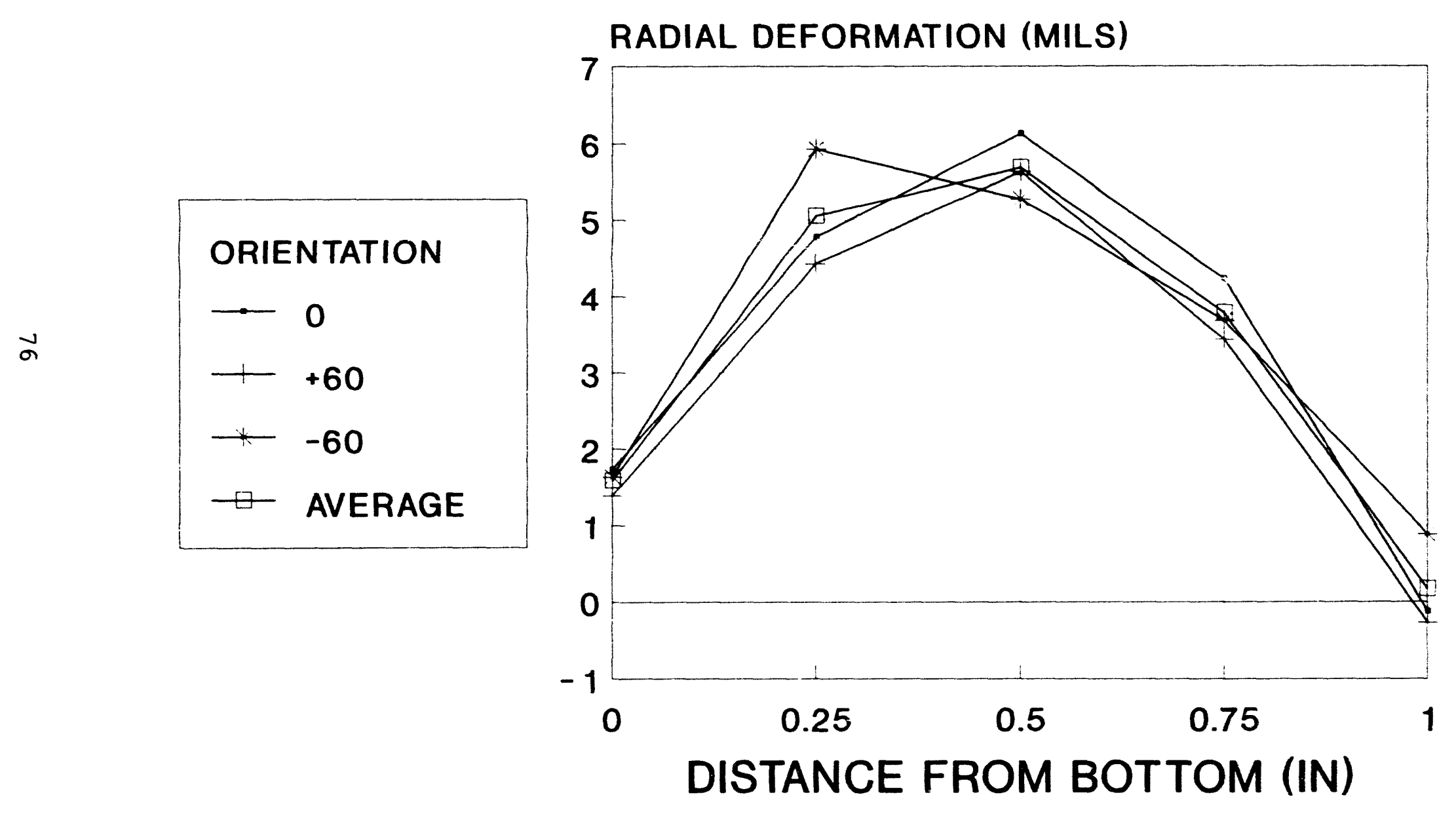




\section{SU3-20 EMITTER DEFORMATION 3.5 AT\% BURNUP, 376 EFPD's}

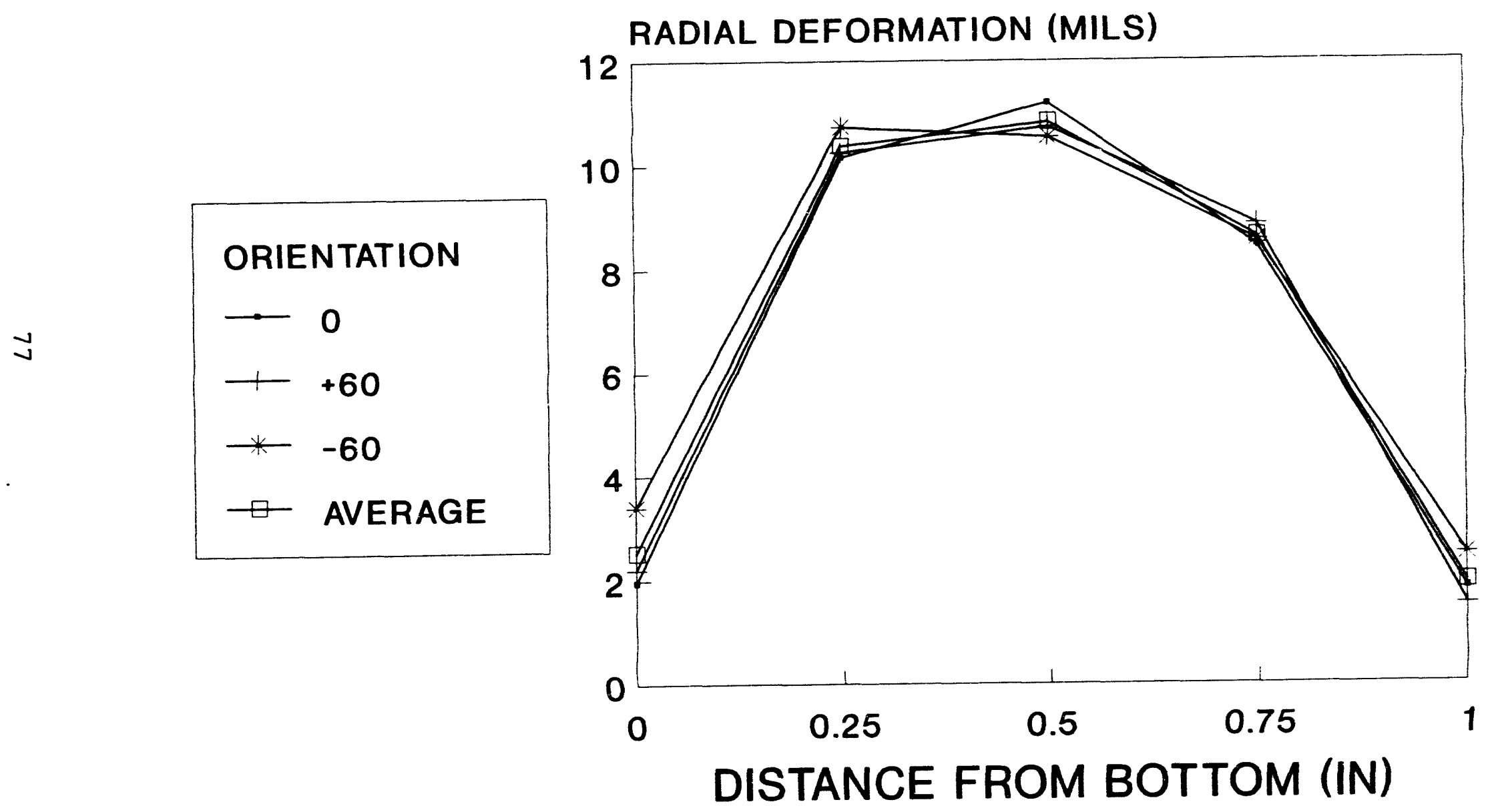



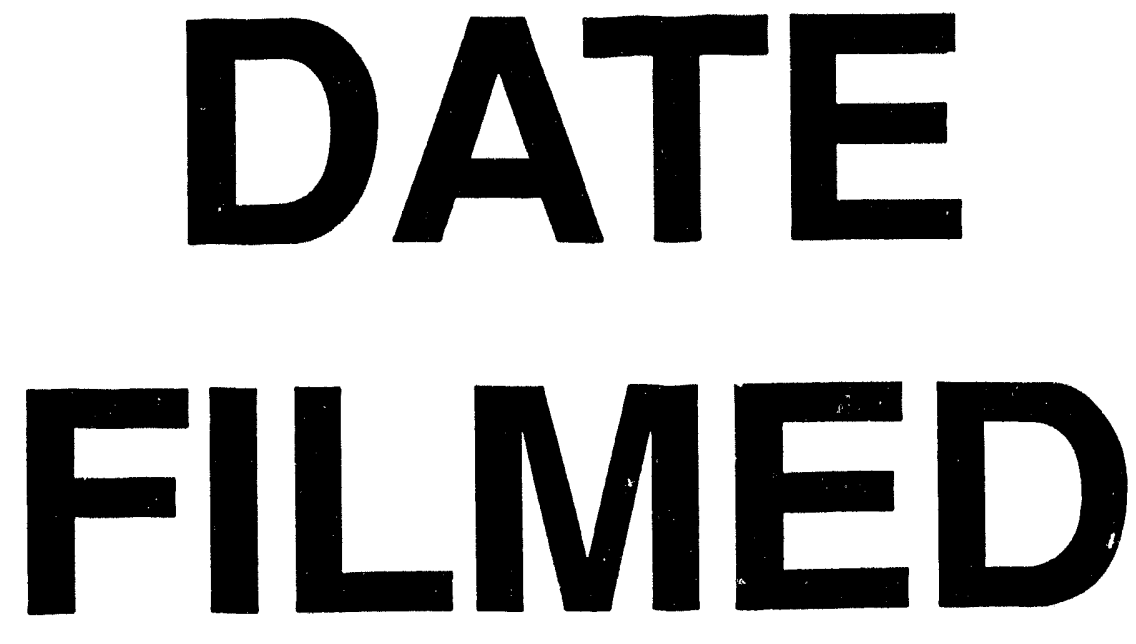

$10 / 24 / 94$
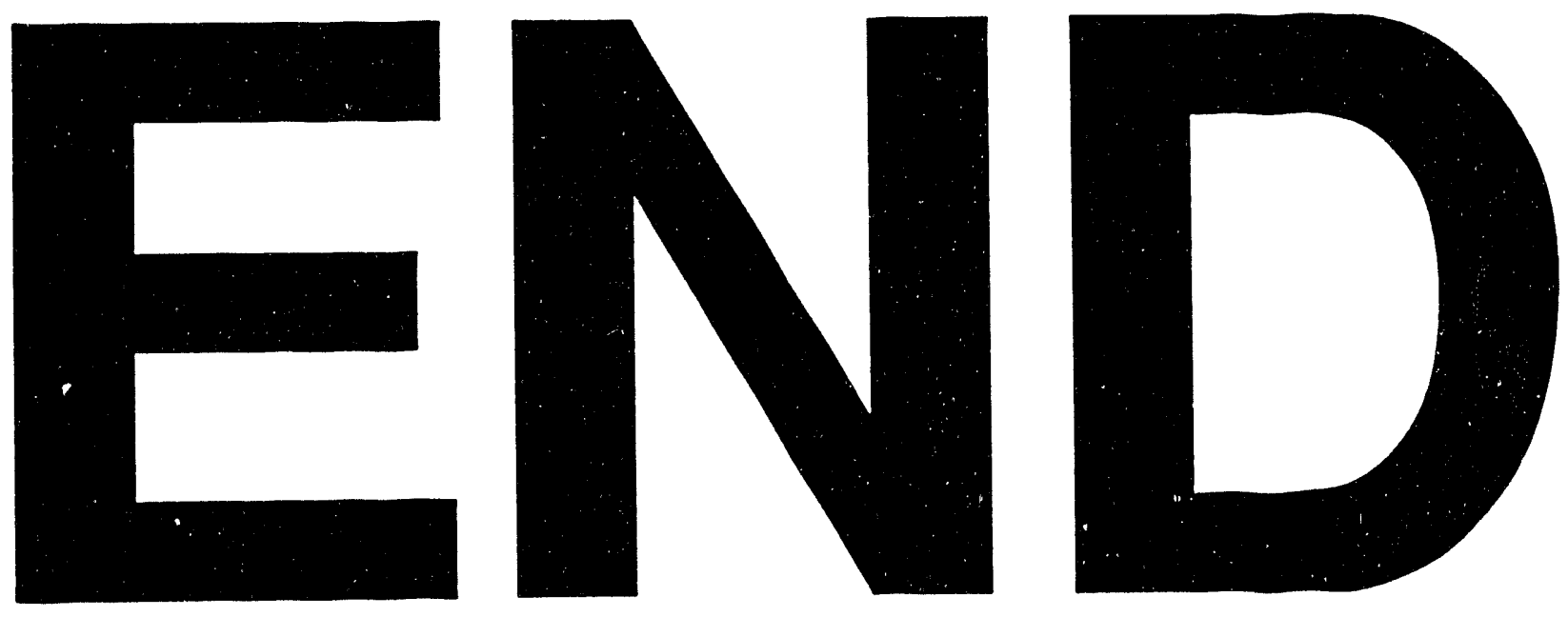